UNIVERSIDADE DE SÃO PAULO

FFCLRP - DEPARTAMENTO DE PSICOLOGIA

PROGRAMA DE PÓS GRADUAÇÃO EM PSICOLOGIA

\title{
Replicabilidade do Programa Posso Pensar na Educação Infantil
}

Letícia Melo de Paulo

Dissertação apresentada à Faculdade de Filosofia, Ciências e Letras de Ribeirão Preto da USP, como parte das exigências para a obtenção do título de Mestre em Ciências, Área: Psicologia em Saúde e Desenvolvimento.

Ribeirão Preto - SP 


\section{LETÍCIA MELO DE PAULO}

Replicabilidade Do Programa Posso Pensar Na Educação Infantil

\section{Versão corrigida}

(Versão original encontra-se na unidade que aloja o Programa de Pós-graduação)

Dissertação apresentada ao Programa de PósGraduação Stricto Sensu em Psicologia, como parte das exigências para obtenção do título de Mestre Ciências. Área de concentração: Psicologia em Saúde e Desenvolvimento.

Orientadora: Prof ${ }^{\mathrm{a}} \operatorname{Dr}^{\mathrm{a}}$ Luciana Carla dos Santos Elias

Ribeirão Preto 
Autorizo a reprodução e divulgação total e parcial deste trabalho, por qualquer meio convencional ou eletrônico para fins de estudo e pesquisa, desde que citada a fonte.

De Paulo, Letícia Melo

Replicabilidade do Programa Posso Pensar na Educação Infantil. Ribeirão Preto, 2020.

126 p. : il. ; $30 \mathrm{~cm}$

Dissertação de mestrado apresentada à Faculdade de Filosofia, Ciências e Letras de Ribeirão Preto - USP. Área de Concentração: Psicologia em Saúde e Desenvolvimento.

Orientadora: $\operatorname{Prof}^{\mathrm{a}} \operatorname{Dr}^{\mathrm{a}}$ Luciana Carla dos Santos Elias

1. Habilidades Sociais 2. Problema de comportamento. 3. Educação Infantil 4. Programa de Intervenção 
Nome: de Paulo, Letícia Melo

Título: Replicabilidade Do Programa Posso Pensar Na Educação Infantil

Dissertação apresentada ao Programa de Pós-Graduação Stricto Sensu em Psicologia, como parte das exigências para obtenção do título de Mestre Ciências. Área de concentração:

Psicologia em Saúde e Desenvolvimento.

Ribeirão Preto, 20 de outubro de 2020.

Resultado:

Banca Examinadora

Presidente da Banca - Profa. Dra. Luciana Carla dos Santos Elias

Universidade de São Paulo

Membro convidado externo:

Membro convidado interno:

Universidade de São Paulo

Membro convidado interno:

Universidade de São Paulo 


\section{AGRADECIMENTOS}

À minha orientadora Prof. ${ }^{\mathrm{a}}$ Dr $^{\mathrm{a}}$ Luciana Carla Elias dos Santos, pela paciência, leveza, empatia e condução tão humana ao longo de todo o processo. Obrigada pelos ensinamentos que foram muito além da academia.

Aos meus pais, que sempre apoiaram minhas decisões, incentivaram meus estudos e demonstraram a importância da Educação. Obrigada por serem modelos de dedicação e amor.

Aos meus irmãos pela parceria e incentivo. Obrigada pelo carinho!

Ao Gabriel, que tornou essa jornada mais leve, com todo carinho, respeito e calma de sempre!

Às minhas amigas, que foram essenciais para os momentos de autocuidado.

Às minhas colegas do LAPEES, pela parceria e companheirismo ao longo desses anos. Compartilhar trabalhos e angústias com vocês fez toda a diferença.

À Marta Correia Zanini e Rafaelle Costa pelos ensinamentos sobre análises e estatística.

À Talita Pereira Dias e Zilda Del Prette por disponibilizarem o PKBS para a coleta de dados.

À Jéssica, que me auxiliou na coleta de dados. Sua ajuda foi essencial!

Aos participantes da pesquisa, tanto crianças quanto seus pais, professores e diretores, que colaboraram com este estudo. 


\section{RESUMO}

DE PAUlO, L. M. (2020). Replicabilidade do Programa Posso Pensar na Educação Infantil. Dissertação de Mestrado, Faculdade de Filosofia, Ciências e Letras de Ribeirão Preto, Departamento de Psicologia, Universidade de São Paulo.

As habilidades sociais (HS) são essenciais para o estabelecimento de relações duradouras e satisfatórias, as quais constituem processos fundamentais no desenvolvimento humano. A aprendizagem destas habilidades ocorre a partir das interações, portanto, desde a infância. As habilidades de solução de problemas interpessoais (HSPI) têm sido destacadas como essenciais ao desenvolvimento infantil, atuando como fator de proteção. Neste cenário, podem ser criadas condições para o aprendizado destas, na forma de programas de treinamento, que atuem como prevenção. O presente estudo teve por objetivo geral avaliar os efeitos de um treinamento de habilidades sociais, com ênfase em habilidades de solução de problemas interpessoais (Programa Posso Pensar), em um ensaio de campo, com alunos da Educação Infantil, de modo a verificar a replicabilidade dos resultados obtidos com alunos dos primeiros anos do Ensino Fundamental I (Elias \& Marturano, 2016). Para responder ao objetivo geral, foram realizados três estudos. Buscando ampliar o conhecimento sobre o tema. O Estudo 1 teve como objetivo revisar sistematicamente a literatura acerca de programas de intervenção para o desenvolvimento de habilidades sociais na Educação Infantil, bem como identificar suas principais características, diferenças e semelhanças. Para tanto, foram consultadas as bases de dados SciELO, Lilacs, Psychinfo, Psycarticles e Web of Science, considerando artigos publicados de 2015 a 2019; utilizou-se o protocolo PRISMA e dois juízes verificaram os procedimentos de seleção e extração de forma independente. Foram encontrados oito artigos que cumpriram os critérios estabelecidos; observou-se que os estudos apontaram o aumento em habilidades sociais e diminuição de problema de comportamento nos participantes após passarem pelos programas; contudo, sinalizaram ressalvas nos ganhos em programas de prevenção universal para crianças com problemas de comportamento pré-existentes. O Estudo 2 teve como objetivo verificar os efeitos de um programa para o desenvolvimento de habilidades de solução de problemas interpessoais, em alunos da Educação Infantil, sobre as variáveis de habilidades sociais, habilidades de solução de problemas interpessoais e problemas de comportamento, realizando a comparação entre grupos (alunos expostos ao programa e alunos não expostos) antes e após a intervenção. Com relação à comparação entre os dois grupos 
investigada no estudo 2, foi observado que as crianças que participaram do grupo de intervenção continuaram apresentando problemas de comportamento significativamente maiores que o grupo de espera mesmo após o treinamento e este grupo, por sua vez, passou a apresentar escores relativos a habilidades sociais significativamente maiores que o grupo de intervenção. Infere-se que programas de prevenção universais não são efetivos para crianças pré-escolares que já apresentam problemas de comportamento e que a escola tem um importante papel no desenvolvimento de habilidades sociais. Por fim, o Estudo 3 buscou comparar as habilidades de solução de problemas interpessoais, total de habilidades sociais e problemas de comportamento antes e após a intervenção, verificando as mudanças intragrupo, comparando as variáveis de cada grupo com ele mesmo. Na comparação intragrupo, percebe-se que as crianças de ambos os grupos aumentaram significativamente a taxa de relevância de solução de problemas e as do grupo de intervenção diminuíram algumas variáveis de problema de comportamento em algumas variáveis investigadas segundo os pais. Nos Estudos 2 e 3, participaram 45 alunos, com idade de cinco anos, devidamente matriculados na rede pública de uma cidade do interior paulista, local onde o estudo foi desenvolvido; ambos tiveram recorte transversal, com medidas repetidas e desenho quase-experimental. Os instrumentos utilizados para avaliar as crianças foram Strengths and Difficulties Questionnaire (SDQ), Escala de Comportamento Social para Pré-Escolares PKBS-BR (PKBS) e Procedimento de Solução de Problemas Interpessoais em Pré-escolares (PIPS) e; para o treinamento das habilidades de solução de problemas interpessoais o Programa Posso Pensar. Conclui-se que o programa trouxe ganhos aos participantes, contudo, adaptações devem ser realizadas para o contexto da Educação Infantil, de forma a alcançar maior efetividade.

Palavras-chave: Habilidades sociais, Solução de problemas, Educação infantil, Prevenção, Programa de intervenção.

\section{ABSTRACT}

DE PAULO, L. M. (2020). Replicability of the program "I can think" at kindergarten. Dissertação de Mestrado, Faculdade de Filosofia, Ciências e Letras de Ribeirão Preto, Departamento de Psicologia, Universidade de São Paulo.

Social skills (SS) are essentials for the establishment of longlasting and satisfactory relationships, which are fundamental processes of human development. Learning this skills may occur thorugh intercations, therefore, since the childhood. The interpersonal solving problems 
skilss (ISPS) have been highlighted as essential to children development, acting as a protection fator. I this scenario, conditions can be created for the skills learning, in the format of training programs, which act as prevention. The general aim of this study was to evaluate the effects of a social skills training, wich enphasize interpersonal solving problems skills (I can think) in a field trial, kindergarten students, to verify the replicability os the results observed with elementar school students (Elias \& Marturano, 2016). Targeting the general aim, three studies were conducted. In order to amplify the knowledge of the theme, the Study 1 aimed to revise sistematically the literature about intervention programs concerning the development of social skills at the kindergarten, as well as identify the main characteristics, diferences and resemblances between them. To acomplish this purpose, those data bases were consulted: SciELO, Lilacs, Psychinfo, Psycarticles and Web of Science. The articles considered were the ones published between 2015 and 2019. The Protocol PRISMA was used and two judges verified the procedures of selection and extraction, independently. Eight articles were considered to acomplish the criteria; it was observed that studies indicates a raise in social skills and a decrease of behavior problem after the intervention. However, diferences were found concerning gains in universal prevention programs directed to children who already had behavior problems. The study 2 had the aim to verify the effects of a program to develop interpersonal solving problems skills in the kindergarten, analyzing the variables social skills, interpersonal solving problems skills, behavior problem, comparing groups (students exposed to the program and students who weren't exposed) before and after the intervention. Concerning the comparison between both groups invetigated in the study 2, it was observed that children who participated in the intervention group continued presenting behavior problems significantly higher than the waiting group eventhough after the training, and this group started to present significantly higher scores of social skills than the intervention group. It is infered that universal prevention programs are not effective to preschool children who already had behavior problems and that the shcool has a importante role in the social skills development. Ultimately, the Study 3 aimed to compare interpersonal solving problems skills, total of social skills and behavior problem before and after the intervention, verifying the chances intragroup, comparing the varibles of wich group with itself; doing this comparison, it was noted that children of both groups started to present significantly higher scores at relevance rate of solving problems and children of the intervention group had their scores decreased in some variables of behavior problems, investigated according to their parentes. The program evaluated in Study 2 and 3 was targeted at 45 five years-old students who were enrolled in public schools in the country side, where the research was developed; This reaserch was a cross-sectional, quasi- 
experimental study, with repeated measures design. The instruments used to assess the behavior of children were foram Strengths and Difficulties Questionnaire (SDQ), Escala de Comportamento Social para Pré-Escolares PKBS-BR (PKBS) and Procedimento de Solução de Problemas Interpessoais em Pré-escolares (PIPS). The intervention procedure used was Programa Posso Pensar. In Conlcusion, it was found that children who participated in the intervention, showed gains in some variables, according to their parents evaluation. To evaluate the children, the instruments used were Strengths and Difficulties Questionnaire (SDQ), Escala de Comportamento Social para Pré-Escolares PKBS-BR(PKBS), Procedimento de Solução de Problemas Interpessoais em Pré-escolares (PIPS) and Programa Posso Pensar- PPP for the training of interpersonal solving problems skills. In conclusion, this program brought benefits for the participants. However, adaptations have to be done for the kindergarten context in order to achieve greater effectiveness.

Key-words: social skills, solving problems, preschool, prevention, intervention program. 


\section{SUMÁRIO}

APRESENTAÇÃO

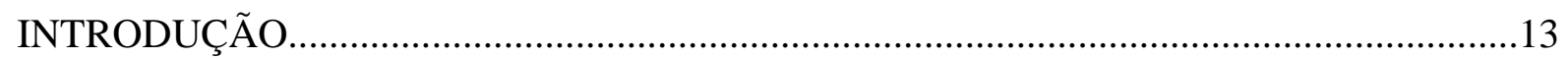

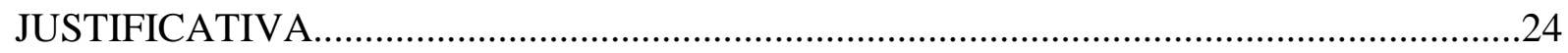

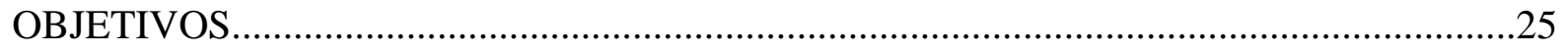

CONTEXTO

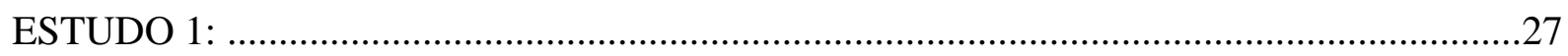

Programas de intervenção para o

desenvolvimento de habilidades

sociais na Educação Infantil: um

estudo de revisão.

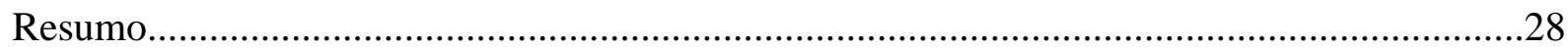

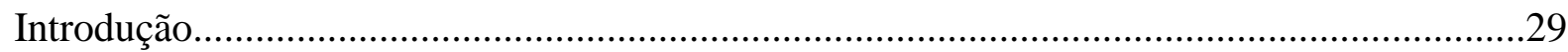

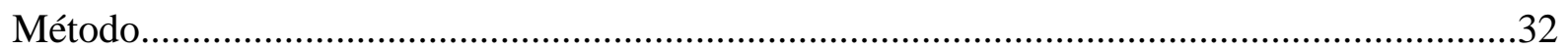

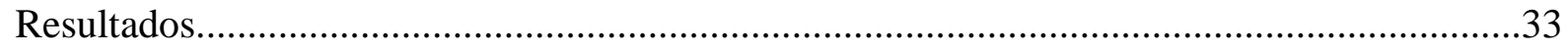

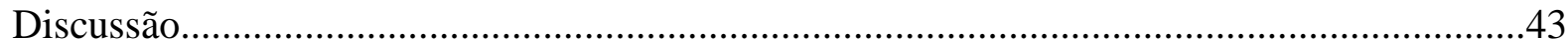

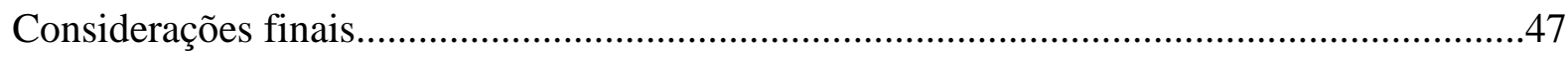

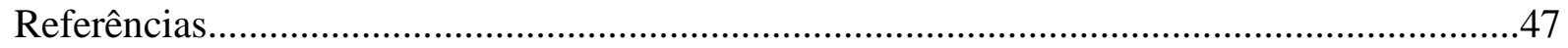

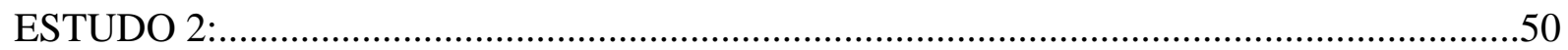

Habilidades de Solução de

Problemas Interpessoais na

Educação Infantil:

Avaliação de intervenção

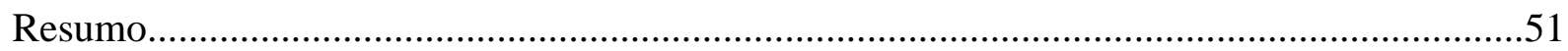

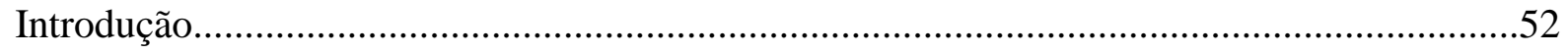


Método.

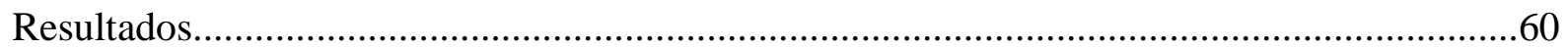

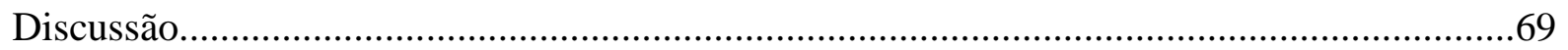

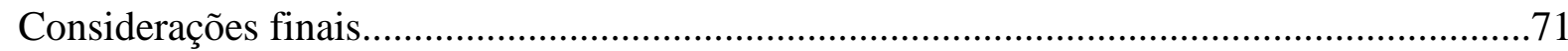

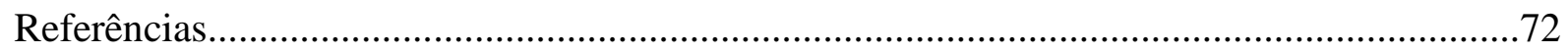

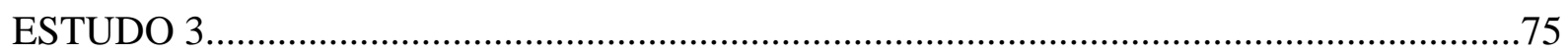

Avaliação dos efeitos de um

Programa de Prevenção

Universal na Educação Infantil

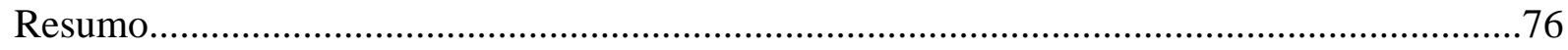

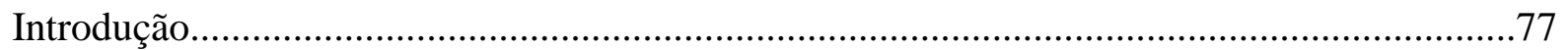

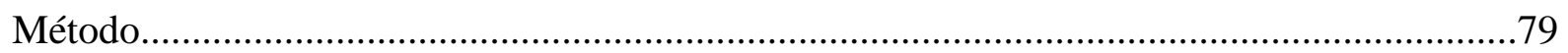

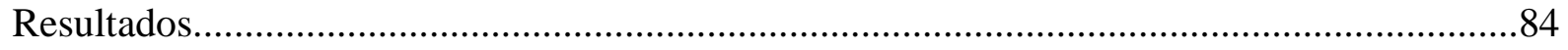

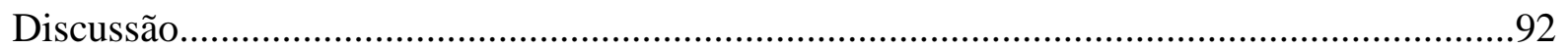

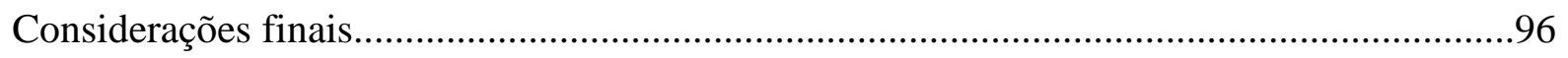

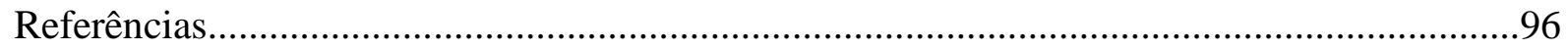

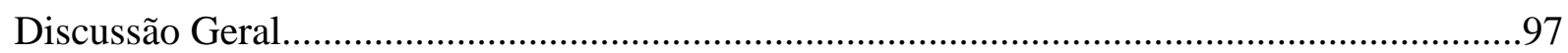

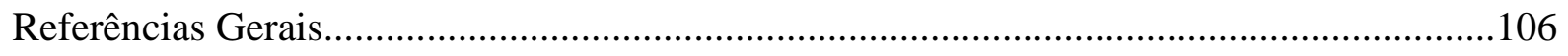

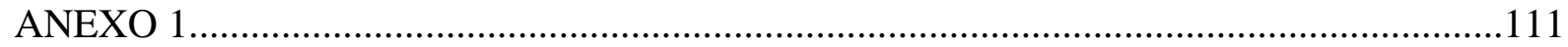

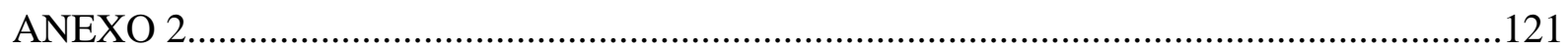

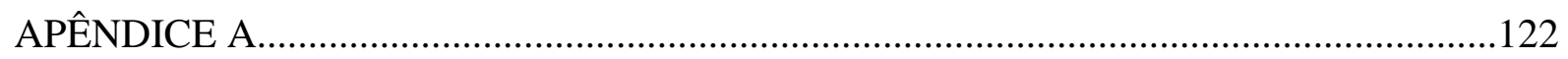

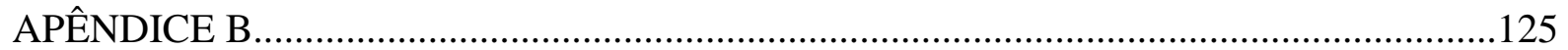




\section{Apresentação}

Ao longo da minha trajetória na graduação, fiz estágios em diferentes áreas, buscando ver com o que eu mais me identificava. Fiz estágio na área de escolar, dificuldade de aprendizagem, clínica, psicologia organizacional e criminal, percebi que em todas essas áreas, meu interesse sempre era voltado para a educação. Quando estava atuando na Fundação Casa, ficou mais evidente, o quanto a Educação pode ser preventiva e; enquanto trabalhava em empresas, meu interesse maior se voltava para os processos de aprendizagem.

Leituras foram me conduzindo a pensar cada vez mais na importância da Educação Infantil quer no desenvolvimento biopsicossocial, consistindo um microssistema diferente do familiar (provavelmente o segundo no desenvolvimento), no qual as crianças começam a ter contato com novas regras, outros responsáveis e pares; no destaque que passou a ter em nosso país nos últimos anos, tornando-se um direito universal e; na importância do desenvolvimento da competência social, que implica, anteriormente, no desenvolvimento de habilidades socias, que tem um papel protetor no desenvolvimento biopsicossocial infantil, fortemente sinalizada na Nova Base Nacional Comum Curricular.

A Educação Infantil enquanto contexto de estudo já estava claro, então surge a demanda de pensar na importância de se promover as habilidades sociais neste período e o quanto psicólogos e professores podem colaborar. Em contato com a literatura nacional e internacional, pude conhecer programas de treinamento de desenvolvimento de habilidades sociais aplicados nas escolas, porém na Educação Infantil ainda de forma escassa; os resultados desses programas mostravam-se significativos, contribuindo para o desenvolvimento de habilidades sociais e para a manutenção da saúde mental em idades mais avançadas.

Então, decidi estudar mais a área da Psicologia Escolar e Educacional e assim, em 2017 surgiu esse projeto, fazendo parte de um conjunto maior do projeto "Programa Posso Pensar: estudo em larga escala", do Laboratório de Psicologia Escolar e da Educação- LAPEES, que estava investigando as variáveis relacionadas às habilidades de solução de problemas interpessoais.

A seguir encontra-se a introdução do presente estudo, a qual traz conteúdos que buscam respaldá-lo. 


\section{Introdução}

\section{O Modelo Bioecológico de Desenvolvimento Humano e Campo Teórico Prático das}

Habilidades Sociais.

O Modelo Bioecológico de Desenvolvimento Humano (MBDH), desenvolvido por Bronfenbrenner (1996), propõe que o desenvolvimento humano é definido como um fenômeno de continuidade e de mudanças. O contexto em que o desenvolvimento se dá, é composto por diferentes sistemas: microssistema - espaço imediato que o indivíduo frequenta, local em que ocorrem os processos proximais (mola propulsora do desenvolvimento), família e escola são exemplos de microssitema; mesossistema- interrelação entre microssistemas como famíliaescola; exossitema - contexto do qual o indivíduo não participa diretamente, contudo, este afeta seu desenvolvimento, como trabalho dos pais ou rede de apoio social e; macrossistema - sistema mais abrangente e também distante do indivíduo, consiste em todo o sistema de valores culturais, ideologias, crenças e abrange a comunidade na qual os outros três sistemas estão inseridos podendo afetá-los (Poletto \& Koller, 2008; Habigzang, Lampert, Antoni \& Koller, 2011).

De acordo com o MBDH o desenvolvimento pode ser entendido pela relação entre o indivíduo e o ambiente em que está inserido, considerando-se quatro componentes: Processo, Pessoa, Contexto e Tempo (Bronfenbrenner, 1996). Nesse modelo, o processo é descrito como todas as mudanças que ocorrem a todo momento ao longo do desenvolvimento e o tempo todo, como a leitura compartilhada de livros entre mãe e filho, por exemplo; pessoa refere-se a características biológicas, psicológicas e aqueles que são resultados da interação do indivíduo com o ambiente; o contexto é explicado como o ambiente ecológico no qual o indivíduo se insere, incluindo elementos físicos, sociais e culturais e; o tempo é constituído pelas estabilidades e mudanças que ocorrem nas características biopsicossociais dos indivíduos, além daquelas que ocorrem através das gerações.

Segundo Bronfenbrenner e Morris (1998), o desenvolvimento humano se realiza através de processos proximais, que podem ser entendidos como as formas de interação entre o organismo e o ambiente, as quais operam ao longo do tempo. Para que essas interações sejam eficazes, elas devem ocorrer com regularidade, em períodos prolongados e deve haver interações recíprocas entre a pessoa que se desenvolve e as pessoas do seu ambiente imediato. 
Os processos proximais podem levar a dois tipos de resultados do desenvolvimento: um $\begin{array}{lllll}\text { positivo } & \text { (competência) um negativo (disfunção). }\end{array}$

Neste mesmo caminho tem-se o campo teórico-prático das habilidades sociais, que destaca as interações sujeito-ambiente e os aprendizados desta decorrentes, podendo contribuir para a competência social do indivíduo.

Del Prette e Del Prette $(2009,2017)$ referem-se às habilidades sociais como aqueles comportamentos aprendidos e requeridos nas tarefas de interações sociais, diretamente observáveis, com alta probabilidade de gerar consequências positivas para o indivíduo e para o seu grupo, em determinado contexto cultural e situacional. Independentemente da faixa etária ou atividade profissional de uma pessoa, o repertório de habilidades sociais é muito importante, pois, possibilita à pessoa lidar competentemente com as demandas interpessoais.

A disponibilidade de um repertório de habilidades sociais é condição necessária, mas não suficiente, para a competência social (Del Prette \& Del Prette, 2006). Esta, por sua vez, é definida como uma aptidão do indivíduo de manejar pensamentos, sentimentos e ações, promovendo resultados positivos tanto pra si mesmo, como para aqueles com quem se relaciona em determinado contexto, assim, a competência social é fundamental ao longo do desenvolvimento (Del Prette \& Del Prette, 2017).

Com base na literatura da área e em estudos empíricos com crianças, Del Prette e Del Prette (2005) propuseram sete classes de habilidades sociais como as de maior relevância para o desenvolvimento interpessoal da criança, definindo os componentes essenciais de cada uma delas. Embora específicas, essas classes, mencionadas a seguir, são também interdependentes e complementares: (1) autocontrole e expressividade emocional (e.g., alterar as próprias reações e expressar emoções positivas e negativas); (2) civilidade (e.g., cumprimentar pessoas); (3) empatia (e.g., expressar compreensão pelo sentimento ou experiência do outro); (4) assertividade (e.g., defender os próprios direitos, resistir à pressão de colegas); (5) fazer amizades (e.g., iniciar e manter conversação); (6) solução de problemas interpessoais (e.g., identificar e avaliar possíveis alternativas de solução); e (7) habilidades sociais acadêmicas (e.g., seguir regras ou instruções orais, participar de discussões).

Considerando que habilidades sociais são comportamentos aprendidos nas interações sociais, devemos levar em conta essas habilidades desde a infância, quando elas começam a ser desenvolvidas. Na infância, a presença de um repertório elaborado de habilidades sociais possibilita à criança estabelecer relacionamentos mais produtivos e harmoniosos com adultos e 
colegas e é um indicador da qualidade das relações interpessoais que ela poderá desenvolver ao longo da vida (Cia \& Barham, 2009). No decorrer do tempo, as habilidades sociais têm sido associadas positivamente a diversos indicadores de funcionamento adaptativo, como responsabilidade, independência, cooperação, autoestima e desempenho acadêmico (Del Prette \& Del Prette, 2005, Marturano \& Elias, 2017). As crianças que desenvolvem habilidades sociais tendem a exibir melhor ajustamento social e melhor satisfação nas relações interpessoais (Rodrigues, Dias \& Freitas, 2010).

Teóricos do desenvolvimento têm destacado a importância do processo de socialização na qualidade de vida psicológica e social dos indivíduos (Da Dalt de Mangione \& Difabio de Anglat, 2002) e no sucesso das etapas formativas destes (Gonçalves \& Murta, 2008). Considerando que o processo de socialização da criança se intensifica na escola, deve-se considerar o papel fundamental da Educação Infantil nesse processo. Ao se relacionar com os outros, a criança tem um desempenho social específico, definido por Del Prette e Del Prette (2017) como qualquer comportamento ou sequência de comportamentos, que podem favorecer ou interferir na qualidade dos relacionamentos e, a partir disso, influenciar o desenvolvimento dela.

A experiência escolar é essencial para as aquisições educacionais e sociais de nossa cultura. Essa experiência molda as trajetórias da vida adulta, referentes às relações interpessoais, progresso na escolarização, adesão às regras da sociedade e imagem positiva de si mesmo (Del Prette \& Del Prette, 2003; Rodrigues, Dias \& Freitas, 2010, Fernandes, Leme, Soares \& Elias, 2018). Os professores são os principais agentes educacionais na escola e são fundamentais no desenvolvimento escolar e socioemocional dos alunos, e por isso, há a necessidade de capacitá-los para promover tal desenvolvimento em sala de aula (Rodrigues, Dias \& Freitas, 2010).

A Educação Infantil e a passagem para o Ensino Fundamental são períodos em que há o desenvolvimento de habilidades essenciais para que, posteriormente, as crianças tenham sucesso acadêmico e social (McCabe \& Altamura, 2011). Conforme ressaltam Correia-Zanini e Marturano (2016), elas passam muito tempo na escola e, por isso, esse ambiente passa a ser o contexto mais importante do desenvolvimento da criança, além do ambiente familiar.

A infância é considerada, por muitos estudiosos, um período crítico para o desenvolvimento de habilidades sociais, devido ao fato de terem seus primeiros contatos além do ambiente familiar, o que possibilita a ampliação de contato com outros modelos e da 
plasticidade do comportamento social infantil (Del Prette \& Del Prette, 2005; Garnica, 2009; De Salvo, Mazzarotto \& Löhr, 2005).

Pesquisadores têm procurado identificar variáveis, sejam elas de risco ou proteção (Reppold, Pacheco, Bardagi, \& Hutz, 2002), associadas ao tipo de desempenho social emitido por uma criança, sejam elas pessoais, familiares ou contextuais (Casali-Robalinho, 2013). Dentre as variáveis pessoais, as habilidades sociais são apontadas, na literatura, como um fator relacionado diretamente ao desenvolvimento socioemocional de uma criança (Michelson, Sugai, Wood, \& Kazdin, 1987; Rosin-Pinola, Del Prette, \& Del Prette, 2007, Marturano \& Elias, 2017). Já dentre as variáveis familiares e contextuais, as estratégias utilizadas por pais e professores ao educar as crianças, permeadas pelas habilidades sociais que estes possuem, destacam-se como fatores essenciais quando se trata de desenvolvimento infantil (BolsoniSilva, 2018).

A partir das considerações tecidas até o momento, pode-se observar aproximações entre o MBDH e o campo das habilidades sociais. Ambos destacam a interdependência e influência mútua entre a pessoa em desenvolvimento e o contexto imediato do qual participa; além disso, a qualidade das relações interpessoais é tida como fundamental para a compreensão do desenvolvimento humano (Leme, Del Prette, Koller \& Dell Prette, 2015). No campo das habilidades sociais, a competência social é influenciada pelas dimensões pessoal, situacional e cultural, as quais configuram o contexto e impactam sobre o desenvolvimento humano (Del Prette \& Del Prette, 2001), estas dimensões podem ser associadas aos componentes Processo, Pessoa, Contexto e Tempo do MBDH. Pode-se dizer que é por meio das relações interpessoais, que ocorrem nos diversos microssistemas (família, escola, vizinhança) e que o indivíduo participa diretamente ao longo da vida, que ele amplia seu repertório de habilidades sociais (Del Prette \& Del Prette, 2005; Leme, Del Prette, Koller \& Dell Prette, 2015). Com essas relações interpessoais nos microssistemas é que ocorrem os processos proximais; ainda a depender destas relações, a pessoa pode desenvolver um repertório de habilidades sociais positivo (Bronfenbrenner denomina de competências), ou pode desenvolver um repertório deficitário (no MBDH são denominadas de disfunção).

Desde suas origens, o MBDH aponta para a importância de se pensar o desenvolvimento de forma a propor bases científicas, para o planejamento de políticas e de programas públicos eficazes que possam neutralizar ou diminuir as influências que podem prejudicar o desenvolvimento. Dentro desta perspectiva é possível pensar em intervenções, que sejam desenhadas de forma a ampliar o repertório de habilidades sociais, com o intuito de ampliar a 
competência social e auxiliar nos processos proximais (desenvolvimento). Conclui-se que o MDBH oferece recursos para o estudo das habilidades sociais, contribuindo para a compreensão da aprendizagem e do desenvolvimento das habilidades sociais (Leme, Del Prette, Koller \& Del Prette, 2015; Del Prette \& Del Prette, 2010).

\section{Habilidades de Solução de Problemas Interpessoais}

No cenário das habilidades sociais, nesse estudo, foram focalizadas as habilidades de solução de problemas interpessoais, em específico.

De acordo com Chrispino (2007), problema interpessoal pode ser definido como um conflito, que seria uma opinião diferente ou uma maneira alternativa de interpretar um acontecimento. O repertório limitado de alternativas de solução de problemas é um dos fatores que leva à agressividade infantil e indiretamente, ao isolamento social a que crianças agressivas são submetidas (Rodrigues, Dias \& Freitas, 2010).

Borges e Maturano (2009) salientam que uma das maneiras de resolver um conflito é a agressividade, que não leva em consideração a opinião e os sentimentos do outro. Em contrapartida, há a passividade, em que seus próprios sentimentos e opiniões não são considerados, mas o dos outros sim. A maneira mais adequada do ponto de vista sociocognitivo, é o modelo assertivo, que explicita seus direitos e sentimentos, respeitando o direito dos outros. As habilidades de solução de problema promovem uma forma reflexiva de tomada de decisão, já que se baseia na análise das consequências de cada comportamento emitido, levando a um enfrentamento mais adaptativo e saudável (Rodrigues, Dias \& Freitas, 2010).

Apesar de extremamente relevantes, na literatura não foram encontrados estudos nacionais que avaliam intervenções voltadas ao desenvolvimento de habilidades sociais de solução de problemas interpessoais (HSPI) para a Educação Infantil, sendo o foco até o momento o Ensino Fundamental. Logo, pretende-se que este estudo possa contribuir para um campo do conhecimento pouco desenvolvido.

De acordo com Shure (2006), as habilidades de solução de problemas interpessoais consistem em criar um planejamento para atingir uma meta pré-estabelecida, pensar em soluções que possam resolver o problema, prever consequências, ter consciência sobre o próprio sentimento e sobre o sentimento do outro, além de entendimento de causa e efeito.

Dessa forma, essa habilidade implica em reconhecer os próprios sentimentos e pensamentos, colocar-se no lugar do outro e, posteriormente, modificar o próprio 
comportamento (Rodrigues, Dias \& Freitas, 2010). O desenvolvimento das habilidades de solução de problemas interpessoais ajuda a criança a ampliar o repertório para que elas sejam capazes de lidar com situações cotidianas conflituosas (Rodrigues, Dias \& Freitas, 2010).

De acordo com Marturano, Elias e Versuti (2017), os conflitos interpessoais permeiam o cotidiano constantemente e as habilidades para lidar com estes são essenciais para manter relacionamentos satisfatórios. As autoras destacam que essas habilidades são aprendidas a partir da experiência dos indivíduos e pode ser entendida como um conjunto de habilidades e um processo de aprendizagem. As habilidades envolvidas no processo de solução de problemas interpessoais são: planejar meios para atingir fins, gerar soluções alternativas para resolver o problema, analisar os possíveis resultados de cada solução concebida, observar os próprios sentimentos e dos outros e analisar a relação entre comportamentos e prováveis consequências.

\section{Habilidades Sociais: Desempenho Acadêmico e Problemas de Comportamento}

Crianças com baixo desempenho acadêmico tendem a apresentar um repertório mais deficitário de habilidades sociais, quando comparadas àquelas com bom rendimento acadêmico (Bandeira, Rocha, Pires, Del Prette, \& Del Prette, 2006; Feitosa, Del Prette, Del Prette, \& Loureiro, 2011; Rosin-Pinola et al., 2007; Amaral \& Elias, 2016). Rendimento escolar baixo associa-se, no Brasil, a fracasso escolar, considerando os altos níveis de repetência e evasão nesses casos (Cia \& Barham, 2009; Fernandes, Leme, Soares \& Elias, 2018).

A correlação positiva entre as habilidades sociais e o desempenho acadêmico pode ser explicada, segundo Del Prette, Rocha e Del Prette (2011), pelo efeito que o repertório de habilidades sociais produz sobre as relações estabelecidas com os colegas e professores, ou sobre a instrumentalização de habilidades específicas relacionadas ao ambiente escolar, tais como solicitar informações, fazer perguntas, participar da aula e discutir pontos de vista. Nessa direção, DiPerna (2006) nomeou as habilidades sociais de facilitadores acadêmicos.

Tem-se que as diferentes habilidades sociais se entrelaçam, complementando-se ao longo do desenvolvimento e nesse sentido, atuam como fator de proteção para o enfrentamento e minimização dos danos causados pelo estresse no cotidiano escolar ou de outros microssistemas dos quais a criança participa. As habilidades sociais são sistematicamente reconhecidas como recursos indispensáveis para o desenvolvimento infantil (Casali-Robalinho, Del Prette \& Del Prette, 2015), além de serem consideradas importantes para o ajustamento social, redução de problemas de comportamento e sucesso no ambiente escolar (Del Prette \& Del Prette, 2003; Borges \& Marturano, 2010). 
Além das habilidades sociais, problemas comportamentais encontram-se associados a desempenho acadêmico, contudo, negativamente (Bandeira, Rocha, Souza, Del Prette, \& Del Prette, 2006). Crianças com um repertório deficitário de habilidades sociais tendem a apresentar maior ocorrência de problemas de comportamento (Bandeira, Rocha, Souza, et al., 2006; Casali-Robalinho, 2013; Cia \& Barham, 2009) e menor desempenho acadêmico (Jovarini, Leme \& Correia-Zanini, 2018).

Em estudo preditivo Breslau, Breslau, Miller e Raykov (2011) encontraram que problemas comportamentais aos seis anos são preditores de problemas de comportamento aos 11 e aos 17 anos e que os problemas de comportamento aos seis e 11 anos são preditores negativos de matemática e leitura aos 17 anos.

Os problemas de comportamento competem com a aquisição e desempenho de habilidades sociais específicas restringindo, assim, oportunidades de emissão de comportamentos pró-sociais (Gresham \& Elliott, 1990) e interferem no desempenho escolar (Montroy, Bowles, Skibbe \& Foster, 2014; Elias \& Marturano, 2016). Nesse sentido, Del Prette et al. (2011) apontam que "as habilidades sociais são concebidas como funcionalmente equivalentes, competindo e substituindo os problemas de comportamento por produzirem consequências imediatas similares para a criança, sem as consequências negativas dos problemas de comportamento" (p. 47), podendo ser consideradas como recursos de proteção ao desenvolvimento.

Segundo Bolsoni-Silva e Del Prette (2003), os problemas de comportamento se referem a excessos ou déficits comportamentais que dificultam o acesso da criança a novas contingências de reforçamento, relevantes para a aprendizagem e promotoras do desenvolvimento. Problemas de comportamento, em geral, tornam-se mais graves em razão de interações negativas da criança com o ambiente e, portanto, a escola tem um papel fundamental nesse processo. Além disso, estes problemas aumentam o risco de problemas psicossociais na adolescência e início da fase adulta (Kirkhaug et al 2016).

Com base na diferenciação inicial de Achenbach e Edelbrock (1979), de forma geral, a literatura de Psicopatologia Infantil classifica os problemas de comportamento em dois grandes grupos: internalizantes e externalizantes. Problemas internalizantes se expressam basicamente em relação ao próprio indivíduo; podem ser observados quando há tristeza, retraimento, timidez, insegurança, medos e inibição excessiva; e estão associados a transtornos psicológicos como ansiedade, depressão, queixas somáticas e fobia social. Problemas externalizantes, por outro lado, se apresentam predominantemente em relação a outras pessoas; envolvem 
impulsividade, agressão, agitação, provocações e comportamento desafiador; e estão associados a comportamentos perturbadores, como o transtorno negativista desafiante ou o transtorno dissocial. Ambos os grupos de problemas são igualmente prejudiciais e podem ter consequências desfavoráveis para o desenvolvimento e, portanto, devem ser foco de intervenções preventivas (Del Prette \& Del Prette, 2005; Falcão, et al, 2016).

\section{Promoção e prevenção}

A literatura sinaliza que um repertório elaborado de habilidades sociais constitui fator protetivo para o desenvolvimento saudável e satisfatório de uma criança, atuando na prevenção de diversos problemas, sejam eles comportamentais ou acadêmicos (Del Prette et al., 2011; Amaral \& Elias, 2016; Fernandes, Leme, Soares \& Elias, 2018). Além disso, diminuir a incidência de problema de comportamento na sala de aula pode ter impacto positivo no desempenho escolar das crianças (Kirkhaug et al 2016; Elias \& Marturano, 2016). Considerando esses fatores, é essencial considerar programas de intervenção preventivos no microssistema escolar.

O desenvolvimento de um repertório de habilidades sociais começa no nascimento e se torna progressivamente mais elaborado ao longo da vida, na interação do indivíduo com as demandas e desafios do seu ambiente. Comportamentos socialmente habilidosos podem, portanto, ser aprendidos de forma incidental/natural no contexto das interações. No entanto, condições ambientais restritivas ou inadequadas à aprendizagem ou aperfeiçoamento podem trazer como consequência diferentes tipos de déficits em habilidades sociais. Estes são caracterizados por falhas ou dificuldades na emissão de comportamentos sociais habilidosos frente às demandas do ambiente (Del Prette \& Del Prette, 2005). A necessidade de estabelecer novas condições de aprendizagem (Del Prette et al., 2011), justifica o investimento de pesquisadores em programas de Treinamento de Habilidades Sociais (THS), que envolvem estratégias psicoeducativas ou terapêuticas eficazes no ensino de novas habilidades sociais ou na ampliação ou aprimoramento do repertório de habilidades sociais já existente.

Considerando-se a função protetora das habilidades sociais e do uso de estratégias educativas positivas por parte dos pais e professores (Del Prette et al., 2011) e que, se atendidas precocemente, as dificuldades interpessoais são mais prováveis de serem superadas (Loeber, 1991), torna-se muito importante promover habilidades sociais nas próprias crianças e nos 
agentes educativos, como mecanismo preventivo de problemas socioemocionais e acadêmicos na infância.

As habilidades sociais são consideradas fatores de proteção para o desenvolvimento dos indivíduos e, portanto, o trabalho que as permeia, pode estar dentro de um contínuo que vai da prevenção universal ao tratamento propriamente dito. Nesse estudo o interesse está em trabalhos preventivos universais, como forma de auxiliar no desenvolvimento de recursos que possam atuar como fator de proteção ao desenvolvimento (Bandeira, et al., 2006).

De acordo com Murta e colaboradores (2015), prevenção define-se como uma ação dirigida aos determinantes sociais da saúde microssociais relativos aos comportamentos e estilos de vida. O objetivo da prevenção é de fortalecer fatores de proteção e intervir sobre os fatores de risco. A prevenção pode ser dividida em três frentes: universal, quando a ação dirigida a toda a população; indicada, na qual age-se em sujeitos que apresentam características de risco e; seletiva, que seria a ação àqueles que já se sabe que necessitam de tal tipo de intervenção A prevenção e promoção de saúde, pode ser realizada a partir de programas de intervenção que visem desenvolvimento/aprimoramento de habilidades sociais e que consequentemente, previnem problemas de comportamento e de desempenho acadêmico. Murta e Santos (2015) destacam, ainda, os trabalhos de prevenção como essenciais na área da psicologia, já que promovem melhores resultados e com menores custos que a remediação.

Segundo a APA - American Psychological Association (2002), os programas de intervenção são propostas de promoção de saúde mental, que devem ser baseadas em evidências, ou seja, antes de serem disponibilizadas e oferecidas como políticas públicas, devem ser testadas quanto à efetividade e eficácia para garantir que cumpram os objetivos propostos.

Organização Mundial da Saúde defende que práticas preventivas devem integrar o currículo de forma contínua e não só transversal, além de colocar o ensino de habilidades sociais como fator protetivo para o desenvolvimento infantil (Who 1999; Rodrigues, Dias \& Freitas, 2010; Elias \& Marturano, 2016).

Programas de intervenção com crianças são conduzidos, em geral, nas instituições educativas, por ser um ambiente propício para a aprendizagem formal de tais habilidades, embora também estejam presentes em ambientes clínicos (Dias, Lopes, \& Del Prette, 2015). No contexto escolar, estudos têm mostrado a efetividade dos modelos em camadas, abrangendo os três níveis de intervenção: universal, seletivo e indicado (Mrazek \& Haggerty, 1994; Kratochwill, Albers, \& Shernoff, 2004). Além disso, programas aplicados em ambiente escolar podem ser implementados por profissionais capacitados (especialistas ou pelos próprios 
professores, entendendo a função mediadora deles na sala de aula). Após o preparo adequado por profissionais, o professor poderia, então, conduzir sessões de intervenção dentro da própria sala, promovendo a replicação do programa ao longo do tempo e com diferentes alunos, atuando assim como multiplicadores (Lopes, 2013).

A literatura tem apontado programas de intervenção com agentes educativos (professores e pais), que objetivam promover as habilidades sociais educativas (HSE) destes, a fim de "capacitá-los no manejo e na promoção de comportamentos de seus filhos ou alunos". Têm crescido o investimento em orientar agentes educativos como via indireta para o ensino de habilidades sociais às crianças (Del Prette et al., 2011).

Além de analisar os efeitos sobre o próprio repertório de habilidades sociais educativas, os programas direcionados a pais e professores geralmente estudam o impacto no desenvolvimento dos filhos ou alunos, sejam eles pré-escolares, escolares ou adolescentes. No Brasil, especificamente, pesquisadores têm desenvolvido treinamentos de habilidades sociais educativas tanto para pais (Bolsoni-Silva \& Borelli, 2012; Bolsoni-Silva, Silveira, \& Marturano, 2008; Pinheiro et al., 2006; Rocha, Del Prette, \& Del Prette, 2011; Sabbag \& Bolsoni-Silva, 2011) quanto para professores (Rosin-Pinola, 2010; Rosin-Pinola, Marturano, Elias e Del Prette, 2018), embora em menor número. No que se refere às práticas educativas, no Brasil, o ambiente escolar tem sido menos estudado que o familiar (Bolsoni-Silva, Mariano, Loureiro, \& Bonaccorsi, 2013).

Um do programa de prevenção estudado no contexto nacional, foi o EPRP - I Can Problem Solve, caracterizado como uma prevenção seletiva, sendo traduzido e adaptado, destinado para crianças em risco de problema de comportamento e desenvolvido a partir do pressuposto de que as habilidades de solução de problemas interpessoais contribuem para a prevenção de problema de comportamento. O programa foi elaborado para os professores aplicarem em sala de aula e mostrou-se como um recurso para melhorar a convivência entre as crianças no início do Ensino Fundamental, uma vez que padrões de relacionamentos estabelecidos nessa fase da infância tendem a se manter. As pesquisas que investigaram os efeitos do programa evidenciaram que este é efetivo para reduzir, consistentemente, problemas de comportamento em crianças (Shure, 2006; Elias, Marturano \& Motta-Oliveira, 2012).

Outro estudo encontrado na literatura, com desenho quasi-experimental, com pré e pósteste, desenvolvido por Kirkhaug et al. (2016) na Noruega, testou um programa universal de intervenção escolar The Incredible Years Teacher Classroom management program (IY-TCM). O objetivo do estudo foi investigar se o programa contribuiria efetivamente para a diminuição de problemas de comportamentos externalizantes e internalizantes graves, aumento das 
habilidades sociais, ganhos no desempenho acadêmico e melhoras na relação com os professores. Participaram do estudo crianças de 6 a 8 anos, distribuídas em 43 escolas, divididas entre grupo de intervenção e controle. Foram incluídos no estudo apenas alunos que tinham problemas externalizantes graves de acordo com as professoras e que responderam ao questionário SESBI-R. O programa foi desenvolvido para ajudar os professores no manejo de problemas de comportamento em sala de aula e promover comportamentos pró-sociais nos alunos. O treinamento foi realizado pelos professores, que tiveram workshops sobre a aplicação do programa e apoio de um manual (contendo checklists, lembretes, sugestões sobre apresentações e discussões pro workshop). Não foram encontradas diferenças entre os dois grupos no pré e no pós-teste com relação a problemas de comportamento externalizantes, habilidades sociais e proximidade com os professores. No entanto, o grupo de intervenção apresentou melhores resultados, após a aplicação do programa, quanto à melhora no desempenho acadêmico e diminuição de conflitos com os professores. Concluiu-se que apenas o programa universal IY-TCM não é suficiente para a diminuição de problemas de comportamentos a nível clínico, indicando que para isso, é necessário outro tipo de intervenção, mais específica. De acordo com Kirkhaug et al. (2016), os resultados não foram satisfatórios como o esperado, já que programas de prevenção seletiva têm se mostrado mais efetivo que programas universais. Além disso, Kirkhaug et al. (2016), afirmam que o treinamento de habilidades parentais simultaneamente, podem melhorar os resultados da intervenção.

Outro estudo encontrado na literatura foi o de Elias e Marturano (2014), que avaliaram os efeitos e a permanência destes de duas intervenções, uma de ênfase acadêmica (Oficinas de Linguagem) e outra interpessoal (Solução de Problemas Interpessoais) para crianças com problemas de comportamento associados à queixa escolar. Participaram do estudo 44 crianças de 7 a 11 anos, inscritas em uma clínica-escola pública de psicologia, encaminhadas com queixa escolar via Sistema Único de Saúde - SUS. O estudo contou com três avaliações: préintervenção; reavaliação, logo após a intervenção; e avaliação de seguimento, meses após a intervenção. Os resultados apontaram efeitos semelhantes nas duas modalidades de intervenção, porém mais intensos na modalidade com ênfase em habilidades de solução de problemas interpessoais, tanto sobre problemas de comportamento quanto sobre indicadores de desempenho acadêmico.

Borges e Marturano (2010) também realizaram um estudo com alunos da $1^{\mathrm{a}}$ série do Ensino Fundamental. Neste, verificaram a efetividade de um programa de intervenção na melhoria da convivência em sala de aula. Foi realizada uma intervenção incluindo o ensino de habilidades sociais de solução de problemas interpessoais, iniciação aos valores humanos e 
autocontrole emocional, que foi conduzida pela professora. Para verificar a efetividade do programa, as crianças foram avaliadas quanto ao desempenho pró-social, a percepção de estressores, o comportamento em sala de aula antes e após a intervenção e os conflitos foram registrados em um diário de campo. A avaliação do programa mostrou que este pode contribuir para a melhora da convivência dos alunos em sala de aula, uma vez que os resultados apontaram redução nos conflitos e aumento no indicador pró-social, comparados a alunos que não passaram pela intervenção.

Rodrigues et al. (2010), aplicaram um programa adaptado, já existente na literatura, em habilidades sociais de problemas interpessoais. Participaram 30 crianças de 6 e 7 anos do $1^{\circ}$ ano do Ensino Fundamental de uma escola pública de Minas Gerais, que havia solicitado ajuda para duas turmas de $1^{\circ}$ ano que apresentavam problemas de comportamento e conflitos interpessoais. O estudo compreendeu pré e pós-avaliação com a utilização da Social Skills Rating System - SSRS-BR. Na intervenção, foi utilizado um programa que visa o desenvolvimento de habilidades de solução de problemas interpessoais em sala de aula. Os resultados indicaram aumento de algumas habilidades, como empatia, assertividade, expressão de sentimento positivo, civilidade e responsabilidade. Esses dados corroboram com as observações realizadas que evidenciam aumento das habilidades prévias e habilidades para solução de conflitos.

Elias e Marturano (2016), verificaram os efeitos do Programa Posso Pensar em alunos do Ensino Fundamental. Participaram 203 alunos, com idade entre 6 e 10 anos e suas professoras. O estudo teve delineamento quase-experimental com grupos de intervenção e controle, realizando medidas pré e pós-intervenção. Os resultados apresentaram que apenas o grupo de intervenção apresentou melhoras significativas em todas as variáveis investigadas, com destaque para redução de problemas de comportamento e desenvolvimento de habilidades de solução de problemas interpessoais e outras habilidades sociais.

Os estudos acima citados foram realizados prioritariamente com crianças no Ensino Fundamental. Buscou-se na literatura outros estudos direcionados a crianças em idade préescolar, contudo não foram encontrados. Segundo Shure (2006), as habilidades de solução de problemas interpessoais podem ser desenvolvidas a partir dos três anos de idade e mostram-se diretamente ligadas a uma melhor condição de adaptação ao longo do desenvolvimento. Diante desse cenário buscou-se verificar se o Programa Posso Pensar poderia trazer contribuições para o desenvolvimento e/ou aprimoramento de habilidades de solução de problemas interpessoais em crianças pré-escolares. 
Considerando todo o cenário apresentado no que tange a importância habilidades sociais e problemas de comportamento na Educação Infantil, assim como a possibilidade de programas de prevenção dirigidos a esta população, o presente estudo foi constituído.

\section{Justificativa}

O presente estudo justifica-se por sua relevância científica e social, à medida que trata de uma lacuna observada na literatura e traz ferramentas diretamente destinadas à comunidade. A literatura aponta a importância de intervenções com objetivo de desenvolver habilidades sociais em crianças e ajudá-las a lidar com os desafios de seu dia-a-dia. Sugere-se que o desenvolvimento das habilidades interpessoais na infância constitui em fator de proteção à medida que o comportamento socialmente habilidoso favorece a obtenção de reforçadores sociais importantes (Bolsoni-Silva, Marturano \& Freiria, 2010; Barker et al., 2010; Rodrigues et al., 2010; Correia-Zanini, 2013; Marturano e Elias, 2016; Gonçalves \& Murta, 2008).

Dentre as habilidades sociais, as habilidades sociais de problemas interpessoais, tem sido destacada como fator de proteção ao desenvolvimento infantil (Elias et al., 2012; Borges \& Marturano, 2009), à medida que que indivíduos que apresentam essas habilidades mais desenvolvidas se mostram adaptados em seus contextos escolar e familiar (Elias et al., 2012; Elias e Marturano, 2016).

\section{Objetivo Geral}

O presente estudo teve por objetivo geral avaliar efeitos de um treinamento de habilidades sociais, com ênfase em habilidades de solução de problemas interpessoais (Programa Posso Pensar), em um ensaio de campo, com alunos da Educação Infantil, de modo a verificar a replicabilidade dos resultados obtidos com alunos dos primeiros anos do Ensino Fundamental I (Elias \& Marturano, 2016).

\section{Objetivos Específicos}

a) Revisar sistematicamente a literatura acerca de programas de intervenção para o desenvolvimento de habilidades sociais na educação infantil, bem como identificar suas principais características, diferenças e semelhanças. 
b) Verificar os efeitos de um programa para o desenvolvimento de habilidades de solução de problemas interpessoais, em alunos da Educação Infantil, sobre as variáveis de habilidades sociais, habilidades de solução de problemas interpessoais e problemas de comportamento, realizando a comparação entre grupos (alunos expostos ao programa e alunos não expostos) antes e após a intervenção.

c) Comparar as habilidades de solução de problemas interpessoais, total de habilidades sociais e problemas de comportamento antes e após a intervenção, verificando as mudanças intragrupo, comparando as variáveis de cada grupo com ele mesmo.

Os objetivos acima descritos foram respondidos e encontram-se descritos nos estudos I, II e III desta dissertação.

\section{Contexto}

O presente estudo foi desenvolvido em uma cidade do interior paulista, que de acordo com consulta feita ao site do IBGE (2020), apresenta um Índice de Desenvolvimento Humano Municipal - IDHM de 0,761, com população estimada para 2013 de 127.142 habitantes, sendo considerado de médio porte. No ano de 2020 a rede municipal de Ensino Fundamental contava com 15.218 alunos matriculados no Ensino Fundamental e com 3. 224 alunos matriculados na pré-escola.

Informa-se que o presente estudo trata de um recorte do projeto maior intitulado "Projeto Posso Pensar: Estudo em larga escala” (Processo: 2015/13617-1), no qual pesquisadora participa juntamente com outros membros ligados ao Laboratório de Psicologia da Educação e Escolar - LAPEES. 
Estudo 1

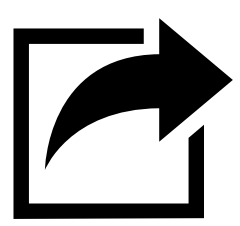




\title{
Programas de intervenção para o desenvolvimento de habilidades sociais na Educação Infantil: um estudo de revisão.
}

\section{Resumo}

As habilidades sociais são aprendidas desde a infância, sendo essenciais para o estabelecimento de relações duradouras e satisfatórias que constituem processos fundamentais no desenvolvimento humano. Neste cenário, podem ser criadas condições para o aprendizado de habilidades sociais na forma de programas de treinamento. O presente estudo teve como objetivo revisar sistematicamente a literatura acerca de programas de intervenção para o desenvolvimento de habilidades sociais na Educação Infantil, bem como identificar suas principais características, diferenças e semelhanças. Para tanto, foram consultadas as bases de dados SciELO, Lilacs, Psychinfo, Psycarticles e Web of Science, considerando artigos publicados de 2015 a 2019. Utilizou-se o protocolo PRISMA e dois juízes verificaram os procedimentos de seleção e extração de forma independente. Foram encontrados oito artigos que cumpriram os critérios estabelecidos. Observou-se que os estudos apontaram o aumento em habilidades sociais e diminuição de problema de comportamento nos participantes após passarem pelos programas; contudo, sinalizaram ressalvas nos ganhos em programas de prevenção universal para crianças com problemas de comportamento pré-existentes.

Palavras-chave: educação, habilidades sociais, pré-escolar.

\begin{abstract}
Social skills are learned since the chidhood and are very important to establish long lasting e satisfactory relashionships, which is part of the human development. Therefore, it can be developed conditions for the learning of social skills by training programs. This study aims to revise sistematically the literature about intervention programs concerning the development of social skills at the kindergarten, as well as identify the main characteristics, diferences and resemblances between them. To acomplish this purpose, those data bases were consulted: SciELO, Lilacs, Psychinfo, Psycarticles and Web of Science. The articles considered were the ones published between 2015 and 2019. The Protocol PRISMA was used and two judges verified the procedures of selection and extraction, independently. Eight articles were
\end{abstract}


considered to acomplish the criteria. It was observed that studies indicates a raise in social skills and a decrease of behavior problem after the intervention. However, diferences were found concerning gains in universal prevention programs directed to children who already had behavior problems.

Key-words: education, social skills, child, preschool.

\section{Resumen}

Habilidades sociales son aprendidas desde la infancia y son cruciales para o establecimiento de relaciones perdurables y satisfactorias que son fundamentales en el desarollo humano. En este escenario, condiciones pueden ser creadas para el aprendizaje de habilidades sociales em forma de treinamiento. El propósito del estúdio es revisar sistematicamente la literatura acerca de programas de intervención para el desarollo de habilidades sociales en la educación infantil, así como identificar sus principales características, diferencias y similutes. Para eso, fueron consultados las bases de datos SciELO, Lilacs, Psychinfo, Psycarticles y Web of Science, analizando artículos publicados de 2015 hasta 2019. Se utilizó el protocolo PRISMA y dos jueces verificaron los procedimentos de selección y extracción de modo independiente. Se encontraron ocho artículos que cumplen los critérios estabelecidos. Se observó que los estudios señalaran un aumento en habilidades sociales y dismunución en problemas de conducta en ninõs que participaran de la intervención. Sin embargo, señalaran reservas em las ganancias de programas de prevención universal para niños com problemas de conducta preexistentes.

Palabras clave: educación, habilidades sociales, pré-escolar.

\section{Introdução}

Habilidades sociais são compreendidas como comportamentos sociais, valorizados em determinada cultura, que contribuem para a qualidade na interação com os pares, dado que possuem alta probabilidade de gerar consequências favoráveis, tanto para o próprio indivíduo, como para seu grupo e comunidade maior (Del Prette \& Del Prette; Del Prette \& Del Prette, 2017). São comportamentos requeridos para manter uma interação de qualidade, na qual ambas as partes se beneficiem. Essas habilidades são aprendidas através das relações desde muito cedo no desenvolvimento e podem ser aprendidas de forma sistemática através de programas a partir da pré-escola, período em que as crianças começam a ter mais contato com seus pares, além de 
outros educadores, como professores. Estudos indicam a importância das habilidades sociais educativas, que perpassam as habilidades sociais dos educadores (pais, professores e outros), que por sua vez, as ensinam para as crianças (Del Prette \& Del Prette, 2017; Feitosa, et al., 2018).

De acordo com Del Prette e Del Prette (2017), habilidades sociais desenvolvidas nos primeiros anos da infância são mantidas a médio e longo prazo, favorecendo o desenvolvimento e o aprimoramento das mesmas e de outras habilidades em idades posteriores. As habilidades sociais são muito importantes ao longo de todo o ciclo vital, já que são requisitos para que sejam estabelecidas relações positivas e duradouras (Marques-Pinto et al., 2015; Walker 2017).

A literatura vem apontado diferentes estudos que associam as habilidades sociais a outras variáveis importantes no desenvolvimento infantil. Destaca-se aqui as correlações positivas entre habilidades sociais e desempenho acadêmico (Feitosa, Del Prette, Del Prette, \& Loureiro, 2011), fator que também exerce grande impacto na vida dos indivíduos. Sabe-se que a escola constitui um importante microssistema no desenvolvimento infantil, visto que as crianças passam grande parte de suas vidas dentro desta, tornando um contexto mais importante do desenvolvimento depois do familiar, durante os anos da infância (Correia-Zanini \& Marturano, 2016).

Estudos têm apontado que crianças que desde cedo apresentam problemas de comportamento, como baixa capacidade de atenção, de controlar emoções negativas e de relacionamento com os colegas estão no grupo de risco para o baixo desempenho escolar (Amaral \& Elias, 2016, Fernandes, Leme, Soares \& Elias, 2018). Um repertório de habilidades sociais que envolve comportamentos como saber solicitar informações, fazer perguntas, participar da aula, discutir pontos de vista, seguir regras entre outros, faz com que os alunos consigam se envolver melhor com as questões acadêmicas, além de facilitar suas relações com pares e professores (Del Prette \& Del Prette, 2011).

Os anos pré-escolares constituem um período ímpar no desenvolvimento, no qual as habilidades essenciais para o posterior sucesso acadêmico e social, são adquiridas (McCabe \& Altamura, 2011). Durante os anos da pré-escola, as crianças aprendem habilidades sociais, valores, comportamentos pró-sociais, como interagir com colegas, além de outras habilidades, sendo essa aprendizagem mediada pelos professores e próprios pares. Neste cenário, o auxílio para o desenvolvimento e/ou aprimoramento de habilidades sociais tanto em professores como alunos, constitui um importante recurso. Estudos sugerem que programas voltados para a préescola podem ter impactos positivos de curto e longo prazo para as crianças e a sociedade, em 
geral, além de ajudarem os alunos a estarem melhor preparados para a entrada no Ensino Fundamental (Aytar et. al, 2017; Leech, 2017).

Sabe-se que as habilidades sociais são ferramentas necessárias para que possa chegar à competência social, destacada em toda a extensão da Base Nacional Comum Curricular BNCC (Ministério da Educação, 2017). Dentro do campo teórico-prático das habilidades sociais, a competência social é considerada como um constructo avaliativo do desempenho social do indivíduo em uma tarefa interpessoal (levando-se em conta objetivos pessoais, demandas da situação e da cultura), gerando consequências positivas para todos (Del Prette \& Del Prette, 2017). As habilidades sociais e a competência social têm sido assinaladas como fatores de proteção ao comportamento antissocial, sendo estes fatores correlacionados negativamente, ou seja, quanto mais competência social, menos problema de comportamento (Casali-Robalinho, 2013). Isso pode ser aplicado na medida em que as mesmas consequências positivas obtidas através de comportamentos antissociais são obtidas através de comportamentos habilidosos, bem aceitos socialmente e ainda sem as consequências negativas. Compreende-se por problemas de comportamento como déficits ou excessos comportamentais que prejudicam a interação da criança com pares e adultos de sua convivência. Dessa forma, em uma análise funcional, estes problemas podem atuar como concorrentes às habilidades sociais para o acesso às contingências relevantes de aprendizagem e para o estabelecimento de relações interpessoais saudáveis (Bolsoni-Silva \& Loureiro, 2016). Os problemas de comportamento têm se tornado uma constante no contexto escolar, interferindo não só no desempenho acadêmico mas também nas relações sociais, chegando muitas vezes, em situações de bullying (Berry \& O'Connor, 2010; Barreto, Freitas \& Del Prette, 2011; Bolsoni-Silva, Loureiro \& Marturano, 2011; Elias \& Marturano, 2014; Pizato, Marturano \& Fontaine, 2014; Bolsoni-Silva \& Loureiro, 2016).

Nota-se, a partir dessas informações, a importância do desenvolvimento de habilidades sociais e o quanto intervenções baseadas em evidências podem contribuir para a prevenção e redução de problemas de comportamento. Cabezas et. al. (2016) apontam que intervenções para a redução de problemas de comportamento nos primeiros anos da infância podem prevenir violência futura, ressaltando que agressão e problemas de comportamento podem aumentar com a exposição da baixa qualidade do ambiente pré-escolar.

Neste cenário, a Educação Infantil representa um importante contexto para a implementação de intervenções preventivas para o desenvolvimento e/ou aprimoramento de habilidades sociais, contribuindo assim para a competência social dos alunos. O objetivo da 
prevenção é de fortalecer fatores de proteção e intervir sobre os fatores de risco. A prevenção pode ser caracterizada como universal, ação dirigida a toda a população; indicada, agindo em sujeitos que apresentam características de risco; e seletiva, ação àqueles que já se sabe que necessitam de tal tipo de intervenção (Abreu, Barletta, \& Murta, 2015).

Estudos sobre treinamentos voltados para a Educação Infantil têm se intensificado e indicam que crianças expostas a programas de treinamento de habilidade sociais, tiveram um aumento de habilidade sociais, quando comparadas as que não participaram do treinamento (Cabezas et a., 2016; Vale et al., 2008; Marques-Pinto, 2015; Walker, 2017; Ladwig, 2018; Ssrker, 2016; Drugli, 2017; Aytar, 2017; Leech, 2018; Elias \& Marturano, 2016). Buscando ampliar o conhecimento sobre o tema, o presente estudo teve como objetivo revisar sistematicamente a literatura acerca de programas de intervenção para o desenvolvimento de habilidades sociais na Educação Infantil, bem como identificar suas principais características, diferenças e semelhanças.

\section{Método}

Como norteador para a elaboração da revisão sistemática, buscou-se encontrar quais são as principais características de programas de intervenção para o desenvolvimento de habilidades sociais na Educação Infantil, assim como suas semelhanças e diferenças.

As palavras-chave foram consultadas nos Descritores em Ciência da Saúde (DeCS) e os termos encontrados foram combinados com os operadores boolianos: ("Habilidades Sociais" or "social skills" or "habilidades sociales" or "competência social") AND ("curso de treinamento" or "intervenção" or "intervention" or "treinamento" or "capacitación" or "capacitação" or "training") AND ("Pré-Escolar" or "Child" or "Preschool" or "Preescolar" or "Criança" or "crianças" or "Pré-escolar" or "pré-escolares" or "Niño") AND ("Instituições Acadêmicas" OR "Schools" OR "SCHOOL" OR "Instituição Acadêmica" OR "Instituciones Académicas" OR "Instituição de ensino" OR "Instituições de ensino" OR "escola" OR "escolas")

A busca foi realizada nas bases SciELO, Lilacs, Psychinfo, Psycarticles e Web of Science entre abril e junho de 2020. Foram filtrados os artigos publicados nos últimos 5 anos, de janeiro de 2015 a dezembro 2019, nos idiomas português, inglês e espanhol. A seleção dos estudos foi baseada no título e resumo e na extração dos dados na análise dos artigos completos. Os critérios de inclusão foram: estudos sobre programas de intervenção para o desenvolvimento de habilidades sociais, população entre 3 e 6 anos, no formato de grupo e no contexto escolar. Já os critérios de exclusão foram: revisões sistemáticas, desenvolvimento ou validação de 
instrumentos, como testes ou escalas, percepção de pais ou professores sobre as intervenções, programas destinados a crianças com desenvolvimento atípico ou com problemas psiquiátricos, programas não relacionados a psicologia e voltados para crianças maiores de 6 anos. Todos os artigos foram importados para o software gerenciador de bibliografias para publicação de artigos científicos Endnote. No software, foram excluídos os artigos duplicados. Os artigos que cumpriram todos esses critérios foram lidos e analisados pela pesquisadora. Os critérios do PRISMA (Preferred Reporting Items for Systematic Reviews and Meta-Analyses) foram utilizados para redigir o relatório dessa revisão. Ressalta-se que, para amenizar o risco de viés, dois juízes realizaram os procedimentos de seleção e extração de forma independente, com índice de concordância satisfatório. Esse procedimento foi realizado pela aluna, pela orientadora e por uma integrante do laboratório em momentos diferentes. Após cada uma ter seus resultados, os compararam, discutiram e entraram em acordo com uma taxa de $80 \%$.

\section{Resultados}

A seguir serão apresentados os resultados obtidos nesse estudo de revisão. Inicialmente, na Figura 1, encontram-se os artigos identificados na busca de dados, assim como os selecionados, elegíveis e incluídos. Na Tabela 1, são descritos os artigos selecionados no que se refere a nome do artigo, ano de publicação e nome do autor, país de origem, objetivo e variáveis analisadas no artigo. Já na Tabela 2, as características dos artigos são descritas por metodologia, tipo de prevenção, $\mathrm{N}$ da amostra, idade dos participantes, duração do treinamento e resultados dos estudos. 


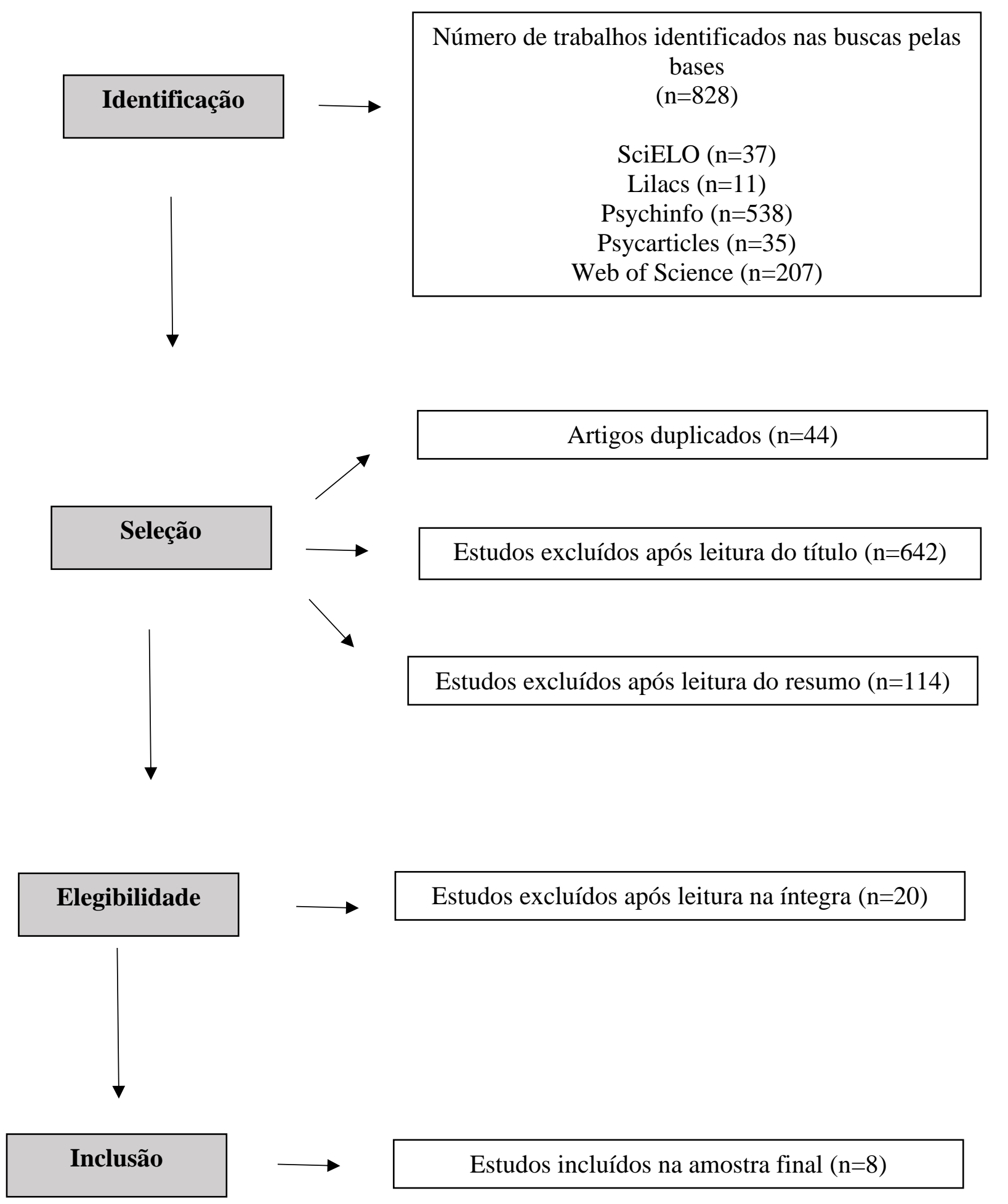

Figura 1. Fluxograma dos estudos selecionados para a revisão. 
A Figura 1 ilustra o número de artigos que foram incluídos na revisão sistemática. Percebe-se que 828 artigos foram identificados nas bases de dados e destes, 44 foram considerados duplicados, ou seja, foram encontrados em mais de uma base e, portanto, considerados apenas uma vez; 642 estudos foram excluídos por não atenderem os critérios definidos pela leitura do título, por se referirem a outra faixa etária ou a criança com autismo, por exemplo e; 114 foram excluídos após a leitura dos resumos devido ao fato de tratarem-se de estudos de treinamentos de outras habilidades, que não sociais ou de estudos que descreviam associações e percepções, e não avaliavam os efeitos de um treinamento aplicado. Foram então selecionados 28 lidos na íntegra e, desses, 20 foram excluídos, já que não estava explícito no título ou no resumo variáveis que os levaram a não preencher critérios de elegibilidade. Assim, oito artigos foram incluídos na revisão. A seguir se encontram as análises das semelhanças e diferenças entre os artigos incluídos.

Tabela 1.

Descrição Dos Estudos Sobre Treinamentos De Habilidades Sociais Na Educação Infantil De 2015 a 2019

\begin{tabular}{|c|c|c|c|c|}
\hline Artigo & \begin{tabular}{|l|} 
Autores/ano \\
\end{tabular} & País & \begin{tabular}{|l|} 
Objetivo \\
\end{tabular} & Variáveis analisadas \\
\hline $\begin{array}{l}\text { 1. Desarollo De La } \\
\text { Competência Social Y } \\
\text { Prevencion } \quad \text { De } \\
\text { Problemas De Conducta } \\
\text { En El Aula Infantil }\end{array}$ & $\begin{array}{l}\text { Martínez, } \\
\text { Justicia-Arráez, } \\
\text { Corredor, e } \\
\text { Cabezas (2016) }\end{array}$ & Espanha & $\begin{array}{l}\text { Analisar o efeito longitudinal do programa de } \\
\text { prevenção universal "Aprender a Conviver" } \\
\text { sobre a competência social e os problemas de } \\
\text { conduta infantis }\end{array}$ & $\begin{array}{l}\text { Habilidade social e problema de } \\
\text { comportamento internalizante e } \\
\text { externalizante. }\end{array}$ \\
\hline $\begin{array}{l}\text { 2.Promoting } \\
\text { Health } \\
\text { Disadvantaged } \\
\text { Preschoolers: A } \\
\text { Randomized Controller } \\
\text { Trial Of Teacher } \\
\text { Training Effects }\end{array}$ & $\begin{array}{l}\text { Seabra-Santos, } \\
\text { Gaspar, Major, } \\
\text { Patras, Azevedo, } \\
\text { Homem, } \\
\text { Pimentel, } \\
\text { Baptista, Klest e } \\
\text { Vale (2018) }\end{array}$ & Portugal & $\begin{array}{l}\text { Analisar o impacto de um programa de } \\
\text { treinamento para professores baseado em } \\
\text { evidências "The Incredible Years Teacher } \\
\text { Classroom Management (IY-TCM)" no } \\
\text { comportamento de crianças portuguesas } \\
\text { desfavorecidas economicamente. }\end{array}$ & $\begin{array}{l}\text { Habilidades sociais, problema de } \\
\text { e desvantagem econômica }\end{array}$ \\
\hline
\end{tabular}




\begin{tabular}{|c|c|c|c|c|}
\hline $\begin{array}{l}3 . \text { Effect } \\
\text { Transporting Af An } \\
\text { Evidence-Based, } \\
\text { Violence Prevention } \\
\text { Intervention To } \\
\text { Jamaican Preschools On } \\
\text { Teacher And Class- } \\
\text { Wide Child Behaviour: } \\
\text { A Cluster Randomised } \\
\text { Trial }\end{array}$ & $\begin{array}{l}\text { Baker- } \\
\text { Henningham e } \\
\text { Walker }(2017)\end{array}$ & Jamaica & $\begin{array}{l}\text { Avaliar os efeitos do programa de treinamento } \\
\text { para professores "The Incredible Years (IY)" } \\
\text { adaptado à realidade da pré-escola jamaicana no } \\
\text { comportamento de crianças que estão em alto } \\
\text { risco de desenvolver problemas de conduta. }\end{array}$ & $\begin{array}{l}\text { Comportamentos positivos e } \\
\text { negativos de professores para a } \\
\text { classe toda e para as crianças de } \\
\text { alto risco, interesse e } \\
\text { entusiasmo das crianças, assim } \\
\text { como problema de } \\
\text { comportamento e habilidades } \\
\text { sociais destas, entusiasmo do } \\
\text { professor e oportunidades de } \\
\text { compartilhamento e ajuda. }\end{array}$ \\
\hline $\begin{array}{l}\text { 4.Prevention } \\
\text { Treatment Of Problem } \\
\text { Behaviors In Young } \\
\text { Children: } \\
\text { Implications From A } \\
\text { Randomized Controlled } \\
\text { Trial Of BEST In } \\
\text { CLASS }\end{array}$ & $\begin{array}{l}\text { Conroy, } \\
\text { Virginia, Algina, } \\
\text { Werch e Ladwig } \\
\text { (2018) }\end{array}$ & $\begin{array}{l}\text { Estados } \\
\text { Unidos }\end{array}$ & $\begin{array}{l}\text { Investigar a efetividade do "BEST in CLASS", } \\
\text { uma intervenção de prevenção indicada, } \\
\text { baseado em sala de aula, com crianças com risco } \\
\text { de distúrbios emocionais e de comportamento, } \\
\text { no que se refere a problemas de comportamento } \\
\text { e habilidades sociais. }\end{array}$ & $\begin{array}{l}\text { Problema de comportamento e } \\
\text { habilidades sociais }\end{array}$ \\
\hline $\begin{array}{l}\text { 5.Does Attending an } \\
\text { Enhanced-quality } \\
\text { Preschool have an } \\
\text { Effect on the Emergent } \\
\text { Literacy, Emergent } \\
\text { Math, Social Skills and } \\
\text { Knowledge of Health, } \\
\text { Hygiene, Nutrition and } \\
\text { Safety of Young } \\
\text { Children? Evidence } \\
\text { from a Quasi- } \\
\text { experiment with Two }\end{array}$ & $\begin{array}{l}\text { Diazgranad, } \\
\text { Borisova } \\
\text { Sarker }(2016)\end{array}$ & Bangladesh & $\begin{array}{l}\text { Identificar os efeitos de participar de um } \\
\text { programa de qualidade aprimorada de pré- } \\
\text { escola, no que se refere a matemática, } \\
\text { linguagem, alfabetismo emergentes, habilidades } \\
\text { socioemocionais e conhecimento sobre saúde, } \\
\text { higiene, nutrição e segurança. }\end{array}$ & $\begin{array}{l}\text { Habilidades sociais, } \\
\text { conhecimento sobre saúde, } \\
\text { higiene, nutrição, segurança, } \\
\text { matemática, linguagem e } \\
\text { alfabetismo emergentes. }\end{array}$ \\
\hline
\end{tabular}




\begin{tabular}{|c|c|c|c|c|}
\hline $\begin{array}{l}\text { Control Groups in } \\
\text { Bangladesh. }\end{array}$ & & & & \\
\hline $\begin{array}{l}\text { 6.The Incredible Years } \\
\text { Teacher Classroom } \\
\text { Management } \\
\text { Programme In } \\
\text { Kindergartens: Effects } \\
\text { Of A Universal } \\
\text { Preventive Effort }\end{array}$ & $\begin{array}{l}\text { Fossum, } \\
\text { Handegård e } \\
\text { Drugli (2017) }\end{array}$ & Noruega & $\begin{array}{l}\text { Identificar os efeitos preventivos do programa } \\
\text { "the Incredible Years (IY) teacher classroom } \\
\text { management (TCM)" que foi aplicado a pré- } \\
\text { escolares da Noruega. }\end{array}$ & $\begin{array}{l}\text { Problema de comportamento } \\
\text { internalizante e externalizante, } \\
\text { problema de atenção e } \\
\text { habilidades sociais. }\end{array}$ \\
\hline $\begin{array}{l}\text { 7.The Effect Of Social } \\
\text { Skills Training On } \\
\text { Social Skills In Early } \\
\text { Childhood, } \\
\text { Relationship Between } \\
\text { Social Skills And } \\
\text { Temperament }\end{array}$ & $\begin{array}{l}\text { Kilıç e Aytar } \\
(2017)\end{array}$ & Turquia & $\begin{array}{l}\text { Investigar os efeitos de um programa de } \\
\text { treinamento de habilidades sociais, no que se } \\
\text { refere a habilidades sociais de crianças pré- } \\
\text { escolares a relação entre habilidades sociais e } \\
\text { temperamento. }\end{array}$ & $\begin{array}{lr}\text { Habilidades } & \text { sociais, } \\
\text { temperamento, } & \text { controle } \\
\text { inibitório, comunicação, nível } \\
\text { de atividade, impulsividade. }\end{array}$ \\
\hline $\begin{array}{lr}8 . \text { A } & \text { Randomized } \\
\text { Controlled Evaluation } \\
\text { Of Prevent-Teach- } \\
\text { Reinforce For Young } \\
\text { Children }\end{array}$ & $\begin{array}{l}\text { Dunlap, Strain, } \\
\text { Lee, Joseph e } \\
\text { Leech }(2018)\end{array}$ & $\begin{array}{l}\text { Estados } \\
\text { Unidos }\end{array}$ & $\begin{array}{l}\text { Comparar os efeitos do programa "Prevent- } \\
\text { Teach-Reinforce for Young Children (PTR- } \\
\text { YC)", um programa padronizado para aplicar } \\
\text { intervenções individualizadas para crianças da } \\
\text { pré-escola com comportamentos desafiadores } \\
\text { severos e persistentes, com a condição de } \\
\text { comparação "BAU" (business as usual) } \\
\text { implementada em um semestre escolar. }\end{array}$ & $\begin{array}{l}\text { Habilidades sociais, problema } \\
\text { de comportamento, tempo de } \\
\text { engajamento e comportamento } \\
\text { desafiador. }\end{array}$ \\
\hline
\end{tabular}


Na Tabela 1, encontra-se a descrição dos estudos sobre treinamentos de habilidades sociais na Educação Infantil, de 2015 a 2019. Com relação ao ano de publicação, nota-se que não houve publicações com relação a esse tema em 2015 e 2019. Dos artigos incluídos na revisão sistemática, dois foram publicados em 2016, três foram publicados em 2017 e três em 2018. Já com relação aos países de publicação dos artigos, estes foram distribuídos da seguinte forma: um da Espanha, um de Portugal, um da Jamaica, dois dos Estados Unidos, um de Bangladesh, um da Noruega e um da Turquia.

Quanto aos objetivos dos estudos, percebe-se que todos consistiram em investigar os efeitos de um treinamento e comparar os escores de determinadas variáveis antes e após a intervenção. Com relação às variáveis, além de habilidades sociais e problema de comportamento que aparecem em todos os estudos, também foram investigados desvantagem econômica, temperamento, controle inibitório, nível de atividade, impulsividade, tempo de engajamento, comunicação, comportamento desafiador, conhecimento sobre saúde, higiene, nutrição, segurança, matemática, linguagem e alfabetismo emergentes, comportamento dos professores diante da sala e de crianças com alto risco de problema de comportamento, comportamento da sala como um todo, interesse e entusiasmo das crianças, acolhimento do professor, além da oportunidades de compartilhar e ajudar.

Outra característica observada foi que em todos os estudos, o programa foi aplicado pelos professores, embora, tenha sido critério de inclusão ser um programa desenvolvido no contexto escolar, não limitando o aplicador e o contexto de sala de aula. 
Tabela 2.

Características Dos Estudos: Metodologia, Tipo De Prevenção, N Da Amostra, Idade Dos Participantes, Duração Do Treinamento, Resultados Dos Estudos.

\begin{tabular}{|c|c|c|c|c|c|c|}
\hline Artigo & Metodologia & Prevenção & $\mathbf{N}$ & Idade & Duração & Resultados dos estudos \\
\hline 1 & $\begin{array}{l}\text { Quase-experimental, } \\
\text { com um grupo, } \\
\text { longitudinal e } \\
\text { medidas repetidas de } \\
\text { pré e pós-teste }\end{array}$ & Universal & 197 & $3-5$ anos & $\begin{array}{lr}4 & \text { meses } / 2 \\
\text { sessões } & \text { por } \\
\text { semana/ } & 45 \\
\text { minutos } & \text { cada } \\
\text { sessão. } & \\
\end{array}$ & $\begin{array}{l}\text { Houve melhora significativa do grupo } \\
\text { experimental, tanto nas variáveis de } \\
\text { habilidades sociais, como em problema de } \\
\text { comportamento. }\end{array}$ \\
\hline 2 & $\begin{array}{l}\text { Estudo experimental } \\
\text { randomizado } \\
\text { controlado entre } \\
\text { grupos, com pré e pró } \\
\text { teste. }\end{array}$ & Universal & 1030 & 3-6 anos & 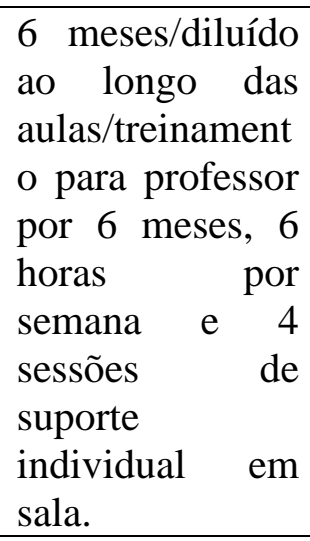 & $\begin{array}{l}\text { Houve melhora nas crianças do grupo de } \\
\text { intervenção no que se refere a habilidade } \\
\text { sociais e diminuição de problema de } \\
\text { comportamento. Crianças em alto risco e } \\
\text { aquelas vindas de famílias com baixo } \\
\text { poder aquisitivo, tiveram mais melhorias } \\
\text { nas habilidades sociais, mas não houve } \\
\text { melhora com relação a problema de } \\
\text { comportamento. }\end{array}$ \\
\hline 3 & $\begin{array}{l}\text { Estudo experimental } \\
\text { randomizado } \\
\text { controlado por } \\
\text { cluster e medidas } \\
\text { repetidas de pré e } \\
\text { pós-teste }\end{array}$ & Universal & 225 & $3-6$ anos & $\begin{array}{l}6 \text { meses/diluído } \\
\text { ao longo das } \\
\text { aulas/treinament } \\
\text { o para professor } \\
\text { por } 8 \text { dias e } 4 \\
\text { sessões de } \\
\text { suporte } \\
\text { individual. }\end{array}$ & $\begin{array}{l}\text { A intervenção promoveu benefícios em } \\
\text { relação ao aumento de comportamentos } \\
\text { positivos diante da classe e das crianças } \\
\text { com alto risco e diminuição de } \\
\text { comportamentos negativos. Houve } \\
\text { melhora também no comportamento das } \\
\text { crianças da sala como um todo, além do } \\
\text { interesse e entusiasmo das crianças, } \\
\text { entusiasmo da professora e oportunidades }\end{array}$ \\
\hline
\end{tabular}




\begin{tabular}{|c|c|c|c|c|c|c|}
\hline & & & & & & $\begin{array}{l}\text { de compartilhamento e ajuda. Os } \\
\text { benefícios da intervenção foram mantidos } \\
\text { após seis meses. }\end{array}$ \\
\hline 4 & $\begin{array}{l}\text { Estudo experimental } \\
\text { randomizado } \\
\text { controlado por } \\
\text { cluster, entre grupos } \\
\text { e medidas repetidas } \\
\text { de pré e pós-teste }\end{array}$ & Indicada & 462 & $3-5$ anos & $\begin{array}{l}3,5 \text { meses } \\
\text { /diluído ao longo } \\
\text { das } \\
\text { aula/treinamento } \\
\text { para professor de } \\
1 \text { dia e coaching } \\
\text { semanal }\end{array}$ & $\begin{array}{l}\text { O grupo de intervenção teve uma } \\
\text { diminuição significativa no percentual de } \\
\text { crianças consideradas como clínicas ou } \\
\text { limítrofes, além de aumento nas } \\
\text { habilidades sociais em comparação ao } \\
\text { grupo controle no que se refere a problema } \\
\text { de comportamento. }\end{array}$ \\
\hline 5 & $\begin{array}{l}\text { Quase-experimental } \\
\text { transversal com } \\
\text { medidas de pré e pós } \\
\text { teste e dois grupos de } \\
\text { comparação }\end{array}$ & Universal & 709 & 4-6 anos & $\begin{array}{l}7 \text { meses/diluído } \\
\text { ao longo das } \\
\text { aula/treinamento } \\
\text { para professor } \\
\text { por } 15 \text { dias } \\
\text { anteriormente e } \\
\text { treinamento } \\
\text { mensal, além de } \\
\text { monitoramento }\end{array}$ & $\begin{array}{l}\text { Todas as variáveis investigadas } \\
\text { (Habilidades sociais, conhecimento sobre } \\
\text { saúde, higiene, nutrição, segurança, } \\
\text { matemática, linguagem e alfabetismo } \\
\text { emergentes) tiveram aumento } \\
\text { significativo nas crianças que } \\
\text { frequentavam a pré-escola de qualidade, } \\
\text { com relação às que não frequentavam a } \\
\text { escola. Os pré-escolares da escola de } \\
\text { qualidade tiveram pequenos ganhos e } \\
\text { vantagens positivas com relação às } \\
\text { crianças que frequentavam a escola de } \\
\text { qualidade padrão. }\end{array}$ \\
\hline 6 & $\begin{array}{l}\text { Quase-experimental } \\
\text { transversal com } \\
\text { medidas de pré e pós } \\
\text { teste e dois grupos de } \\
\text { comparação }\end{array}$ & Universal & 1049 & 3-5 anos & $\begin{array}{l}9 \text { meses /diluído } \\
\text { ao longo das } \\
\text { aula/treinamento } \\
\text { para professor de } \\
7 \text { horas por } 6 \\
\text { dias. }\end{array}$ & $\begin{array}{l}\text { Foram encontradas redução em problemas } \\
\text { de comportamento, de atenção e aumento } \\
\text { de habilidades sociais do grupo que } \\
\text { participou da intervenção. Em crianças } \\
\text { consideradas clínicas com relação a } \\
\text { comportamento agressivo, houve melhora } \\
\text { com relação a habilidades sociais nas }\end{array}$ \\
\hline
\end{tabular}




\begin{tabular}{|c|c|c|c|c|c|c|}
\hline & & & & & & $\begin{array}{l}\text { crianças do grupo de intervenção, porém, } \\
\text { poucos ganhos foram encontrados. }\end{array}$ \\
\hline 7 & $\begin{array}{l}\text { Quase-experimental } \\
\text { transversal com } \\
\text { medidas de pré e pós } \\
\text { teste e dois grupos de } \\
\text { comparação }\end{array}$ & Universal & 55 & 4 e 5 anos & $\begin{array}{l}2 \text { meses/ } 3 \text { vezes } \\
\text { por semana com } \\
\text { duração de uma } \\
\text { hora. }\end{array}$ & $\begin{array}{l}\text { As médias de habilidades sociais do pós- } \\
\text { teste das crianças que participaram da } \\
\text { intervenção foram maiores que as do } \\
\text { grupo controle. Foi observada uma } \\
\text { correlação significativamente negativa } \\
\text { entre habilidades sociais e timidez, e } \\
\text { temperamento e controle inibitório, além } \\
\text { de habilidades sociais e comunicação, } \\
\text { temperamento e nível de atividade, } \\
\text { temperamento e impulsividade, } \\
\text { assertividade e habilidades sociais. }\end{array}$ \\
\hline 8 & $\begin{array}{l}\text { Estudo clínico } \\
\text { randomizado } \\
\text { controlado }\end{array}$ & Seletiva & 169 & Pré-escolar & $\begin{array}{l}4 \text { meses//diluído } \\
\text { ao longo das } \\
\text { aula/treinamento } \\
\text { para professor } \\
\text { por duas } \\
\text { semanas antes, } \\
\text { além de } \\
\text { treinamento } \\
\text { extensivo. }\end{array}$ & $\begin{array}{l}\text { Foram encontradas melhoras } \\
\text { significativas entre pré e pós teste no que } \\
\text { se refere a problema de comportamento e } \\
\text { habilidades sociais, além de engajamento } \\
\text { apropriado das crianças e diminuição de } \\
\text { comportamento desafiante nas crianças do } \\
\text { grupo de intervenção. }\end{array}$ \\
\hline
\end{tabular}


Através da Tabela 2, pode-se observar que no que tange a metodologia de estudo, quatro trabalhos apresentaram desenho quase-experimental e quatro experimental (randomizados e controlados por clusters). No entanto, os sete contam com metodologias transversais e apenas um com metodologia longitudinal -avaliações pré e pós intervenção e de seguimento (Cabezas et. al, 2016).

Com relação ao tipo de prevenção, percebe-se que seis constituem programa de prevenção universal, um refere-se à prevenção indicada (Ladwig et. al., 2018) e um à prevenção seletiva (Leech et. al., 2018).

Quanto ao N da amostra, este variou de 55 a 1049 crianças. A idade dos participantes esteve entre de 3 e 6 anos (o que foi critério de inclusão), compreendendo a Educação Infantil. No que se refere à duração do treinamento, esta variou de 2 a 9 meses de extensão. Dos oito artigos, seis tratam sobre treinamento realizados com professores, a partir dos quais, eles aplicavam estratégias aprendidas ao longo das aulas, sendo assim, diluído entre estas. Nesses casos, os treinamentos para os professores envolveram sessões de suporte individual, monitoramento, coaching e workshops. Nos outros dois artigos, não há informação sobre o treinamento que os professores receberam. No entanto, em um deles (Cabezas et al., 2016), o treinamento que os professores aplicam com as crianças ocorre duas vezes por semana, tendo 45 minutos cada sessão e o outro (K1lıç \& Aytar, 2017) três vezes na semana, com duração de uma hora cada sessão. Não foram encontradas relações entre a duração das intervenções e os resultados dos estudos.

Os estudos, de modo geral, mostraram resultados satisfatórios acerca das intervenções, respondendo aos objetivos tratados quanto a aumento em habilidades sociais, redução de problemas de comportamento e outras variáveis, como melhora no comportamento dos professores diante da sala e diante de crianças de alto risco de problema de comportamento, acolhimento delas, entusiasmo e interesse das crianças.

Em seis estudos, as médias das variáveis investigadas tiveram diferenças significativas, no sentido de aumentar as habilidades sociais e diminuir os problemas de comportamento das crianças após participarem da intervenção. Apenas um estudo apontou não ter atingido totalmente seus objetivos, já que os participantes não apresentaram diminuição de problema de comportamento, apesar de terem aumentado as médias de habilidades sociais; os autores inferiram que seus resultados são devido ao fato de que as crianças já apresentavam alto risco com relação a problema comportamentais e viviam em famílias com baixo poder aquisitivo. Neste contexto uma prevenção seletiva ou indicada se mostraria mais efetiva (Vale et al, 2018). 
Observa-se ainda outro estudo que apesar de alcançar aumento nas habilidades sociais, conhecimento sobre saúde, higiene, nutrição, segurança, matemática, linguagem e alfabetismo emergentes, teve um resultado que não era esperado: não foram observadas diferenças significativas nas variáveis investigadas (habilidades sociais e gerais), ao se comparar a préescola padrão com a pré-escola de alta qualidade, o que era hipotetizado inicialmente pelos autores (Sarker et al., 2016).

Com relação a outras variáveis investigadas, Walker et al (2017) aponta que além de diminuição nos problemas de comportamento das crianças e aumento de suas habilidades sociais, também houve, após a intervenção, o aumento de comportamentos positivos dos professores diante da classe e diante das crianças com alto risco para problema de comportamento, aumento do entusiasmo da professora e de oportunidades de compartilhamento, ajuda e diminuição de comportamentos negativos. Kılıç e Aytar (2017) apontaram, além de aumento de habilidades sociais e diminuição de problema de comportamento após a intervenção, a existência de uma correlação significativamente negativa entre habilidades sociais e timidez, temperamento e controle inibitório, além de habilidades sociais e comunicação, temperamento e nível de atividade, temperamento e impulsividade, assertividade e habilidades sociais. E por fim, Leech e colaboradores (2018) indicaram o aumento do engajamento das crianças e a diminuição do comportamento desafiante como ganhos adicionais.

\section{Discussão}

O presente estudo teve como objetivo revisar sistematicamente a literatura acerca de programas de intervenção para o desenvolvimento de habilidades sociais na Educação Infantil, bem como identificar suas principais características, diferenças e semelhanças.

No processo de busca nas bases de dados, constatou-se um maior número de publicações na base de dados na Web of Science. Considerando as palavras de busca e as ferramentas para o refinamento partiu-se de um universo de 828 artigos e após a leitura de seus resumos, considerando os critérios de inclusão (estudos sobre programas de intervenção para o desenvolvimento de habilidades sociais, população entre 3 e 6 anos, no formato de grupo e no contexto escolar) chegou-se ao número 8 , os quais foram analisados integralmente.

Através da revisão, notou-se que todos os estudos foram encontrados na literatura internacional, incluindo os países Espanha, Portugal, Jamaica, Estados Unidos, Bangladesh, 
Noruega e Turquia, além de as datas de publicação se concentrarem entre 2016 e 2018, sendo nula em 2015 e 2019. Esses dados indicam que essa área de conhecimento ainda está em desenvolvimento, apesar da grande importância desta, já que a literatura indica que as habilidades sociais são fatores importantes de proteção para o desenvolvimento (CasaliRobalinho, 2013).

Quanto aos objetivos, todos os artigos buscavam verificar o impacto de programas preventivos específicos sobre variáveis dependentes eleitas. Em todos os estudos as variáveis habilidades sociais e problemas de problema de comportamento, que são consideradas concorrentes (Del Prette et al, 2011; Casali-Robalinho, 2013; Elias e Marturano, 2016) foram investigadas. Além dessas variáveis, também foram avaliadas outras, que se sabe que estão associadas, como as habilidades sociais educativas. Del Prette e Del Prette (2017) indicam que o ensino de habilidades sociais para crianças, perpassam as habilidades dos educadores e nesse sentido, Sarker (2016) vai de encontro com esse dado, avaliando positivamente o aumento das habilidades sociais educativas dos professores após a intervenção.

Observando-se os tipos de metodologias utilizadas, percebe-se que a maioria dos estudos teve delineamento transversal com avaliações pré e pós intervenção, sendo apenas um longitudinal (Cabezas et al, 2016); além disso, os estudos se dividiram em quase-experimental e experimental (randomizados e controlados por clusters). Essas características na metodologia apontam para as limitações presentes ao se realizar pesquisas no ambiente escolar, como manutenção da autorização após mudança de direção, realizar randomização, contar com a estabilidade das crianças numa mesma escola, ter espaço físico e temporal para oferecer treinamento a professores, o programa poder fazer parte da grade curricular, além de questões financeiras (também presentes em outros contextos) para manter estudos longitudinais.

Com relação ao tipo de prevenção, observou-se que a maioria dos estudos envolveram programas de prevenção universal, sendo que apenas um se referiu à prevenção seletiva (Leech, et al, 2018) e um à prevenção indicada (Ledwig et al., 2018). Segundo Abreu et. al. (2015), as diferentes formas de intervenções preventivas atendem diferentes recortes da população. É compreensível que haja mais estudos sobre programas de prevenção universal, que abrangem mais pessoas, sendo o primeiro passo para identificar a necessidade da aplicação de outros programas mais específicos. De acordo com Abreu et al (2015), os trabalhos de prevenção universal atendem uma população maior, mas são mais difíceis de serem executados e são mais dispendiosos. 
Com relação ao N, há uma variação grande entre os estudos, indo de 55 a 1049. Já com relação à idade, esta variou entre 3 e 6 anos, já que este foi o critério de inclusão da revisão.

No que se refere à duração dos treinamentos, percebe-se que houve uma variação de 2 a 9 meses entre o pré e o pós teste. Em todos os estudos, os programas foram aplicados pelos professores e estes receberam treinamentos, o que reforça a importância das habilidades sociais educativas (Del Prette \& Del Prette, 2017). Em dois artigos incluídos na revisão (K1lıç \& Aytar, 2017; Cabezas, et al. 2016), os programas implementados foram estruturados, sendo aplicados duas ou três vezes por semana. Os outros seis artigos consistiram em programas de ensino de habilidades para os professores aplicarem ao longo das aulas, no dia a dia, portanto, diluídas ao longo das semanas. Em todos os artigos, os professores receberam treinamentos extensivos.

Com relação aos resultados encontrados nos estudos, pode-se observar que a maioria deles indicaram que os participantes dos grupos de intervenção tiveram melhores resultados no pós teste quando comprados ao grupo de espera com relação a aumento de habilidades sociais e redução de problema de comportamento.

Em um dos artigos incluídos na revisão, de Vale et al. (2018), no qual o programa avaliado foi universal, observou-se que na maioria das crianças houve aumento de habilidades sociais e diminuição de problema de comportamento. Contudo, participantes avaliados como apresentando alto risco para problema de comportamento e pertencentes a famílias com baixo poder aquisitivo, tiveram aumento nas habilidades sociais, mas não houve melhora com relação aos problemas de comportamento. Destaca-se assim que, a depender das medidas de algumas variáveis eleitas como foco de ação, a prevenção universal pode não se mostrar efetiva, e intervenções seletivas ou indicadas seriam mais efetivas e eficazes (Abreu et. al, 2015). Além disso, a interferência de variáveis não controladas e que se mostram adversas ao desenvolvimento afetam a possibilidade de ganhos de possíveis recursos quando se trata sobre desenhos de promoção e prevenção (Yunes, 2015). Assim, fica evidente mais uma vez, a necessidade de treinamento a outros atores além das crianças, de forma a desenvolver repertório comportamental também nos educadores para que sejam reforçadores de condutas esperadas da criança (Feitosa, et al., 2018).

O estudo, de Drugli et al. (2017), que avaliou o programa universal The Incredible Years Teacher Classroom management program (IY-TCM), apontou que os participantes tiveram ganhos apenas na variável habilidades sociais (foco do programa). Ressaltaram que mesmo as crianças consideradas clínicas para problema de comportamento, tiveram ganhos, 
embora pouco expressivos. Deve-se notar que apesar de estatisticamente significativo, os tamanhos de efeito foram pequenos. Em contrapartida, é relevante observar que Ladwig et al (2018) avaliou um programa de prevenção indicada e obteve resultados bastante positivos com relação a diminuição na porcentagem de crianças consideradas clínicas ou limítrofes para problema de comportamento. Esses dados reforçam o que foi discutido com relação às considerações quanto a programas de prevenção indicada e universal.

No estudo realizado por Sarker et al. (2016), além dos resultados de promoção de habilidades sociais e redução de problemas de comportamento, os autores sinalizaram que todas as variáveis investigadas tiveram aumento significativo nas crianças que frequentavam a préescola de qualidade em comparação com as que não frequentavam. Contudo, na comparação entre pré-escola de qualidade e padrão, não foram encontradas diferenças significativas. Esses dados reforçam a importância da experiência escolar no desenvolvimento de habilidades essenciais das crianças, para que elas tenham sucesso acadêmico e social. A infância é considerada por muitos estudiosos, um período crítico para o desenvolvimento de habilidades sociais, devido ao fato de terem seus primeiros contatos além do ambiente familiar, o que possibilita a ampliação de contato com outros modelos e da plasticidade do comportamento social infantil. (Del Prette \& Del Prette, 2017; Marturano \& Elias, 2016; Correi-Zanini \& Marturano, 2016).

Respondendo aos objetivos traçados, caracterizamos e verificamos semelhanças e diferenças entre os programas de intervenção para o desenvolvimento de habilidades sociais na Educação Infantil. Destaca-se a ausência de artigos publicados no Brasil, nesse período, além de não terem sido encontrado artigos publicados em 2015 e 2019. Além disso, notou-se uma semelhança entre as metodologias utilizadas, as variáveis investigas, os objetivos a serem atingidos e os resultados obtidos. Houve, ainda, uma grande variabilidade no número de participantes e na duração dos programas, sendo todos aplicados por professores em sala de aula.

A partir das análises dos artigos incluídos na revisão, fica evidente a importância do desenvolvimento das habilidades sociais para as crianças, sendo os programas de intervenção preventiva um recurso viável no contexto escolar, atendendo assim um grande número de crianças e formando professores como multiplicadores. A importância desses programas é reforçado por Marturano e Elias (2016) que afirmam que na infância, a presença de um repertório elaborado de habilidades sociais possibilita à criança estabelecer relacionamentos 
mais produtivos e harmoniosos com adultos e colegas, e é um indicador da qualidade das relações interpessoais que ela poderá desenvolver ao longo da vida.

Tal importância também é reafirmada pela Base Nacional Curricular, - BNCC, texto que orienta a educação nacional e que preza pelo desenvolvimento de competência social, que implica no desenvolvimento de habilidades sociais. Sendo assim, apesar de ainda haver um número pequeno de artigos publicados na área, está evidente que esta é um campo frutífero para psicologia.

\section{Considerações finais}

Conclui-se, assim, que estudos empíricos referentes a programas de treinamento de habilidades sociais com alunos da Educação Infantil é restrita mundialmente e sem informações no contexto brasileiro, apesar da literatura indicar como uma fase importante para o desenvolvimento dessas habilidades de forma duradoura (Marques-Pinto et al., 2015; Walker 2017; Del Prette \& Del Prette, 2017), atuando como proteção ao desenvolvimento (CasaliRobalinho, 2013). A partir da revisão sistemática realizada fica evidente a importância de se realizar estudos que desenvolvam e avaliem programa de desenvolvimento de habilidades sociais na Educação Infantil, considerando a importância dessa fase no desenvolvimento.

\section{Referências}

Abreu, S.; Barletta, J. B., Murta, S. G. (2015). Prevenção e promoção em saúde mental: pressupostos teóricos e marcos conceituais. In. Sheila Giardini Murta, Cristineide Leandro-França, Karine Brito dos Santos e Larissa Polejack (Org.) Prevenção e promoção em saúde mental: Fundamentos, Planejamento e Estratégias de Intervenção (pp.54-74). Novo Hamburgo, Rio Grande do Sul: Sinopsys Editora e Sistemas Ltda.

Barreto, S. O., Freitas. L. C., \& Del Prette, Z. A. P. (2011). Habilidades sociais na comorbidade entre dificuldades de aprendizagem e problemas de comportamento: uma avaliação multimodal. Psico42(4), 503-510.

Baker-Henningham, H. \& Walker, S. (2018). Effect of transporting an evidence-based, violence prevention intervention to Jamaican preschools on teacher and class-wide child behaviour: a cluster randomised trial. Global Mental Health (5), 1-16.

Berry, D., \& O'Connor, E. (2010)Behavioral risk, teacher-child relationships, and social skill development across middle childhood: A child-by-environment analysis of change. Journal of Applied Developmental Psychology 31(1), 1-14.

Bolsoni-Silva, A. T.; Loureiro, S. R.; Marturano, E. M. (2018). Roteiro de entrevistas de habilidades sociais educativas de professores- RE-HSE-PR. São Paulo, Hogrefe. 
Bolsoni-Silva, A. T., Marturano, E. M., \& Loureiro, S. R. (2011). Estudos de confiabilidade e validade do Ques-tionário de Respostas Socialmente Habilidosas Versão para Pais - QRSHPais. Psicologia: Reflexão e Crítica, 24(2), 227-235.

Bolsoni-Silva, A. T. Loureiro, S. R. (2019). Práticas Parentais: Conjugalidade, Depressão Materna, Comportamento das Crianças e Variáveis Demográficas. Psico-USF. 24 (1), 69-83.

Casali-Robalinho, I. G. (2013). Relações entre automonitoria, problemas de comportamento e habilidades sociais na infância. Dissertação de mestrado, Programa de Pós-Graduação em Psicologia, Universidade Federal de São Carlos, São Carlos, SP.

Conroy, M. A.; Sutherland, K. S. Algina, J.; Werch, B.; Ladwig, C. (2018).Prevention and Treatment of Problem Behaviors in Young Children: Clinical Implications From a Randomized Controlled Trial of BEST in CLASS. AERA Open 4, (1), 1-16.

Correia-Zanini, M. R. G. \& Marturano, E. M. (2016). Primeiros Passos no Ensino Fundamental: Competência Cognitiva, Habilidades Sociais, Comportamento e Estresse. Psico-USF [online], 21 (2), 305-317.

Del Prette, Z. A. P., \& Del Prette, A. (2011). Práticas baseadas em evidência e treinamento de habilidades sociais. Em A. Del Prette \& Z. A. P. Prette (Orgs.), Habilidades sociais: intervenções efetivas em grupo (pp. 261-288). São Paulo, SP: Casa do Psicólogo.

Del Prette, Z.A., \& Del Prette A. (2017). Compentência Social e Habilidades Sociais; manual teórico-prático. Petropólis: Vozes.

Del Prette, Z. A. P. \& Del Prette, A. (2019). Studies on social skills and social competence in Brazil: A history in construction. In: S. H. Koller (Org.), Psychology in Brazil: Scientists Making a Difference. (SWZ): Springer.

Diazgranados, S. Borisova, I \& Sarker, T. (2016). Does Attending an Enhanced-quality Preschool have an Effect on the Emergent Literacy, Emergent Math, Social Skills and Knowledge of Health, Hygiene, Nutrition and Safety of Young Children? Evidence from a Quasi-experiment with Two Control Groups in Bangladesh. Journal of Human Development and Capabilities, 17(4), 494-515.

Elias, L. C. S.; Amaral, M.V. (2016). Habilidades sociais, comportamentos e desempenho acadêmico em escolares antes e após intervenção. Psico-USF, 21 (1).

Elias, L. C. S., \& Marturano, E. M. (2014). "Eu posso resolver problemas" e oficinas de linguagem: intervenções para queixa escolar. Psicologia: Teoria e Pesquisa, 30(1), 35-44.

Feitosa, F. B., Del Prette Z. A. P., Del Prette, A., \& Loureiro, S. R. (2011). Explorando relações entre o comportamento social e o desempenho acadêmico em crianças. Estudos e Pesquisas em Psicologia 11(2), 442-445.

Fernandes, L. M., Leme, V. B. R., Elias, L. C. S., \& Soares, A. B. (2018). Preditores do desempenho escolar ao final do ensino fundamental: histórico de reprovação, habilidades sociais e apoio social. Temas em Psicologia, 26(1), 215-228.

Fossum, S., Handegård, B. H.; Drugli, M. B. (2017). The Incredible Years Teacher Classroom Management Programme in Kindergartens: Effects of a Universal Preventive Effort. $J$ Chlid Fam Stud. (26), 2215-2223.

Glen Dunlap, G.; Strain, P.; Lee, J. K.; Joseph, J.; Leech, N. (2018). A Randomized Controlled Evaluation of Prevent-Teach-Reinforce for Young Children. Topics in Early Childhood Special Education. 37(4), 195-20.

Kılıç, K. M.; Aytar, F. A. G. (2017). The Effect of Social Skills Training on Social Skills in Early Childhood, the Relationship between Social Skills and Temperament. Education and Science. 42 (191), 185-204.

Marques-Pinto A., Jesus E. H., Mendes A. M. O. C., \& Fronteira I. S. E. (2015). Estudo RN4Cast em Portugal: Work Engagement dos enfermeiros. Revista Investigação em Enfermagem, 10(2), 26-37. 
Marturano, E. M, \& Elias, L. C. S. (2016). Família, dificuldades no aprendizado e problemas de comportamento em escolares. Educar em Revista, (59), 123-139.

Martínez, M. C.P.; Justicia-Arráez, A.; Corredor, G. A.; Cabezas, M. F. (2016). Desarrollo de la competencia social y prevención de problemas de conducta en el aula infantil. Pensamiento Psicológico, (14), 21-31.

McCabe, P.C., Altamura, M. (2011). Empirically valid strategies to improve social and emotional competence of preschool children. Psychology in the Schools, 48(5), 513-540.

Ministério da Educação. (2017). Base Nacional Comum Curricular: educação é a base. Brasília, DF: Autor. Recuperado de http://bit.ly/2PFK5qq.

Pizato, E. C. G., Marturano, E. M., \& Fontaine, A. M. G. V. (2014). Trajetórias de habilidades sociais e problemas de comportamento no ensino fundamental: influência da educação infantil. Psicologia: Reflexão e Crítica 27(1), 189-197.

Seabra-Santos, M. J.; Gaspar, M. F.; Major, S. O.; Patras, J.; Azevedo, A. F.; Homem; T. C.;Pimentel, M.; Baptista, M.; Klest, S; Vale, V. (2018). Promoting Mental Health in Disadvantaged Preschoolers: A Cluster Randomized Controlled Trial of Teacher Training Effects. Journal of Child and Family Studies. (27), 3909-3921.

Yunes, M. A. M. (2015). Prevenção e promoção em saúde mental: pressupostos teóricos e marcos conceituais. In. Sheila Giardini Murta, Cristineide Leandro-França, Karine Brito dos Santos e Larissa Polejack (org.) Sinopsys Editora e Sistemas Ltda. 
Estudo 2

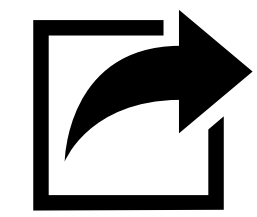




\title{
Habilidades de Solução de Problemas Interpessoais na Educação Infantil: Avaliação de intervenção
}

Resumo: As habilidades de solução de problemas interpessoais (HSPI) são fundamentais para estabelecer relacionamentos satisfatórios ao longo de toda a vida. Estas habilidades são aprendidas e podem ser desenvolvidas desde a infância. A aprendizagem pode ocorrer em contextos naturais ou através de programas de treinamento. O presente trabalho teve como objetivo verificar os efeitos de um programa para o desenvolvimento de HSPI em alunos da Educação Infantil sobre as variáveis de habilidades sociais, HSPI e problemas de comportamento. Participaram 45 alunos, com idade de cinco anos, devidamente matriculados na rede pública de uma cidade do interior paulista, local onde o estudo foi desenvolvido. $\mathrm{O}$ estudo teve recorte transversal, com medidas repetidas e desenho quase-experimental. Os instrumentos utilizados para avaliar as crianças foram Strengths and Difficulties Questionnaire (SDQ), Escala de Comportamento Social para Pré-Escolares PKBS-BR (PKBS) e Procedimento de Solução de Problemas Interpessoais em Pré-escolares (PIPS) e; para o treinamento das HSPI o Programa Posso Pensar. Os resultados mostraram-se significativos no que tange ao aumento das HSPI, porém não foram observadas diferenças em problemas de comportamento. Conclui-se que crianças com problemas de comportamentos elevado não se beneficiaram de um programa universal.

Palavras-chave: Pré-escolar, Solução de problemas, Comportamento problema.

\begin{abstract}
Solving problems skills are very importante to establish long-lasting and satisfactory relationships throughout life. This skills are learned and can be developed since the childhood. The process of learning may be natural or through training programs. The aim of this study was to verify the effects of a program to develop solving problems skills in the kindergarten. Problem behavior, social skills and solving problem skills were analyzed. The program was targeted at 45 five years-old students who were enrolled in public schools in the country side. This reaserch was a cross-sectional, quasi-experimental study, with repeated measures design. The instruments used to assess the behavior of children were SDQ, PKBS e PIPS. The intervention procedure used was Programa Posso Pensar. The results indicates significantly raises concerning problem solving skills. However, there were no significant diferences in the problem behavior. In conclusion, children with severe behvior problem did not benefited from a universal program.
\end{abstract}


Key-words: Child, Preschool; Problem solving, Problem behavior, Education.

\section{Introdução}

A experiência escolar é essencial para as aquisições educacionais e sociais, exercendo grande influência nas trajetórias da vida adulta, referentes à relações interpessoais, progresso na escolarização, adesão às regras da sociedade e imagem positiva de si mesmo (Del Prette \& Del Prette, 2003; Rodrigues, Dias \& Freitas, 2010, Fernandes, Leme, Soares \& Elias, 2018). Os professores são os principais agentes educacionais na escola e são fundamentais no desenvolvimento escolar e socioemocional dos alunos, e por isso, há a necessidade de capacitálos para promover tal desenvolvimento em sala de aula (Rodrigues, et al, 2010).

A Educação Infantil e a passagem para o Ensino Fundamental são períodos em que há o desenvolvimento de habilidades essenciais para que, posteriormente, as crianças tenham sucesso acadêmico e social (McCabe \& Altamura, 2011). Conforme ressaltam Correia-Zanini e Marturano (2016), as crianças passam muito tempo na escola e, por isso, esse ambiente passa a ser o contexto mais importante do desenvolvimento da criança, além do ambiente familiar.

Del Prette e Del Prette $(2009,2017)$ referem-se às habilidades sociais como aqueles comportamentos requeridos nas tarefas de interações sociais, diretamente observáveis, com alta probabilidade de gerar consequências positivas para o indivíduo e para o seu grupo, em determinado contexto cultural e situacional. No cenário das habilidades sociais, neste estudo, foram focalizadas as habilidades de solução de problemas interpessoais (HSPI), em específico. Segundo Shure (2006), as HSPI consistem na capacidade de pensar sobre uma situação problema e tomar uma decisão, ou seja, fazer leitura do que está acontecendo ou pode acontecer, entender causa e efeito, pensar em soluções que possam resolver o problema, prever consequências, planejar para atingir uma meta pré-estabelecida e escolha de uma solução. De acordo com Marturano, Elias e Versuti (2017), os conflitos interpessoais permeiam o cotidiano constantemente e as habilidades para lidar com estes são essenciais para manter relacionamentos satisfatórios. As autoras destacam que as habilidades de solução de problemas interpessoais são aprendidas a partir da experiência dos indivíduos e podem ser entendidas como um conjunto de habilidades e como um processo de aprendizagem. As habilidades envolvidas no processo de solução de problemas interpessoais são planejar meios para atingir fins, gerar soluções alternativas para resolver o problema, analisar os possíveis resultados de cada solução concebida, observar os próprios sentimentos e dos outros e analisar a relação entre comportamentos e prováveis consequências. 
O desenvolvimento das habilidades sociais na infância constitui fator de proteção, à medida que o comportamento socialmente habilidoso favorece a obtenção de reforçadores sociais importantes (Bolsoni-Silva, Marturano \& Freiria, 2010; Barker et al., 2010; Rodrigues et al., 2010; Correia-Zanini, 2013; Marturano \& Elias, 2016; Gonçalves \& Murta, 2008). Na infância, a presença de um repertório elaborado de habilidades sociais possibilita à criança estabelecer relacionamentos mais produtivos e harmoniosos com adultos e colegas, e é um indicador da qualidade das relações interpessoais que ela poderá desenvolver ao longo da vida (Cia \& Barham, 2009). No que tange às HSPI, especificamente, os estudos apontam que indivíduos que apresentam essas habilidades mais desenvolvidas se mostram melhor ajustados (Elias \& Marturano, 2016).

Ao longo do tempo, as habilidades sociais têm sido associadas positivamente a diversos indicadores de funcionamento adaptativo, como responsabilidade, independência, cooperação, autoestima e desempenho acadêmico (Del Prette \& Del Prette, 2005, Marturano \& Elias, 2016). As crianças que desenvolvem habilidades sociais tendem a exibir melhor ajustamento social e melhor satisfação nas relações interpessoais (Rodrigues, et al, 2010).

Considerando que habilidades sociais são comportamentos aprendidos nas interações sociais e funcionam como fator de proteção, devemos promovê-las desde muito cedo no desenvolvimento. A Organização Mundial da Saúde defende que práticas preventivas devem integrar o currículo de forma contínua e não só transversal, além de colocar o ensino de habilidades sociais como fator protetivo para o desenvolvimento infantil (Rodrigues, et al., 2010; Marturano \& Elias, 2016).

A literatura sinaliza que um repertório elaborado de habilidades sociais constitui fator protetor para o desenvolvimento saudável e satisfatório de uma criança, atuando na prevenção de diversos problemas, sejam eles comportamentais ou acadêmicos (Elias \& Amaral, 2016; Fernandes et al, 2018). Além disso, diminuir a incidência de problema de comportamento na sala de aula pode ter impacto positivo no desempenho escolar das crianças (Kirkhaug et al 2016; Elias \& Marturano, 2016). Correia-Zanini (2013) argumenta que a associação entre problemas de comportamento externalizante precoces e baixo desempenho escolar podem contribuir para maior risco acadêmico, sobretudo nos meninos, visto que eles parecem apresentar mais problemas externalizantes que as meninas. Além disso, estes problemas aumentam o risco de problemas psicossociais na adolescência e início da fase adulta (Kirkhaug et al 2016).

Segundo Bolsoni-Silva e Del Prette (2003), os problemas de comportamento se referem a excessos ou déficits comportamentais que dificultam o acesso da criança a novas contingências de reforçamento, relevantes para a aprendizagem e promotoras do 
desenvolvimento. Achenbach e Edelbrock (1979) sinalizam duas grandes classes de problemas de comportamento: os externalizantes que se expressam em relação à outras pessoas (impulsividade, agressão, agitação, provocações e comportamento desafiador) e os internalizantes que se expressam em relação ao próprio indivíduo (tristeza, retraimento, timidez, insegurança, medos e inibição excessiva). Ambas categorias de problemas de comportamento podem levar a dificuldades de interação do indivíduo com o ambiente, visto que mesmo que mantidos por reforços, são acompanhados de subprodutos negativos que prejudicam as relações (Falcão et al, 2016).

Ambos os grupos de problemas são igualmente prejudiciais e podem ter consequências desfavoráveis para o desenvolvimento e, portanto, devem ser foco de intervenções preventivas (Del Prette \& Del Prette, 2005); em geral, tornam-se mais graves em razão de interações negativas da criança com o ambiente e, portanto, a escola tem um papel fundamental nesse processo. No contexto escolar, estudos têm mostrado a importância de programas no modelo de camadas, abrangendo os três níveis de intervenção: universal, seletivo e indicado (Mrazek \& Haggerty, 1994), porém com a ideia de coordenar tais níveis de forma tal que, se não há progresso suficiente em um nível, uma intervenção mais intensiva e focada pode ser realizada no nível posterior (Kratochwill, Albers, \& Shernoff, 2004). Além disso, programas aplicados em ambiente escolar podem ser implementados por profissionais capacitados (Lopes, 2013; Rocha et al, 2011) ou pelos próprios professores, entendendo a função mediadora deles na sala de aula, após o preparo adequado por profissionais, o professor poderia, então, conduzir sessões de intervenção dentro da própria sala, promovendo a replicação do programa ao longo do tempo (Lopes, 2013).

Têm crescido o investimento em orientar agentes educativos no desenvolvimento de suas habilidades sociais e habilidades sociais educativas, como via indireta para o ensino de habilidades sociais às crianças (Rocha et al, 2011). No Brasil, especificamente, pesquisadores têm desenvolvido treinamentos de habilidades sociais educativas tanto para pais (Bolsoni-Silva \& Borelli, 2012; Bolsoni-Silva, Silveira, \& Marturano, 2008; Pinheiro et al., 2006; Rocha, et al, 2011; Sabbag \& Bolsoni-Silva, 2011) quanto para professores (Rosin-Pinola, 2010), embora em menor número. No que se refere às práticas educativas (das quais fazem parte as habilidades sociais educativas), no Brasil o ambiente escolar tem sido menos estudado que o familiar (Bolsoni-Silva, Mariano, Loureiro, \& Bonaccorsi, 2013).

Marturano, Bolsoni-Silva e Elias (2015), apresentam intervenções preventivas realizadas na escola no cenário brasileiro. Uma delas utilizou o programa I Can Problem Solve”, - Eu posso resolver problemas - EPRP, traduzido e adaptado para o contexto brasileiro (Shure, 
2006), destinado a alunos, tendo como mediadores professores, desenvolvido a partir do pressuposto de que as HSPI contribuem para a prevenção de problema de comportamento. $\mathrm{O}$ programa foi aplicado em larga escala, junto à rede municipal de ensino de uma cidade do interior paulista, tendo participado professoras e alunos do Ensino Fundamental I. Foi utilizado como um programa de capacitação, com duração de um ano, dividido em dois módulos, um teórico-vivencial e o outro de treinamento em serviço. No segundo módulo, as professoras aplicavam suas lições em sala de aula e discutiam semanalmente em supervisão suas dificuldades e ganhos. As crianças foram avaliadas antes e após passarem pelo programa. Os resultados foram significativos apontando ganhos nas crianças no que tange o repertório total de habilidades sociais e de algumas classes específicas (o que facilitava as interações dentro e fora de sala); redução de problemas de comportamento e; melhora no desempenho acadêmico. Resultados relativos às professoras foram da ordem de melhoras no relacionamento professoraluno; aumento de reflexão antes de responder às crianças, buscando maior assertividade e; questionamento contínuo sobre suas habilidades e necessidades de aprimoramento.

Kirkhaug et al. (2016) realizaram um estudo quase-experimental, utilizando o programa universal de intervenção escolar "The Incredible Years Teacher Classroom management program" -IY-TCM. O objetivo do estudo foi investigar se o programa contribuiria efetivamente para a diminuição de problemas de comportamentos externalizantes e internalizantes graves e aumento das habilidades sociais, desempenho acadêmico e melhora na relação com os professores. Participaram do estudo crianças de 6 a 8 anos, distribuídas em 43 escolas, divididas entre grupo de intervenção e controle. Foram incluídos no estudo apenas alunos que tinham problemas externalizantes graves de acordo com as professoras. O programa foi desenvolvido para ajudar os professores no manejo de problemas de comportamento em sala de aula e promover comportamentos pró-sociais nos alunos. O treinamento foi realizado pelos professores, que tiveram workshops sobre a aplicação do programa e apoio de um manual. Não foram encontradas diferenças entre os dois grupos no pré e no pós-teste com relação a problemas de comportamento externalizantes, habilidades sociais e proximidade com os professores. No entanto, o grupo de intervenção apresentou melhores resultados, após a aplicação do programa, quanto à melhora no desempenho acadêmico e diminuição de conflitos com os professores. Concluiu-se que apenas o programa universal IY-TCM não é suficiente para a diminuição de problemas de comportamentos a nível clínico, indicando que para isso, é necessário outro tipo de intervenção, mais específica. De acordo com os autores, os resultados não foram satisfatórios como o esperado, já que programas de prevenção seletiva têm se 
mostrado mais efetivo que programas universais; além disso afirmam que o treinamento de habilidades parentais, simultaneamente, pode melhorar os resultados da intervenção.

Elias e Marturano (2016) verificaram os efeitos do Programa Posso Pensar, programa de prevenção universal, a ser aplicado na escola por educadores. Participaram do estudo 203 alunos, com idade entre 6 e 10 anos e suas professoras, pertencentes ao Ensino Fundamental I, de uma cidade do interior paulista. O estudo teve delineamento quase-experimental com grupos de intervenção e controle, realizando medidas pré e pós-intervenção. Os resultados apresentaram que apenas o grupo de intervenção apresentou melhoras significativas em todas as variáveis investigadas, com destaque para redução de problemas de comportamento e desenvolvimento de HSPI e outras habilidades sociais

Não foram encontrados na literatura, estudos que avaliam intervenções voltadas ao desenvolvimento de habilidades sociais e/ou HSPI para a Educação Infantil, no contexto brasileiro, parecendo que o foco têm sido o estudo acerca do Ensino Fundamental, médio e universitário (Brandão, Bolsoni-Silva \& Loureiro, 2017; Jovarini, Leme \& Correia-Zanini, 2018; Pereira-Guizzo, Del Prette \& Leme, 2018). Logo, pretende-se que o presente estudo possa contribuir para um campo do conhecimento pouco desenvolvido, programa de intervenção universal para a pré-escolares. Neste cenário, teve-se como objetivo verificar os efeitos de um programa para o desenvolvimento de HSPI, em alunos da Educação Infantil, sobre as variáveis de habilidades sociais, HSPI e problemas de comportamento, realizando a comparação entre grupos (alunos expostos ao programa e alunos não expostos) no início e no término da intervenção.

\section{Método}

Amostra

Participaram do estudo 45 crianças da Educação Infantil (22 meninas, 23 meninos, com média de idade de cinco anos, $\mathrm{DP}=4$ meses); 45 pais e três professoras. Inicialmente fizeram parte 71 alunos, contudo, ao final apenas 45 tiveram todas as avaliações realizadas pelos diferentes avaliadores professores, pais e pesquisadora.

Os participantes foram divididos em dois grupos: GI-grupo de intervenção, composto por 33 crianças, pertencentes a duas diferentes turmas de alunos e; GE-grupo de espera, com 12 crianças, de uma mesma sala. O GE recebeu intervenção após o término do estudo.

\section{Contexto}


O estudo foi desenvolvido junto à Rede Municipal de Educação de uma cidade do interior paulista.

\section{Instrumentos}

- Escala de Comportamento Social para Pré-Escolares PKBS-BR (School Social Behavior Scales-2, Merrell, 2002) produzido nos EUA e traduzido para o contexto brasileiro (Dias, Freitas, Z. Del Prette \& Del Prette, 2011), o PKBS é um inventário de relato, apresentado em duas versões (pais e professores) evidenciou propriedades psicométricas satisfatórias quanto à consistência interna da escala total de habilidades sociais $(\alpha=0,92)$ e seus três fatores obediência/civilidade $(\alpha=0,89)$, sociabilidade com pares $(\alpha=0,86)$, empatia/assertividade $(\alpha=0,79)$ e; escala de comportamentos-problema $(\alpha=0,95)$ e para seus dois fatores comportamentos-problema externalizantes $(\alpha=0,95)$ e internalizantes $(\alpha=0,88)$.

- Strengths and Difficulties Questionnaire (SDQ) - Questionário de Capacidades e Dificuldades. Elaborado e validado para o contexto brasileiro por Fleitlich e Goodman (2001), o questionário é destinado a crianças e adolescentes (4 a 16 anos) e apresenta três versões: autoavaliação do aluno, avaliação de pais e de professores. Este estudo utilizou a versão para os pais, na qual eles avaliam seus filhos respondendo a 25 perguntas relacionadas às habilidades sociais e problemas de comportamento, numa escala de zero a dois e há quanto tempo existem. Ao final, soma-se os valores atribuídos a cada escala e classifica-se o comportamento da criança como normal, limítrofe ou anormal, de acordo com a pontuação atingida. Em estudos de validação do SDQ, foi verificada a variação de índice de correlação de 0,63 a 0,88 para a versão dos pais. Com relação à consistência interna, apresentam-se valores próximos de 0,80 para o escore total de dificuldade.

- Procedimento de Solução de Problemas Interpessoais em Pré-escolares (PIPS)- Este procedimento foi desenvolvido por Shure (1990) para avaliar crianças de 4 a 8 anos. Diferentes situações problemas relacionadas a pares (EX: Paulo está brincando com o skate faz muito tempo. Agora Mateus quer ter uma oportunidade de brincar com este skate, mas Paulo continua brincando com ele. O que Mateus pode fazer/falar para ter uma oportunidade de brincar com o skate?) e com a mãe (Ex: Marina quebrou o vaso de flor preferido da mãe dela. O que ela pode fazer/falar para a mãe dela não ficar brava com ela?). As situações são apresentadas com auxílio de cartões, o que deixa a situação mais lúdica e concreta. A depender das respostas da criança um número maior ou menor de situações são apresentadas (de sete a 13 com pares e de 7 a 9 com mães). O manual apresenta diferentes categorias nas quais as respostas devem ser classificadas como de solução (respostas relevantes que resolvem o problema, podendo ser 
classificada em diferentes categorias ou repetidas) ou de não solução (irrelevantes). Calcula-se um escore final -taxa de relevância, que consiste na razão entre o número de soluções relevantes e o total de respostas relevantes e de não solução. Também pode-se avaliar a taxa de força pela proporção entre o número de soluções vigorosas dadas pela criança e a soma do número de vigor e de soluções relevantes não vigorosas. O manual foi traduzido e adaptado por (Elias, 2003).

- Programa Posso Pensar (Elias, 2013): Desenvolvido e testado no contexto brasileiro, visa promover e aprimorar as HSPI e outras habilidades sociais, em crianças de seis a dez anos, em ambiente educacional. Por meio de atividades lúdico-pedagógicas, o programa foi concebido para ensinar a criança como pensar em situações problemas e não o que pensar. É um programa de prevenção universal a ser aplicado às crianças por educadores, constituído de 40 lições (temas a serem trabalhados) e 40 atividades de reforço a serem aplicadas no dia seguinte à lição. As lições estão agrupadas em duas categorias habilidades prévias para solução de problemas, que são desenvolvidas nas 15 lições iniciais que têm como meta ensinar a identificar os próprios sentimentos e os sentimentos dos outros, considerar o ponto de vista dos outros (diferentes sentimentos) e sequenciar os eventos; e habilidades para solução de problemas, que são desenvolvidas nas 25 lições subsequentes, que têm por meta ensinar a pensar em mais de uma solução (diferentes caminhos para um mesmo objetivo), considerar as consequências (ações e sentimentos) e decidir que solução tomar. O desenvolvimento das lições se dá por meio de diferentes atividades, materiais e técnicas. Os materiais necessários são de baixo custo. As lições e seus respectivos reforços estão descritos no anexo 1. O tempo de duração das lições varia entre 30 e 40 minutos e a atividade de reforço a ser aplicada no dia seguinte tem duração em torno de 10 a 15 minutos. O processo de diálogo desempenha papel central no programa. Durante os diálogos dos roteiros pré-estabelecidos ou dos que ocorrem espontaneamente durante as sessões, o coordenador-professor do grupo guia as crianças na aplicação dos conceitos do programa para resolver problemas cotidianos. Existem orientações ao aplicador em como lidar com situações que possam ocorrer espontaneamente, estimulando e sempre elogiando o pensar, o elogio é para o pensar e não para o conteúdo da ideia; estimulase, assim, o "brainstorming” e evita-se inibir posterior pensamento sobre outras soluções.

\section{Procedimento}

Contactou-se a Secretaria Municipal de Educação que aceitou a execução do projeto e indicou escolas para a realização, dentre as indicadas duas apresentavam alunos na faixa etária pretendida. $\mathrm{O}$ projeto foi então apresentado para as diretoras que aceitaram e indicaram salas 
que deveriam participar. Na sequência foi realizada conversa com as professoras, que aceitaram participar e assinaram ao Termo de Consentimento Livre e Esclarecido (TCLE) e; estabelecido contato com os pais por meio de reunião para apresentar o estudo, frente a aceitação realizouse o preenchimento do TCLE e aplicação do SDQ. Em uma escola tanto TCLE quanto SDQ foram enviados pelas agendas dos alunos, pela falta de adesão à reunião. Somente após a autorização dos pais foi solicitado aos professores as avaliações do repertório comportamental das crianças. Houve dificuldades em receber os questionários preenchidos pelas professoras e pelos pais, que não cumpriram os prazos estabelecidos.

Concomitantemente à avaliação dos professores, os alunos foram avaliados individualmente pela pesquisadora em uma sala reservada. Após o término das avaliações deuse início a intervenção. As atividades ocorreram com duas turmas, separadamente, uma em cada escola e tinham duração de uma hora cada, incluindo as a atividades de reforço, que tinham duração em torno de 10 a 15 minutos. As sessões ocorreram duas vezes na semana, totalizando 20 sessões, as professoras acompanharam as atividades, como uma forma de capacitação para as mesmas. Após a intervenção, as crianças foram reavaliadas pelos diferentes informantes. A intervenção também foi realizada com o Grupo de Espera um ano após a espera.

\section{Procedimento de Análise de Dados}

Os dados obtidos foram transpostos para planilha de excel e posteriormente para o programa estatístico JASP (versão 9.2). Realizou-se as análises estatísticas descritivas para a amostra total e os diferentes grupos constituídos (GI e GE), como média, desvio padrão e mediana. Para verificar o pressuposto de normalidade, foram observadas a curtose e simetria, sendo consideráveis aceitáveis valores até 7 e 3, respectivamente, como indica Marôco (2011). As comparações entre grupos GI e GE foram realizadas, para todos os instrumentos através do teste $t$ de Student para amostras independentes, com nível de confiança de $95 \%$ ou correlato não-paramétrico (Man-Whitney) no caso de anormalidade dos dados. Para a avaliação da magnitude das diferenças, considerou-se o efeito como pequeno quando $\mathrm{d} \leq 0,2$; médio, quando d entre 0,2 e 0,5; elevado para d entre 0,50 e 1; muito elevado quando d > 1 (Marôco, 2011). O mesmo foi considerado nas variáveis não paramétricas, considerando o índice de correlação rrb (rank-biserial correlation).

\section{Aspectos Éticos}

O projeto foi aprovado pelo Comitê de Ética da Faculdade de Filosofia, Ciências e Letras da Universidade de São Paulo de Ribeirão Preto- SP (CAAE 36475614.0.0000.5407). 
Participaram do estudo somente crianças cujos pais e professores assinaram o Termo de Consentimento Livre e Esclarecido.

\section{Resultados}

A seguir serão apresentadas comparações entre Grupo de Intervenção e Grupo de Espera nos diferentes momentos: antes de intervenção e espera e após intervenção e espera.

Tabela 1.

Comparação Entre Grupo de Intervenção e Grupo de Espera, Antes Da Intervenção E Espera Respectivamente, Em Variáveis Investigadas Pelo SDQ.

\begin{tabular}{|c|c|c|c|c|c|c|}
\hline Variável & $\begin{array}{l}\text { GI } \\
\text { Média } \\
(d p)\end{array}$ & $\begin{array}{l}\text { GE } \\
\text { Média } \\
(d p) \\
\end{array}$ & $\mathbf{t}$ & gl & $p$ & $d$ \\
\hline $\begin{array}{l}\text { Comportamento } \\
\text { Pró-Social }\end{array}$ & $\begin{array}{l}8,636 \\
(1,537)\end{array}$ & $\begin{array}{l}7,833 \\
(2,250)\end{array}$ & 1,363 & 43,000 & 0,180 & 0,460 \\
\hline Hiperatividade & $\begin{array}{l}3,667 \\
(2,594)\end{array}$ & $\begin{array}{l}2,917 \\
(2,906)\end{array}$ & 0,831 & 43,000 & 0,411 & 0,280 \\
\hline $\begin{array}{l}\text { Sintomas } \\
\text { Emocionais }\end{array}$ & $\begin{array}{l}3,485 \\
(2,210)\end{array}$ & $\begin{array}{l}2,167 \\
(1,749)\end{array}$ & 1,861 & 43,000 & 0,070 & 0,627 \\
\hline $\begin{array}{l}\text { Problema de } \\
\text { Conduta }\end{array}$ & $\begin{array}{l}2,909 \\
(2,241)\end{array}$ & $\begin{array}{l}2,417 \\
(2,353)\end{array}$ & 0,643 & 43,000 & 0,523 & 0,217 \\
\hline $\begin{array}{l}\text { Problemas de } \\
\text { Relacionamento } \\
\text { com colegas }\end{array}$ & $\begin{array}{l}2,061 \\
(2,015)\end{array}$ & $\begin{array}{l}1,750 \\
(1,712)\end{array}$ & 0,475 & 43,000 & 0,638 & 0,160 \\
\hline $\begin{array}{l}\text { Total de } \\
\text { Dificuldades }\end{array}$ & $\begin{array}{l}12,121 \\
(6,299)\end{array}$ & $\begin{array}{l}9,250 \\
(5,562)\end{array}$ & $\begin{array}{l}1,392 \\
\boldsymbol{U}\end{array}$ & 43,000 & $\begin{array}{l}0,171 \\
p\end{array}$ & $\begin{array}{l}0,469 \\
\text { rrb }\end{array}$ \\
\hline Aborrecem & $\begin{array}{l}0,030 \\
(0,174)\end{array}$ & $\begin{array}{l}0,000 \\
(0,000)\end{array}$ & $\mathrm{NaN}$ & & & \\
\hline Dia-a-dia & $\begin{array}{l}0,030 \\
(0,174)\end{array}$ & $\begin{array}{l}0,091 \\
(0,302)\end{array}$ & 170,500 & 0,430 & $-0,061$ & \\
\hline Amizade & $\begin{array}{l}0,061 \\
(0,242)\end{array}$ & $\begin{array}{l}0,083 \\
(0,289)\end{array}$ & 193,500 & 0,812 & $-0,023$ & \\
\hline
\end{tabular}




\begin{tabular}{llllll} 
Aprendizado & 0,000 & 0,000 & $\mathrm{NaN}$ & & \\
& $(0,000)$ & $(0,000)$ & & \\
Lazer & 0,000 & 0,000 & $\mathrm{NaN}$ & & \\
& $(0,000)$ & $(0,000)$ & & & \\
\multirow{2}{*}{ Total } & 0,182 & 0,333 & & & \\
& $(0,727)$ & $(0,651)$ & 167,000 & 0,185 & $-0,157$ \\
\hline
\end{tabular}

Nota. $G I=$ Grupo de Intervenção; $G E=$ Grupo de Espera; $N=$ tamanho da amostra; GI N=33;GE N=12; $d p=$ desvio padrão; $t=$ estatística do teste $\mathrm{t}$ de student $\mathrm{gl}=$ grau de liberdade; $p \leq 0,05, d=$ tamanho de efeito; $u=$ Man-Whitney; $\mathrm{rrb}=$ rank-biserial correlation.

Através da Tabela 1, observa-se que não houve diferenças significativas entre GI e GE antes da intervenção e espera, nas variáveis comportamentais, avaliadas pelo SDQ através do relato dos pais. 
Tabela 2.

Comparação Entre Grupo De Intervenção E Grupo de Espera, Antes E Após A Intervenção E A Espera, Respectivamente, Na Variável Total De Problema De Comportamento E De Sua Respectiva Classificação, Investigada Pelo SDQ (N=33).

\begin{tabular}{|c|c|c|c|c|c|c|c|c|}
\hline \multirow[t]{2}{*}{ Participante } & \multicolumn{2}{|c|}{ SDQ - ANTES INT } & \multicolumn{2}{|l|}{ SDQ- APÓS INT } & \multicolumn{2}{|c|}{ SDQ - ANTES ESP } & \multicolumn{2}{|l|}{ SDQ- APÓS ESP } \\
\hline & $\begin{array}{l}\text { Pontuação Total } \\
\text { - Problema de } \\
\text { Comportamento }\end{array}$ & Classificação & $\begin{array}{l}\text { Pontuação Total } \\
\text { - Problema de } \\
\text { Comportamento }\end{array}$ & Classificação & $\begin{array}{l}\text { Pontuação Total } \\
\text { - Problema de } \\
\text { Comportamento }\end{array}$ & Classificação & $\begin{array}{l}\text { Pontuação Total } \\
\text { - Problema de } \\
\text { Comportamento }\end{array}$ & Classificação \\
\hline 1 & 6 & Não clínico & 14 & Limítrofe & 10 & Não clínico & 3 & Não clínico \\
\hline 2 & 20 & Clínico & 15 & Limítrofe & 5 & Não clínico & 6 & Não clínico \\
\hline 3 & 17 & Clínico & 14 & Limítrofe & 8 & Não clínico & 6 & Não clínico \\
\hline 4 & 5 & Não clínico & 8 & Não clínico & 15 & Limítrofe & 19 & Clínico \\
\hline 5 & 12 & Não clínico & 0 & Não clínico & 6 & Não clínico & 15 & Limítrofe \\
\hline 6 & 19 & Clínico & 24 & Clínico & 24 & Clínico & 16 & Limítrofe \\
\hline 7 & 5 & Não clínico & 3 & Não clínico & 10 & Não clínico & 4 & Não clínico \\
\hline 8 & 19 & Clínico & 18 & Clínico & 8 & Não clínico & 12 & Não clínico \\
\hline 9 & 26 & Clínico & 18 & Clínico & 4 & Não clínico & 2 & Não clínico \\
\hline 10 & 8 & Não clínico & 7 & Não clínico & 4 & Não clínico & 9 & Não clínico \\
\hline 11 & 6 & Não clínico & 10 & Não clínico & 8 & Não clínico & 6 & Não clínico \\
\hline
\end{tabular}




\begin{tabular}{|c|c|c|c|c|c|c|c|c|}
\hline 12 & 22 & Clínico & 8 & Não clínico & 9 & Não clínico & 8 & Não clínico \\
\hline 13 & 0 & Não clínico & 2 & Não clínico & & & & \\
\hline 14 & 10 & Não clínico & 11 & Não clínico & & & & \\
\hline 15 & 10 & Não clínico & 3 & Não clínico & & & & \\
\hline 16 & 15 & Limítrofe & 16 & Limítrofe & & & & \\
\hline 17 & 11 & Não clínico & 9 & Não clínico & & & & \\
\hline 18 & 7 & Não clínico & 5 & Não clínico & & & & \\
\hline 19 & 14 & Limítrofe & 4 & Não clínico & & & & \\
\hline 20 & 22 & Clínico & 17 & Clínico & & & & \\
\hline 21 & 9 & Não clínico & 10 & Não clínico & & & & \\
\hline 22 & 10 & Não clínico & 13 & Não clínico & & & & \\
\hline 23 & 17 & Clínico & 16 & Limítrofe & & & & \\
\hline 24 & 15 & Limítrofe & 10 & Não clínico & & & & \\
\hline 25 & 11 & Não clínico & 8 & Não clínico & & & & \\
\hline 26 & 15 & Limítrofe & 8 & Não clínico & & & & \\
\hline 27 & 18 & Clínico & 15 & Limítrofe & & & & \\
\hline 28 & 11 & Não clínico & 10 & Não clínico & & & & \\
\hline
\end{tabular}


29

30

31

32
10

Não clínico

1

11

Não clínico 1

Não clínico 13

Limítrofe 14

Não clínico 6
Não clínico

Não clínico

Não clínico

Limítrofe

Não clínico

De acordo com a Tabela 2, nota-se que inicialmente 19 (58\%) participantes apresentavam comportamentos não clínicos e 14 (42\%) apresentavam comportamentos clínicos ou limítrofes. Após a intervenção oito (24\%) apresentaram melhoras no comportamento, ou seja, 57\% das que inicialmente apresentavam problemas de comportamento melhoraram; 18 (55\%) permaneceram não clínicas; quatro (12\%) permaneceram clínicas; duas (6\%) permaneceram limítrofes e; apenas uma (3\%) apresentou piora no que tange à classificação de problema de comportamento.

Com relação ao grupo de espera, nota-se que inicialmente das 12 crianças, 10 (83\%) apresentavam classificação não clínica para problema de comportamento e duas (17\%) apresentavam classificação limítrofe e clínico. Após a intervenção das que já apresentavam problemas de comportamento uma melhorou e uma piorou. Ainda se observa que uma criança anteriormente não clínica para problemas de comportamento passou para limítrofe, ou seja, piorou seu comportamento. 
Tabela 3.

Comparação Entre Grupo de Intervenção e Grupo de Espera Antes Da Intervenção E Espera Respectivamente, Nas Variáveis Investigadas Pelo PKBS.

\begin{tabular}{|c|c|c|c|c|c|c|}
\hline \multirow[t]{2}{*}{ Variável } & GI & \multirow{2}{*}{$\begin{array}{l}\text { GE } \\
\text { Média } \\
\text { (dp) }\end{array}$} & \multirow[t]{2}{*}{$\mathbf{t}$} & \multirow[t]{2}{*}{ gl } & \multirow[t]{2}{*}{$p$} & \multirow[t]{2}{*}{$d$} \\
\hline & $\begin{array}{l}\text { Média } \\
\text { (dp) }\end{array}$ & & & & & \\
\hline $\begin{array}{l}\text { Total de Habilidades } \\
\text { Sociais }\end{array}$ & $\begin{array}{l}23,388 \\
(5,856)\end{array}$ & $\begin{array}{l}26,050 \\
(5,165)\end{array}$ & -1.389 & 43,000 & 0,172 & $-0,468$ \\
\hline Cooperação Social & $\begin{array}{l}29,182 \\
(7,630)\end{array}$ & $\begin{array}{l}31,750 \\
(6,837)\end{array}$ & -1.025 & 43,000 & 0,311 & $-0,345$ \\
\hline Independência Social & $\begin{array}{l}24,606 \\
(7,075)\end{array}$ & $\begin{array}{l}27,167 \\
(5,096)\end{array}$ & -1.146 & 43,000 & $0,258 \mathrm{a}$ & $-0,386$ \\
\hline Interação Social & $\begin{array}{l}16,394 \\
(4,401)\end{array}$ & $\begin{array}{l}19,250 \\
(5,065)\end{array}$ & -1.850 & 43,000 & 0,071 & $-0,624$ \\
\hline $\begin{array}{l}\text { Total de Problema de } \\
\text { comportamento }\end{array}$ & $\begin{array}{l}20,121 \\
(9,780)\end{array}$ & $\begin{array}{l}10,750 \\
(7,172)\end{array}$ & 3.027 & 43,000 & 0,004 & 1,020 \\
\hline $\begin{array}{l}\text { Problema de } \\
\text { Comportamento } \\
\text { externalizante }\end{array}$ & 23,000 & 10,000 & 2,471 & 43,000 & 0,017 & 0,833 \\
\hline $\begin{array}{l}\text { Problema de } \\
\text { comportamento } \\
\text { internalizante }\end{array}$ & $\begin{array}{l}17,242 \\
(8,246)\end{array}$ & $\begin{array}{l}11,500 \\
(6,948)\end{array}$ & 2,147 & 43,000 & 0,037 & 0,724 \\
\hline
\end{tabular}

Nota. $G I=$ Grupo de Intervenção; $G E=$ Grupo de Espera; $N=$ tamanho da amostra; $G I N=33, G E N=12 ; d p$ $=$ desvio padrão; $t=$ estatística do teste $\mathrm{t}$ de student; $\mathrm{gl}=$ grau de liberdade; $p \leq 0,05, d=$ tamanho de efeito.

De acordo com os dados apresentados na Tabela 3, nota-se que segundo os professores, GI apresenta médias de total de problema de comportamento, problema de comportamento externalizante e internalizante significativamente maiores que GE, antes da intervenção e espera, respectivamente. O tamanho de efeito foi considerado grande nas 
variáveis total de problema de comportamento e problema de comportamento externalizante; já na variável problema de comportamento internalizante, o tamanho de efeito foi considerado médio.

Tabela 4.

Comparação Entre Grupo de Intervenção e Grupo de Espera Antes Da Intervenção E Espera Respectivamente, Nas Variáveis Investigadas Pelo PIPS.

\begin{tabular}{|c|c|c|c|c|c|c|c|}
\hline \multirow[t]{2}{*}{ Variável } & & GI & GE & \multirow[t]{2}{*}{$\mathbf{t}$} & \multirow[t]{2}{*}{ gl } & \multirow[t]{2}{*}{$p$} & \multirow[t]{2}{*}{$d$} \\
\hline & & $\begin{array}{l}\text { Média } \\
\text { (dp) }\end{array}$ & $\begin{array}{l}\text { Média } \\
\text { (dp) }\end{array}$ & & & & \\
\hline \multirow[t]{2}{*}{$\begin{array}{l}\text { Taxa } \\
\text { relevância }\end{array}$} & de & $\begin{array}{l}0,719 \\
(0,166)\end{array}$ & $\begin{array}{l}0,785 \\
(0,181)\end{array}$ & $-1,144$ & 43,000 & 0,259 & $-0,386$ \\
\hline & & & & $\boldsymbol{U}$ & & $p$ & rrb \\
\hline Força & & $\begin{array}{l}0,039 \\
(0,066)\end{array}$ & $\begin{array}{l}0,053 \\
(0,132)\end{array}$ & 215,000 & & 0,586 & 0,086 \\
\hline
\end{tabular}

Nota. $G I=$ Grupo de Intervenção; $G E=$ Grupo de Espera; $N=$ tamanho da amostra; GI N=33;GE N=12; $d p$ $=$ desvio padrão; $t=$ estatística do teste $\mathrm{t}$ de student $\mathrm{gl}=$ grau de liberdade; $p \leq 0,05, d=$ tamanho de efeito; $u=$ Man-Whitney; $r$ rb= rank-biserial correlation.

De acordo com a Tabela 4, percebe-se que não houve diferenças significativas entre os grupos de intervenção e espera nos escores de habilidades de solução de problemas interpessoais relacionados a taxa de relevância e força de respostas, avaliadas diretamente com a criança.

Tabela 5.

Comparação Entre Grupo de Intervenção e Grupo de Espera Após A Intervenção E Espera Respectivamente, Nas Variáveis Investigadas Pelo SDQ.

\begin{tabular}{lllllll}
\hline Variável & GI & GE & t & gl & $\boldsymbol{p}$ & $\boldsymbol{d}$ \\
\cline { 2 - 6 } & $\begin{array}{l}\text { Média } \\
(\boldsymbol{d} \boldsymbol{p})\end{array}$ & $\begin{array}{l}\text { Média } \\
(\boldsymbol{d} \boldsymbol{p})\end{array}$ & & & & \\
\hline Comportamento & 8,485 & 8,750 & $-0,491$ & 43,000 & 0,626 & $-0,165$ \\
Pró-Social & $(1,698)$ & $(1,288)$ & & & & \\
Hiperatividade & 3,727 & 3,750 & $-0,025$ & 43,000 & 0,980 & $-0,008$ \\
& $(2,649)$ & $(2,864)$ & & & & \\
& 2,758 & 1,833 & 1,326 & 43,000 & 0,192 & 0,477
\end{tabular}




\begin{tabular}{|c|c|c|c|c|c|c|}
\hline $\begin{array}{l}\text { Sintomas } \\
\text { Emocionais }\end{array}$ & $(2,166)$ & $(1,749)$ & & & & \\
\hline $\begin{array}{l}\text { Problema de } \\
\text { Conduta }\end{array}$ & $\begin{array}{l}2,273 \\
(1,859)\end{array}$ & $\begin{array}{l}1,750 \\
(1,603)\end{array}$ & 0,863 & 43,000 & 0,393 & 0,291 \\
\hline $\begin{array}{l}\text { Problemas de } \\
\text { Relacionamento } \\
\text { com colegas }\end{array}$ & $\begin{array}{l}1,485 \\
(1,482)\end{array}$ & $\begin{array}{l}1,500 \\
(2,023)\end{array}$ & $-0,027$ & 43,000 & 0,978 & $-0,009$ \\
\hline $\begin{array}{l}\text { Total de } \\
\text { Dificuldades }\end{array}$ & $\begin{array}{l}10,242 \\
(5,618)\end{array}$ & $\begin{array}{l}8,833 \\
(5,491)\end{array}$ & $\begin{array}{l}0,748 \\
\boldsymbol{U}\end{array}$ & 43,000 & $\begin{array}{l}0,458 \\
p\end{array}$ & $\begin{array}{l}0,252 \\
\text { rrb }\end{array}$ \\
\hline Aborrecem & $\begin{array}{l}0,030 \\
(0,174)\end{array}$ & $\begin{array}{l}0,000 \\
(0,000)\end{array}$ & $\mathrm{NaN}$ & & & \\
\hline Dia-a-dia & $\begin{array}{l}0,000 \\
(0,000)\end{array}$ & $\begin{array}{l}0,000 \\
(0,000)\end{array}$ & $\mathrm{NaN}$ & & & \\
\hline Amizade & $\begin{array}{l}0,000 \\
(0,000)\end{array}$ & $\begin{array}{l}0,083 \\
(0,289)\end{array}$ & $\mathrm{NaN}$ & & & \\
\hline Aprendizado & $\begin{array}{l}0,030 \\
(0,174)\end{array}$ & $\begin{array}{l}0,167 \\
(0,577)\end{array}$ & 187,000 & & 0,450 & $-0,056$ \\
\hline Lazer & $\begin{array}{l}0,000 \\
(0,000)\end{array}$ & $\begin{array}{l}0,000 \\
(0,000)\end{array}$ & $\mathrm{NaN}$ & & & \\
\hline Total & $\begin{array}{l}0,061 \\
(0,242)\end{array}$ & $\begin{array}{l}0,250 \\
(0,622)\end{array}$ & 176,000 & & 0,263 & $-0,111$ \\
\hline
\end{tabular}

Nota. $G I=$ Grupo de Intervenção; $G E=$ Grupo de Espera; $N=$ tamanho da amostra; GI N=33;GE N=12; $d p$ $=$ desvio padrão; $t=$ estatística do teste $\mathrm{t}$ de student $\mathrm{gl}=$ grau de liberdade; $p \leq 0,05, d=$ tamanho de efeito; $u=$ Man-Whitney; rrb= rank-biserial correlation; NaN: variância=0.

A partir da Tabela 5, nota-se que não foram observadas diferenças significativas entre os grupos, após a intervenção e espera, respectivamente, nas variáveis comportamentais, avaliadas pelo SDQ, segundo os pais. 
Tabela 6.

Comparação Entre Grupo de Intervenção e Grupo de Espera Após A Intervenção E Espera Respectivamente, Nas Variáveis Investigadas Pelo PKBS.

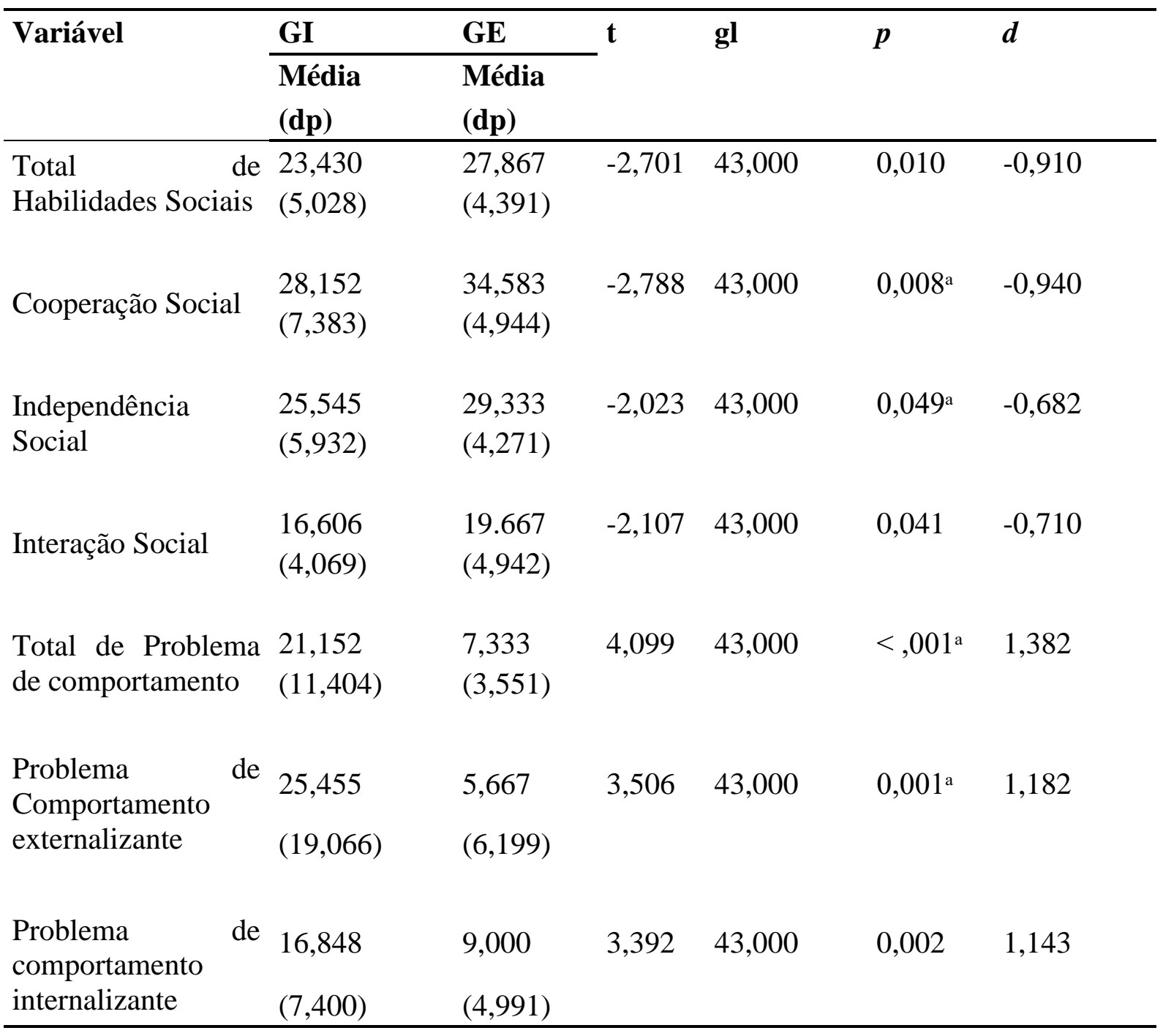

Nota. $G I=$ Grupo de Intervenção; $G E=$ Grupo de Espera; $N=$ tamanho da amostra; GI N=33;GE N=12; $d p$ $=$ desvio padrão; $t=$ estatística do teste $\mathrm{t}$ de student $\mathrm{gl}=$ grau de liberdade; $p \leq 0,05, d=$ tamanho de efeito.

Como pode-se observar na Tabela 6, foram identificadas diferenças significativas em todas as variáveis investigadas pelo PKBS após a intervenção e a espera, respectivamente. GE apresentou significativamente maiores médias que GI em total de habilidades sociais, cooperação social, independência social e interação social. Já nas variáveis problema de comportamento, problema de comportamento externalizante e problema de comportamento internalizante, GE apresentou médias significativamente menores que GI. Com relação ao tamanho de efeito, este foi considerado grande nas 
variáveis problema de comportamento internalizante, problema de comportamento externalizante, cooperação social e total de habilidades sociais. Já o tamanho de efeito da variável total de problema de comportamento foi considerado muito grande, enquanto que, das variáveis independência social e interação social foi considerado médio.

Tabela 7.

Comparação Entre Grupo de Intervenção e Grupo de Espera Após A Intervenção E Espera Respectivamente, Nas Variáveis Investigadas Pelo PIPS.

\begin{tabular}{|c|c|c|c|c|c|c|c|}
\hline \multirow[t]{2}{*}{ Variável } & & GI & GE & \multirow[t]{2}{*}{$t$} & \multirow[t]{2}{*}{ gl } & \multirow[t]{2}{*}{$p$} & \multirow[t]{2}{*}{$d$} \\
\hline & & $\begin{array}{l}\text { Média } \\
\text { (dp) }\end{array}$ & $\begin{array}{l}\text { Média } \\
\text { (dp) }\end{array}$ & & & & \\
\hline \multirow{3}{*}{$\begin{array}{l}\text { Taxa } \\
\text { relevância }\end{array}$} & de & 0,857 & 0,910 & $-1,087$ & 43,000 & 0,283 & $-0,367$ \\
\hline & & $(0,149)$ & $(0,127)$ & & & & \\
\hline & & & & $\boldsymbol{U}$ & & $p$ & rrb \\
\hline Força & & $\begin{array}{l}0,060 \\
(0,164)\end{array}$ & $\begin{array}{l}0,019 \\
(0,046)\end{array}$ & 221,500 & & 0,434 & 0,119 \\
\hline
\end{tabular}

Nota. $G I=$ Grupo de Intervenção; $G E=$ Grupo de Espera; $N=$ tamanho da amostra; GI N=33;GE N=12; $d p=$ desvio padrão; $t=$ estatística do teste $\mathrm{t}$ de student $\mathrm{gl}=$ grau de liberdade; $p \leq 0,05, d=$ tamanho de efeito; $u=$ ManWhitney; rrb= rank-biserial correlation.

De acordo com a Tabela 7, não há diferenças significativas entre GI e GE nos escores de taxa de relevância e força de respostas de habilidades de solução de problemas interpessoais, avaliadas diretamente com a criança, pela pesquisadora.

\section{Discussão}

A discussão a seguir apresentará algumas considerações sobre o presente trabalho que teve por objetivo geral verificar os efeitos de um programa para o desenvolvimento de HSPI em alunos da Educação Infantil, sobre as variáveis de habilidades sociais, HSPI e problemas de comportamento.

A partir dos resultados obtidos antes da intervenção e espera, respectivamente, pode-se perceber que não havia diferenças significativas entre os grupos segundo a avaliação dos pais no que se refere a variáveis comportamentais. Também não existiram diferenças nas habilidades de solução de problemas interpessoais, avaliadas diretamente com as crianças pela pesquisadora. Segundo os professores, os grupos não diferiram quanto a comportamentos como habilidades sociais, independência, interação e 
cooperação sociais, contudo, no que se refere a problemas comportamentais, os participantes do GI apresentavam escores significativamente maiores no total de problemas de comportamento e em suas duas classes internalizante e externalizante, tendo tamanho de efeito de médio para grande.

De acordo com a literatura, problemas de comportamento são concorrentes às habilidades sociais, já que restringem as possibilidades de emissão de comportamentos pró-sociais (Del Prette et al., 2011). Os problemas de comportamento dificultam o acesso da criança a reforçadores importantes para a aprendizagem e desenvolvimento socioemocional (Bolsoni-Silva \& Del Prette, 2003). No presente estudo, as crianças do GI, já apresentavam problemas de comportamentos significativos antes da intervenção e apesar de apresentarem comportamentos pró-sociais (sem diferenças significativas em relação ao GE), seus comportamentos problemáticos impendiam-nas de receberem naturalmente reforçadores ambientais para os comportamentos considerados positivos.

Após a intervenção e a espera, respectivamente, não foram observadas diferenças significativas entre os grupos com relação às variáveis comportamentais investigadas pela avaliação dos pais, nem de habilidades de solução de problemas interpessoais, avaliadas pela pesquisadora. Na avaliação das professoras, as crianças do GI continuaram apresentando escores significativamente maiores em problemas de comportamento (total, internalizante e externalizante) comparado com GE. Por sua vez, o GE passou a apresentar resultados significativamente superior ao GI no total de habilidades sociais, cooperação, independência e interação sociais, com tamanho de efeito importante. Esses dados indicam que as crianças do GI, não foram impactadas pelo programa em nenhuma das variáveis investigadas, ou seja, não se beneficiaram do programa e nem mesmo foram impactadas positivamente pelas interações sociais vivenciadas com família e escola. Já o GE naturalmente apresentou progressos no desenvolvimento do repertório comportamental, promovidos pela escola e família, o que provavelmente ocorreu pela ausência de problemas de comportamento, fazendo com que as crianças recebessem reforçadores sociais por seus bons comportamentos, aumentando assim os escores dos mesmos. Em nossa cultura, a experiência escolar é central para aquisição e expansão das habilidades acadêmicas (domínio cognitivo), habilidades sociais e ajuste comportamental (domínio psicossocial); desta forma é um contexto essencial para a promoção e exercício de habilidades relevantes ao longo de toda a vida (Del Prette \& Del Prette, 2003; CorreiaZanini \& Marturano, 2016); sabe-se o quanto problemas comportamentais impactam nas relações estabelecidas na escola quer de aprendizado ou interpessoal. Em suma, nem a 
escola e nem um programa de prevenção universal foi capaz de contribuir para ganhos de habilidades sociais em crianças com problemas de comportamento significativos.

Os dados encontrados nesse estudo confirmam os resultados apresentados por Kirkhaug et al. (2016), que testou um programa universal de intervenção escolar intitulado The Incredible Years Teacher Classroom management program (IY-TCM) junto a crianças do Ensino Fundamental com problemas de comportamento a nível clínico. A intervenção utilizada na pesquisa citada, também não foi efetiva para a diminuição de problemas de comportamento, o que sugere que intervenções de prevenção universal não são eficazes para aumentar habilidades sociais e diminuir problemas de comportamento quando estes já existem e são graves. Segundo Kirkhaug (2016), programas universais não são efetivos quando aplicados a crianças com problemas de comportamentos graves; nesse quadro deve-se pensar em programas de tratamento ou de prevenção indicada. De acordo com a literatura, programas de prevenção indicada são efetivos para reduzir, consistentemente, problemas de comportamento em crianças de Ensino Fundamental (Shure, 2006; Elias \& Marturano, 2014).

Finalmente sinalizamos que os resultados encontrados neste estudo não corroboraram com os encontrados por Elias e Marturano (2016) e Elias e Amaral (2016), ao avaliarem os efeitos do Programa Posso Pensar. Em estudos quase-experimental, quando aplicado a crianças em diferentes anos do Ensino Fundamental, essas autoras sinalizaram ganhos dos participantes nas diferentes variáveis investigadas. Ressalta-se que os participantes destes estudos não apresentavam problemas de comportamento dessa ordem.

\section{Considerações finais}

Os resultados do presente estudo trazem luz a algumas considerações. Primeiramente, que crianças com problemas de comportamentos significativos não se beneficiam de intervenções universais. Um segundo ponto é que intervenções que associem não só o treinamento a crianças, mas também a pais e professores podem ser mais produtivas, visto que podem impactar nas práticas educativas e então mudar interações e contingências a certos comportamentos.

Quanto a limitações do estudo, apontamos três, uma que pode estar associada a forma de aplicação do programa utilizado, inicialmente pensado para crianças do Ensino Fundamental e para ser aplicado pelo professor em sala de aula durante o ano letivo; outra que se refere ao fato da pesquisadora não ter podido fazer uma inserção ecológica antes 
da aplicação do programa, devido as condições postas pelo contexto; a última se dá pelo viés causado pela falta de possibilidade de randomização das salas que participaram do estudo. Sugere-se que próximos estudos utilizando o programa em contexto escolar sejam realizados por professores durante o ano escolar, incluído no currículo.

\section{Referências}

Achenbach, T. M., \& Edelbrock, C. S. (1979). The Child Behavior Profile: II. Boys aged 12-16 and girls aged 6-11 and 12-16. Journal of consulting and clinical psychology, 47(2), 223.

Barker, E. D., Vitaro, F., Lacourse, E., Fontaine, N. M. G., Carbonneau, R., \& Tremblay, R. E. (2010). Testing the developmental distinctiveness of male proactive and reactive aggression with a nested longitudinal experimental intervention. Aggressive Behavior, 36(2), 127-140.

Bolsoni-Silva, A. T., \& Borelli, L. M. (2012). Treinamento de Habilidades Sociais Educativas Parentais: Comparação de Procedimentos a partir do Tempo de Intervenção. Estudos e Pesquisas em Psicologia, 12(1), 36-58.

Bolsoni-Silva, A. T., \& Del Prette, A. (2003). Problemas de comportamento: um panorama da área. Revista Brasileira de Terapia Comportamental e Cognitiva, 5(2), 91-103.

Bolsoni-Silva, A. T., Mariano, M. L., Loureiro, S. R., \& Bonaccorsi, C. (2013). Contexto escolar: Práticas educativas do professor, comportamento e habilidades sociais infantis. Revista Semestral da Associação Brasileira de Psicologia Escolar e Educacional, 17(2),259-269.

Bolsoni-Silva, A. T., Marturano, E. M., \& Freiria, R. L. B. (2010). Indicativos de problemas de comportamento e de habilidades sociais em crianças: um estudo longitudinal. Psicologia: Reflexão e Crítica, 23(3), 506-515.

Bolsoni-Silva, A. T., Silveira, F. S., \& Marturano, M. M. (2008). Promovendo habilidades sociais educativas parentais na prevenção de problemas de comportamento. Revista Brasileira de Terapia. Comportamental-Cognitiva, 10, 125-142.

Brandão, A. S.; Bolsoni-Silva, A. T. \& Loureiro, S. R. (2017). Preditores da Conclusão da Graduação: Habilidades Sociais, Saúde Mental, Características Acadêmicas. Paidéia (Ribeirão Preto), 27(66), 117-125.

Cia, F., \& Barham, E. J. (2009). Repertório de habilidades sociais, problemas de comportamento, autoconceito e desempenho acadêmico de crianças no início da escolarização. Estudos de Psicologia, 26(1), 45-55.

Correia-Zanini, M. R. G. (2013). Um estudo prospectivo sobre o percurso escolar de crianças nos primeiros anos do Ensino Fundamental. Tese de Doutorado, Programa de Pós-Graduação em Psicologia, Universidade de São Paulo, Ribeirão Preto, SP.

Correia-Zanini, M. R. G. \& Marturano, E. M. (2016). Primeiros Passos no Ensino Fundamental: Competência Cognitiva, Habilidades Sociais, Comportamento e Estresse. Psico-USF [online], 21(2), 305-317.

Del Prette, Z. A. P., \& Del Prette, A. (2003). Habilidades sociais e dificuldades de aprendizagem: Teoria e pesquisa sob um enfoque multimodal. In: A. Del Prette \& A. P. Del Prette (Orgs.), Habilidades Sociais, Desenvolvimento e Aprendizagem: Questões conceituais, avaliação e intervenção (pp. 167-206). Campinas: Alínea.

Del Prette, Z. A. P., \& Del Prette, A. (2005). Psicologia das habilidades sociais na infância: Teoria e prática. Petrópolis, RJ: Vozes. 
Del Prette, Z. A. P., \& Del Prette, A. (2009). Avaliação de habilidades sociais: Bases conceituais, instrumentos e procedimentos. In Del Prette e Del Prette (Orgs.), Psicologia das habilidades sociais: Diversidade teórica e suas implicações (pp. 187229). Petrópolis, RJ: Vozes.

Del Prette, Z.A., \& Del Prette, A. (2017). Competência Social e Habilidades Sociais; manual teórico-prático. Petropólis: Vozes.

Elias, L. C. S., \& Amaral, M. V. (2016). Habilidades Sociais, Comportamentos e Desempenho Acadêmico em Escolares antes e após Intervenção. Psico-USF, Bragança Paulista, 21(1), 49-61.

Elias, L. C. S., \& Marturano, E. M. (2016). Promovendo habilidades de solução de problemas interpessoais em crianças. Interação Psicol.,20(1), 91-100.

Falcão, A. P. \& Bolsoni-Silva, A. T., Magri, N., Moretto, L. A. (2016). PromoveCrianças: treinamento de habilidades sociais. São Paulo: Hogrefe.

Fernandes, L. M., Leme, V. B. R., Elias, L. C. S., \& Soares, A. B. (2018). Preditores do desempenho escolar ao final do ensino fundamental: histórico de reprovação, habilidades sociais e apoio social. Temas em Psicologia, 26(1), 215-228.

Gonçalves, E. S. \& Murta, S. G. (2008). Avaliação dos efeitos de uma modalidade de treinamento de habilidades sociais para crianças. Psicologia Reflexão Crítica, 21(3), 430-436.

Jovarini, N. V., Leme, V. B. R., \& Correia-Zanini, M. R. G. (2018). Influence of Social Skills and Stressors on Academic Achievement in the Sixth-Grade. Paidéia (Ribeirão Preto), 28, e2819.

Kratochwill, T. R., Albers, C. A., \& Shernoff, E. S. (2004). School-based intervention. Child Adolescent Psychiatric Clinics of North America, 13, 885-903.

Kirkhaug, B., Drugli, M. B., Handegard, B. H. Stian Lydersen, Åsheim, M., Fossum, S. (2016). Does the Incredible Years Teacher Classroom Management Training programme have positive effects for Young children exhibiting severe externalizing problems in school?: a quasi-experimental pre-post study. BMC Psychiatry

Lopes, D. C. (2013). Programa universal de habilidades sociais aplicado pelo professor: impacto sobre comportamentos sociais e acadêmicos. Tese de Doutorado, Programa de Pós-Graduação em Psicologia, Universidade Federal de São Carlos, São Carlos, SP.

Marôco, J. (2011). Análise estatística com o SPSS statistics (5a ed.). Pero Pinheiro, Portugal: Report Number.

Marturano, S., Bolsoni-Silva, A. T. \& Elias, L. C. S. (2015). Intervenções na escola. In. S. G. Murta, C. Leandro-França, K. B. Santos \& L. Polejack (Org.) Prevenção e promoção em saúde mental: Fundamentos, Planejamento e Estratégias de Intervenção (pp.54-74). Novo Hamburgo: Sinopsys Editora e Sistemas Ltda.

Marturano, E. M, \& Elias, L. C. S. (2016). Família, dificuldades no aprendizado e problemas de comportamento em escolares. Educar em Revista, (59), 123-139.

Marturano, E. M.; Elias, L. C. S. \& Versuti, F. M. (2017). Solução de problemas e conflitos interpessoais. In Z. A. P, Del Prette, \& A. Del Prette, A. (Eds). Habilidades sociais e competência social para uma vida melhor. (pp. 83-89). São Carlos, SP: EdUFSCAR.

McCabe, P.C., Altamura, M. (2011). Empirically valid strategies to improve social and emotional competence of preschool children. Psychology in the Schools, 48(5), 513540.

Mrazek, P. B., \& Haggerty, R. J. (1994). Reducing risks for mental disorders: frontiers for preventive intervention research. Washington, DC: The National Acade mies Press. 
Pereira-Guizzo, C. S., Del Prette, Z. A. P., Leme, V. B. R. (2018). Programa de habilidades sociais para adolescentes em preparação para o trabalho. Psicologia Escolar e Educacional, 22 (3), 573-581.

Pinheiro, M. I. S., Haase, V. G., Del Prette, A., Amarante, C. L. D., \& Del Prette, Z. A. P. (2006). Treinamento de habilidades sociais educativas para pais de crianças com problemas de comportamento. Psicologia: Reflexão e Crítica, 19(3), 407-414.

Rocha, M. M., Del Prette, Z. A. P., \& Del Prette, A. (2011). Programa de habilidades sociais educativas com mães de crianças com déficit de atenção. In A. Del Prette \& Z. A. P. Del Prette. (Orgs). Habilidades Sociais: Intervenções efetivas em grupo. São Paulo: Casa do Psicólogo.

Rodrigues, M. C., Dias, J. P. \& Freitas, M. F. R. L. (2010). Resolução de problemas interpessoais: promovendo o desenvolvimento sociocognitivo na escola. Psicologia em Estudo, 15, 831-839.

Rosin-Pinola, A. R. (2010). Efeitos de um programa de treinamento de habilidades sociais educativas junto a professores de alunos com deficiência mental incluídos. Tese de Doutorado, Programa de Pós-Graduação em Psicologia, Universidade de São Paulo, Ribeirão Preto, SP.

Sabbag, G. M., \& Bolsoni-Silva, A. T. (2011). A relação das Habilidades Sociais educativas e das práticas educativas maternas com os problemas de comportamento em adolescentes. Estudos e Pesquisas em Psicologia, 11(2), 423-441.

Shure, M. B. (2006). Eu posso resolver problemas: educação infantil e ensino funadamental: um programa de solução cognitive para problemas interpessoais. (E. M. Marturano, A. M. A. Motta, \& L. C. S. Elias, Trads.). Petrópolis: Vozes. 
Estudo 3

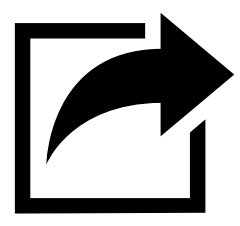




\title{
Avaliação dos efeitos de um Programa de Prevenção Universal na Educação Infantil
}

Resumo: As habilidades de solução de problemas interpessoais (HSPI) têm sido destacadas como essenciais ao desenvolvimento infantil, atuando como fator de proteção. O objetivo do presente estudo foi verificar os efeitos de um programa de prevenção universal para o desenvolvimento de habilidades de solução de problemas interpessoais, com alunos da Educação Infantil, de modo a verificar a replicabilidade dos resultados obtidos com alunos dos primeiros anos do Ensino Fundamental I (Elias \& Marturano, 2016). Para isso, buscou-se comparar as habilidades de solução de problemas interpessoais, total de habilidades sociais e problemas de comportamento antes e após a intervenção. Participaram 45 alunos, com idade de cinco anos, devidamente matriculados na rede pública de uma cidade do interior paulista, local onde o estudo foi desenvolvido. O estudo teve recorte transversal, com medidas repetidas e desenho quase-experimental. Os instrumentos utilizados para avaliar as crianças foram Strengths and Difficulties Questionnaire (SDQ), Escala de Comportamento Social para Pré-Escolares PKBS-BR (PKBS) e Procedimento de Solução de Problemas Interpessoais em Pré-escolares (PIPS) $e$; para o treinamento das HSPI o Programa Posso Pensar. Conclui-se que a intervenção realizada apresentou, segundo os pais, ganhos aos participantes em algumas das variáveis investigadas.

Palavras-chave: Solução de problemas, Pré-escolar, Intervenção educacional precoce.

\begin{abstract}
Interpersonal solving problems skills are highlighted as essential for children development and considered to be a protection factor. We seek to verify the effects of an universal prevention program on the development of preschoolers interpersonal solving problems skills. By doing so, we aim to verify the replicability of the results obtained with elementary school (Elias \& Marturano, 2016). Therefore, we compared the solving problems skills, total of social skills and behavior problems before and after the intervention. The program targeted 45 students with five years-old who were enrolled in public schools in an inland city. This research was a cross-sectional, quasi-experimental study, with repeated measures design. The intervention procedure used was Programa Posso Pensar. The instruments used to assess the children's behavior were Strengths and Difficulties Questionnaire (SDQ), Escala de Comportamento Social para Pré-Escolares
\end{abstract}


PKBS-BR (PKBS) and Procedimento de Solução de Problemas Interpessoais em Préescolares (PIPS). We have concluded that children who participated in the intervention, showed gains in some variables, according to their parents evaluation.

Key-words: Problem solving; Child, preschool; Early intervention, Educational.

\section{Introdução}

Del Prette e Del Prette (2017) referem-se às habilidades sociais como aqueles comportamentos requeridos nas tarefas de interações sociais, diretamente observáveis, com alta probabilidade de gerar consequências positivas para o indivíduo e para o seu grupo, em determinado contexto cultural e situacional. A disponibilidade de um repertório de habilidades sociais é condição necessária, mas não suficiente, para a competência social. Tem-se competência social como um construto avaliativo do desempenho social do indivíduo. Em uma relação interpessoal, a competência está ligada à capacidade do sujeito de manejar pensamentos, sentimentos e ações; promovendo resultados positivos tanto pra si mesmo, como para aqueles com quem se relaciona em determinado contexto (Del Prette \& Del Prette, 2017).

As habilidades são aprendidas e seu desempenho varia em função de diversos fatores: ambientais, cognitivos, estágio do desenvolvimento e interação entre esses aspectos. Espera-se, então, que o repertório de habilidades sociais se torne progressivamente mais elaborado ao longo da vida, sendo estes importantes em todo ciclo vital, podendo atuar como fator de proteção ao desenvolvimento (Bandeira, Rocha, Souza, 2006).

Marturano, Elias e Versuti (2017) apontam que entre diferentes classes de habilidades sociais temos as habilidades de solução de problemas interpessoais (HSPI), constituídas de comportamentos que envolvem: gerar soluções alternativas, considerar a consequência dos atos, desenvolvimento de pensamento meio-fim, desenvolvimento de pensamento social-causal, sensibilidade para problemas e orientação. De acordo com as autoras, as HSPI são essenciais para manter relacionamentos satisfatórios desde a infância, uma vez que que essas habilidades auxiliam a lidar com conflitos interpessoais que ocorrem diariamente. As autoras reforçam que os comportamentos envolvidos nas HSPI, consistem em analisar as possíveis consequências de cada solução, relações entre ação e consequência, observar os próprios sentimentos e os dos outros, além de planejar ações para atingir os objetivos desejáveis. 
Segundo Borges e Marturano (2009), o repertório limitado de alternativas de HSPI é um dos fatores que leva à agressividade infantil e, indiretamente, ao isolamento social a que crianças agressivas são submetidas. Crianças com repertório deficitário de habilidades sociais tendem a apresentar maior ocorrência de problemas de comportamento. Da mesma forma, problemas de comportamento competem com a aquisição e desempenho de habilidades sociais específicas, restringindo, assim, oportunidades de emissão de comportamentos pró-sociais (Gresham \& Elliott, 1990).

Segundo Bolsoni-Silva e Del Prette (2003), os problemas de comportamento se referem a excessos ou déficits comportamentais que dificultam o acesso da criança a novas contingências de reforçamento, relevantes para a aprendizagem e promotoras do desenvolvimento. Problemas de comportamento, em geral, tornam-se mais graves em razão de interações negativas da criança com o ambiente e, portanto, a escola tem um papel fundamental nesse processo. Além disso, estes problemas aumentam o risco de problemas psicossociais na adolescência e início da fase adulta (Kirkhaug et al, 2016).

Com base na diferenciação inicial de Achenbach e Edelbrock (1979), a literatura de Psicopatologia Infantil classifica os problemas de comportamento em dois grandes grupos: internalizantes (se expressam basicamente em relação ao próprio indivíduo, como a excessiva timidez) e externalizantes (se apresentam predominantemente em relação a outras pessoas, como a agressividade, por exemplo). Ambos os grupos de problemas são igualmente prejudiciais e podem ter consequências desfavoráveis para o desenvolvimento e, portanto, devem ser foco de intervenções preventivas (Del Prette \& Del Prette, 2005; Elias \& Marturano, 2016).

Considerando as relações entre habilidades sociais e problemas de comportamento, se torna essencial considerar programas preventivos para o desenvolvimento/aprimoramento destas habilidades. Dentre as possibilidades de prevenção tem-se a universal (ação dirigida a toda a população), indicada (destinada a indivíduos que apresentam características de risco) e seletiva (indicada àqueles que já se sabe que necessitam de tal tipo de intervenção), diferentes modelos a diferentes focos (Murta et. al., 2015). Programas preventivos com foco em habilidades sociais podem ser implementados na escola e destinados a diferentes atores presentes neste contexto (Del Prette \& Del Prette, 2017).

Um estudo relevante da área foi o trabalho desenvolvido com o programa de prevenção universal Posso Pensar (Elias, 2013). Elias e Marturano (2016) verificaram os efeitos do programa em alunos do Ensino Fundamental. Participaram 203 alunos, com 
idade entre 6 e 10 anos e suas professoras. O estudo teve delineamento quaseexperimental com grupos de intervenção e controle, realizando medidas pré e pósintervenção. Os resultados apontam que apenas o grupo de intervenção apresentou melhoras significativas em todas as variáveis investigadas, com destaque para redução de problemas de comportamento, desenvolvimento de HSPI e outras habilidades sociais.

$\mathrm{Na}$ literatura, foram encontrados inúmeros estudos de intervenção com o objetivo de desenvolver habilidades sociais em crianças do Ensino Fundamental e ajudá-las a lidar com os desafios de seu dia-a-dia e relações interpessoais (Marturano, Bolsoni-Silva \& Elias, 2015). Falcão, Bolsoni-Silva, Magri e Moretto (2016) observaram aumento significativo da frequência de habilidades sociais após a intervenção Promove-Crianças com crianças de sete a nove anos, que frequentavam o segundo ano do Ensino Fundamental e eram consideradas clínicas para problema de comportamento. Rodrigues, Dias e Freitas (2010), aplicaram um programa adaptado em HSPI, já existente na literatura, e observaram aumento de algumas habilidades, como empatia, assertividade, expressão de sentimento positivo, civilidade e responsabilidade.

No entanto, apesar de não haver muitos estudos na Educação Infantil, esta é bastante propícia para esse tipo de intervenção, já que além da família, a escola é o contexto mais importante do desenvolvimento da criança e, portanto, de construção do repertório de habilidades sociais (Correia-Zanini e Marturano, 2016).

Diante desse cenário buscou-se desenvolver um programa de prevenção universal na pré-escola de modo a verificar seus efeitos.

\section{Objetivos}

O presente estudo teve como objetivo geral verificar os efeitos de um programa de prevenção universal para o desenvolvimento de habilidades de solução de problemas interpessoais com alunos da Educação Infantil, de modo a verificar a replicabilidade dos resultados obtidos com alunos dos primeiros anos do Ensino Fundamental I (Elias \& Marturano, 2016). Como objetivo específico buscou-se comparar as habilidades de solução de problemas interpessoais, total de habilidades sociais e problemas de comportamento antes e após a intervenção, verificando as mudanças intragrupo, comparando as variáveis de cada grupo com ele mesmo.

\section{Método}

\section{Participantes}


Participaram da pesquisa, inicialmente, 71 crianças da Educação Infantil (22 meninas, 23 meninos, com média de idade de cinco anos, $\mathrm{DP}=4$ meses), seus pais e 3 professoras. Ao final do estudo, 45 crianças tinham as avaliações completas realizadas pelos professores, pais e pesquisadora. As crianças foram subdivididas em Grupo de Intervenção (GI) e Grupo de Espera (GE). O GI foi composto por duas salas de aula em que a intervenção foi aplicada imediatamente. Já o GE composto por apenas uma sala em que a intervenção foi feita após um ano de espera.

\section{Instrumentos}

Questionário de Capacidades e Dificuldades (SDQ)- versão para pais: elaborado e validado para o contexto brasileiro por Fleitlich-Bilyk e Goodman (2001), destinado a crianças e adolescentes (quatro a 16 anos). Nesta versão, pais avaliam seus filhos utilizando uma escala que varia de zero (falso) a dois (verdadeiro). Constituído de 25 perguntas, divididas em cinco subescalas: sintomas emocionais, problemas de conduta, hiperatividade, problemas de relacionamento com colegas e comportamento pró-social. A pontuação de cada subescala pode variar de zero a dez e a pontuação total pode chegar ao máximo de 40, pois são somadas apenas as quatro primeiras subescalas. Quanto maior a pontuação obtida nas subescalas e no escore total, maior a indicação de problema de comportamento, com exceção da última escala, por se tratar de um indicador de capacidade. A classificação do comportamento da criança é dada pela soma dos valores de cada subescala, sendo "normal" quando for menor que 16, "limítrofe" quando for igual a 16 e "anormal" quando for maior que 16. Em estudos de validação foi verificada a variação de índice de correlação de 0,63 a 0,88 para a versão dos pais; à consistência interna, apresentam-se valores próximos de 0,80 para o escore total de dificuldade.

PKBS-BR - Escala de Comportamento Social para Pré-Escolares (School Social Behavior Scales-2; Merrell, 2002): produzido nos Estados Unidos e traduzido para o contexto brasileiro (Dias, Freitas, Z. Del Prette\& Del Prette, 2011), é um inventário de relato apresentado em duas versões (pais e professores). Contém 34 itens relativos a habilidades sociais e 42 a problemas de comportamento (PC), respondidos em uma escala Likert de frequência de quatro pontos. Evidenciou propriedades psicométricas satisfatórias quanto à consistência interna da escala total de habilidades sociais $(\alpha=0,92)$ e de PC $(\alpha=0,95)$, para os três fatores da estrutura de habilidades sociais: 
obediência/civilidade $(\alpha=0,89)$, sociabilidade com pares $(\alpha=0,86)$ empatia/assertividade $(\alpha=0,79)$, e os dois de comportamentos-problema: externalizantes $(\alpha=0,95)$ e internalizantes $(\alpha=0,88)$. No presente estudo, a escala foi aplicada na versão para professores.

Procedimento de Avaliação de Habilidades de Solução de Problemas Interpessoais em Pré-escolares (PIPS): procedimento desenvolvido por Shure (1990) para avaliar crianças de quatro a oito anos. O aplicador conta uma mesma história alternando brinquedos, a qual envolve uma situação de um possível problema interpessoal (uma criança que estava brincando com um brinquedo há um tempo, quando chega outra que quer brincar com o mesmo objeto; após a apresentação da situação-problema, o avaliador pergunta o que a segunda criança pode fazer para ter a chance de brincar com o brinquedo que quer. A outra fase da aplicação é referente a problemas com as mães. $\mathrm{O}$ aplicador conta histórias em que a criança fez algum dano a um objeto pessoal da mãe ou a um objeto da casa e pergunta o que pode ser feito para evitar que a mãe fique brava. As histórias são contadas de forma lúdica, com cartões representando os meninos, as meninas, os brinquedos e as mães. À criança é solicitado que encontre uma solução diferente para cada nova situação apresentada, conforme ela se depara com variações da mesma situação-problema. No manual do procedimento são fornecidos critérios para classificação das respostas como de solução (quando resolve o problema) ou de não solução (quando não resolve), além de fornecer um sistema de classificação para o julgamento de classes de respostas. O escore final é a taxa de relevância, que consiste na razão entre o número de soluções relevantes e o total de respostas relevantes e de não solução. Também pode-se avaliar a taxa de força pela proporção entre o número de soluções vigorosas (certas classes de respostas) dadas pela criança e a soma do número de vigor e as relevantes não vigorosas. A utilização dos critérios de classificação das respostas em 10 protocolos por três avaliadores forneceu índices de concordância entre 85 e $90 \%$.

Programa Posso Pensar (Elias, 2013): desenvolvido e testado no contexto brasileiro, visa promover e aprimorar as HSPI e outras habilidades sociais, em crianças de seis a dez anos, em ambiente educacional. Por meio de atividades lúdico-pedagógicas, o programa foi concebido para ensinar a criança a pensar em situações-problemas em vez de ensinar o que elas devem pensar diante dessas situações.É um programa de prevenção universal a ser aplicado às crianças por educadores. O programa é composto por 40 lições (temas a serem trabalhados) e 40 atividades de reforço a serem aplicadas no dia seguinte 
à lição. Cada lição tem um roteiro a ser seguido, que inclui objetivos/metas da lição, uma lista dos recursos necessários para conduzi-la, esquemas de diálogos com as crianças e sugestões de jogos a serem desenvolvidos. As lições e seus respectivos reforços estão descritos no anexo 1Originalmente o programa aplicado por professores em suas salas de aula, após treinamento e supervisão na aplicação (Elias \& Marturano, 2016).

\section{Procedimento}

O estudo foi desenvolvido junto à Rede Municipal de Educação de uma cidade do interior paulista. A Secretaria de Educação desta autorizou a aplicação do projeto e indicou possíveis escolas para a realização da pesquisa. As diretoras das escolas também aceitaram e indicaram salas que teria maior probabilidade do interesse das professoras. Foi, então, apresentado o projeto para as professoras, que aceitaram participar da pesquisa, após a leitura e concordância com o Termo de Consentimento Livre e Esclarecido (TCLE). Então foi solicitado aos pais (responsáveis legais) a permissão para a participação de seus filhos, realizada a assinatura do TCLE e entregue o instrumento para avaliação do repertório comportamental da criança. Na sequência, os professores foram contatados novamente e solicitado aos mesmos as avaliações do repertório comportamental das crianças, através dos instrumentos citados anteriormente. Houve dificuldades em receber os questionários preenchidos pelas professoras e pelos pais, que não cumpriram o prazo estabelecido. Concomitantemente à avaliação dos professores, os alunos foram avaliados individualmente pela pesquisadora, em uma sala reservada; as avaliações ocorreram durante o período das aulas e o procedimento durava em torno de 20 minutos com cada aluno. Houve dificuldades em avaliar todas as crianças devido às faltas recorrentes de algumas delas.

Após o término das avaliações deu-se início à intervenção, desenvolvida pela primeira autora. As atividades ocorreram com duas turmas, separadamente, uma em cada escola e tinham duração de uma hora cada, incluindo as a atividades de reforço, que tinham duração em torno de 10 a 15 minutos. As sessões ocorreram duas vezes na semana, totalizando 20 sessões, cujas atividades foram acompanhadas pelas professoras como uma forma de capacitação para as mesmas. Após a intervenção, foi solicitado novamente aos pais e professores que respondessem aos mesmos instrumentos e a pesquisadora reavaliou as crianças. As mesmas dificuldades encontradas na primeira avaliação, também ocorreram neste segundo momento. 


\section{Procedimento de Análise de Dados}

Os dados obtidos foram transpostos para planilha do Microsoft Excel (2019) e, posteriormente para o programa estatístico JASP (versão 9.2). Foi feita a verificação de frequências para identificar possíveis erros de digitação. Em seguida, foram realizadas as estatísticas descritivas para a amostra total e os diferentes grupos constituídos (GI e GE). Para verificar o pressuposto de normalidade, foram observadas a curtose e simetria, sendo consideráveis aceitáveis valores até 7 e 3, respectivamente, como indica Marôco (2011).

Para a avaliação da magnitude das diferenças, considerou-se o efeito como pequeno quando $\mathrm{d} \leq 0,2$; médio, quando $\mathrm{d}$ entre 0,2 e 0,5 ; elevado para $\mathrm{d}$ entre 0,50 e 1 ; muito elevado quando d > 1 (Marôco, 2011). O mesmo foi considerado nas variáveis não paramétricas, considerando o índice de correlação rrb (rank-biserial correlation).

As comparações entre antes e após a intervenção e a espera, respectivamente, para todos os instrumentos foi realizada através do teste $t$ de Student, para amostras pareadas, com nível de confiança de $95 \%$ ou correlato não-paramétrico Wilcoxon para variáveis em que não foram encontradas a normalidade dos dados. 


\section{Aspectos éticos}

O projeto foi iniciado após a aprovação do Comitê de Ética da Faculdade de Filosofia, Ciências e Letras da Universidade de São Paulo de Ribeirão Preto- SP (CAAE 36475614.0.0000.5407). Participaram do estudo somente crianças cujos pais assinaram o Termo de Consentimento Livre e Esclarecido. A intervenção também foi realizada com GE, respeitando questões éticas.

\section{Resultados}

Serão apresentados os resultados de GI (antes e após intervenção) e de GE (antes e após espera). Seguindo a seguinte ordem de instrumentos SDQ, PKBS e PIPS.

A Tabela 1 apresenta resultados dos grupos nas variáveis avaliadas pelo SDQ segundo relato dos pais.

Tabela 1.

Comparação Entre GI e GE, Antes E Após A Intervenção E A Espera, Respectivamente, Nas Variáveis Investigada Pelo SDQ.

\begin{tabular}{|c|c|c|c|c|c|c|c|c|}
\hline \multirow{3}{*}{ Variável } & \multicolumn{4}{|c|}{ GI } & \multicolumn{3}{|c|}{ GE } & \multirow{3}{*}{$d$} \\
\hline & Antes Int & Após Int & $p$ & $d$ & Antes Esp & Após Esp & $p$ & \\
\hline & $\begin{array}{c}\text { Média } \\
(d p)\end{array}$ & $\begin{array}{c}\text { Média } \\
(d p)\end{array}$ & & & $\begin{array}{c}\text { Média } \\
(d p)\end{array}$ & $\begin{array}{c}\text { Média } \\
(d p)\end{array}$ & & \\
\hline $\begin{array}{c}\text { Comportamento } \\
\text { Pró-Social }\end{array}$ & $\begin{array}{c}8,636 \\
(1,537)\end{array}$ & $\begin{array}{c}8,485 \\
(1,698)\end{array}$ & 0,454 & 0,132 & $\begin{array}{c}7,833 \\
(2,250)\end{array}$ & $\begin{array}{c}8,750 \\
(1,288)\end{array}$ & 0,085 & $-0,547$ \\
\hline Hiperatividade & $\begin{array}{c}3,667 \\
(2,594)\end{array}$ & $\begin{array}{c}3,727 \\
(2,649)\end{array}$ & 0,857 & $-0,032$ & $\begin{array}{c}2,917 \\
(2,906)\end{array}$ & $\begin{array}{c}2,917 \\
(2,864)\end{array}$ & 0,175 & $-0,418$ \\
\hline
\end{tabular}




\begin{tabular}{|c|c|c|c|c|c|c|c|c|c|c|}
\hline $\begin{array}{l}\text { Sintomas } \\
\text { Emocionais }\end{array}$ & $\begin{array}{l}3,485 \\
(2,21)\end{array}$ & $\begin{array}{c}2,758 \\
(2,166)\end{array}$ & 0,023 & 0,414 & & $\begin{array}{c}2,167 \\
(1,749)\end{array}$ & $\begin{array}{c}1,833 \\
(1,749)\end{array}$ & 0,551 & 0,178 & \\
\hline $\begin{array}{l}\text { Problema de } \\
\text { Conduta }\end{array}$ & $\begin{array}{c}2,909 \\
(2,241)\end{array}$ & $\begin{array}{c}2,273 \\
(1,859)\end{array}$ & 0,042 & 0,368 & & $\begin{array}{c}2,417 \\
(2,253)\end{array}$ & $\begin{array}{c}1,750 \\
(1,603)\end{array}$ & 0,255 & 0,347 & \\
\hline $\begin{array}{l}\text { Problemas de } \\
\text { Relacionamento } \\
\text { com colegas }\end{array}$ & $\begin{array}{c}2,061 \\
(2,015)\end{array}$ & $\begin{array}{r}1,485 \\
(1,482)\end{array}$ & 0,089 & 0,305 & & $\begin{array}{c}1,750 \\
(1,712)\end{array}$ & $\begin{array}{c}1,500 \\
(2,023)\end{array}$ & 0,623 & 0,146 & \\
\hline $\begin{array}{c}\text { Total de } \\
\text { Dificuldades }\end{array}$ & $\begin{array}{l}12,121 \\
(6,299)\end{array}$ & $\begin{array}{l}10,242 \\
(5,618)\end{array}$ & 0,033 & 0,388 & rrb & $\begin{array}{c}9,250 \\
(5,562)\end{array}$ & $\begin{array}{c}8,833 \\
(5,491)\end{array}$ & 0,787 & 0,080 & rrb \\
\hline Aborrecem & $\begin{array}{c}0,030 \\
(0,174)\end{array}$ & $\begin{array}{c}0,030 \\
(0,174)\end{array}$ & 1,500 & 1,000 & 0,000 & $\begin{array}{c}0,000 \\
(0,000)\end{array}$ & $\begin{array}{c}0,000 \\
(0,000)\end{array}$ & $\mathrm{NaN}$ & & \\
\hline Dia-a-dia & $\begin{array}{c}0,030 \\
(0,174)\end{array}$ & $\begin{array}{l}0,000 \\
0,000\end{array}$ & $\mathrm{NaN}$ & & & $\begin{array}{c}0,091 \\
(0,302)\end{array}$ & $\begin{array}{c}0,000 \\
(0,000)\end{array}$ & $\mathrm{NaN}$ & & \\
\hline Amizade & $\begin{array}{c}0,061 \\
(0,242)\end{array}$ & $\begin{array}{l}0,000 \\
0,000\end{array}$ & $\mathrm{NaN}$ & & & $\begin{array}{c}0,000 \\
(0,000)\end{array}$ & $\begin{array}{c}0,000 \\
(0,000)\end{array}$ & $\mathrm{NaN}$ & & \\
\hline Aprendizado & $\begin{array}{c}0,000 \\
(0,000)\end{array}$ & $\begin{array}{c}0,030 \\
(0,174)\end{array}$ & $\mathrm{NaN}$ & & & $\begin{array}{c}0,000 \\
(0,000)\end{array}$ & $\begin{array}{c}0,167 \\
(0,577)\end{array}$ & $\mathrm{NaN}$ & & \\
\hline
\end{tabular}




\begin{tabular}{|c|c|c|c|c|c|c|c|c|c|c|}
\hline \multirow[t]{2}{*}{ Lazer } & 0,000 & 0,030 & \multicolumn{3}{|l|}{$\mathrm{NaN}$} & & & \multicolumn{3}{|l|}{$\mathrm{NaN}$} \\
\hline & 0,000 & $(0,174)$ & & & & $\begin{array}{c}0,182 \\
(0,405)\end{array}$ & $\begin{array}{c}0,000 \\
(0,000)\end{array}$ & & & \\
\hline \multirow[t]{2}{*}{ Total } & 0,182 & 0,061 & 10,000 & 0,572 & 0,333 & & & & & \\
\hline & $(0,727)$ & $(0,242)$ & & & & $\begin{array}{c}0,333 \\
(0,651)\end{array}$ & $\begin{array}{c}0,250 \\
(0,622)\end{array}$ & 3.500 & 1,000 & 0,167 \\
\hline
\end{tabular}

Nota. GI- grupo de intervenção; GE=grupo de espera; int=intervenção; esp=espera; $\mathrm{n}=$ tamanho da amostra; GI N=33;GE N=12; $d p=$ desvio padrão; $t=$ estatística do teste $\mathrm{t}$ de student; $\mathrm{gl}=$ grau de liberdade; $p \leq 0,05, d=$ tamanho de efeito; $w=$ teste wilcoxon; ; $p \leq 0,05$; rrb= rank-biserial correlation; NaN: variância=0. 
Observa-se na Tabela 1 que nas variáveis sintomas emocionais, problema de conduta e total de dificuldades, as crianças diminuíram significativamente seus escores após a intervenção, com tamanho de efeito médio. Já com relação ao GE, pode-se perceber que não foram encontradas diferenças significativas para os participantes antes e após a espera. Nas variáveis não-paramétricas não foram observadas diferenças significativas.

Ainda utilizando resultados fornecidos pelo SDQ, foi realizada uma análise de frequência de problemas de comportamento e sua classificação para cada grupo, antes e após intervenção/espera. Para os participantes de GI foi observado que inicialmente 19 (58\%) apresentavam comportamentos não clínicos e 14 (42\%) apresentavam comportamentos clínicos ou limítrofes. Após a intervenção oito (24\%) apresentaram melhoras no comportamento, 18 (55\%) permaneceram não clínicas; quatro (12\%) permaneceram clínicas; duas (6\%) permaneceram limítrofes e; apenas uma (3\%) apresentou piora no que tange à classificação de problema de comportamento. Com relação a GE, nota-se que inicialmente das 12 crianças, 10 (83\%) apresentavam classificação não clínica para problema de comportamento e duas (17\%) apresentavam classificação limítrofe e clínico; após a espera dos que já apresentavam problemas de comportamento um melhorou e um piorou, ainda foi observado que uma criança anteriormente não clínica para problemas de comportamento passou para limítrofe, ou seja, piorou seu comportamento. 
A seguir na Tabela 2 estão apresentados os resultados relativos a habilidades sociais e problemas de comportamento das crianças avaliados pelo PKBS, segundo relato dos professores.

Tabela 2.

Comparação Entre GI e GE, Antes E Após A Intervenção E A Espera, Respectivamente, Nas Variáveis Investigadas Pelo PKBS.

\begin{tabular}{|c|c|c|c|c|c|c|c|c|c|}
\hline \multirow[b]{2}{*}{ Variável } & \multicolumn{3}{|c|}{ GI } & \multicolumn{4}{|c|}{ GE } & \multirow[b]{2}{*}{$d$} & \\
\hline & $\begin{array}{c}\text { Antes Int } \\
\text { Média } \\
\text { (dp) }\end{array}$ & $\begin{array}{c}\text { Após Int } \\
\text { Média } \\
\text { (dp) }\end{array}$ & $p$ & $d$ & $\begin{array}{c}\text { Antes Esp } \\
\text { Média }\end{array}$ & $\begin{array}{c}\text { Após Esp } \\
\text { Média } \\
\text { (dp) }\end{array}$ & $p$ & & \\
\hline $\begin{array}{c}\text { Total de } \\
\text { Habilidades } \\
\text { Sociais }\end{array}$ & $\begin{array}{l}23,388 \\
(5,856)\end{array}$ & $\begin{array}{l}23,430 \\
(5.028)\end{array}$ & 0,946 & $-0,012$ & $\begin{array}{l}31,750 \\
(6,837)\end{array}$ & $\begin{array}{l}34,583 \\
(4,944)\end{array}$ & 0,103 & $-0,513$ & \\
\hline $\begin{array}{l}\text { Cooperação } \\
\text { Social }\end{array}$ & $\begin{array}{l}29,182 \\
(7,630)\end{array}$ & $\begin{array}{l}28,152 \\
(7.383)\end{array}$ & 0,210 & 0,223 & $\begin{array}{l}10,750 \\
(7,172)\end{array}$ & $\begin{array}{c}7,333 \\
(3,551)\end{array}$ & 0,131 & 0,471 & \\
\hline $\begin{array}{l}\text { Independência } \\
\text { Social }\end{array}$ & $\begin{array}{l}24.606 \\
(7.075)\end{array}$ & $\begin{array}{l}25,545 \\
(5.932)\end{array}$ & 0,169 & $-0,245$ & $\begin{array}{c}10,000 \\
(12,721)\end{array}$ & $\begin{array}{c}5,667 \\
(6,199)\end{array}$ & 0,159 & 0,436 & \\
\hline Interação Social & $\begin{array}{l}16,394 \\
(4,401)\end{array}$ & $\begin{array}{l}16,606 \\
(4,069)\end{array}$ & 0,734 & $-0,060$ & $\begin{array}{l}11,500 \\
(6,948)\end{array}$ & $\begin{array}{c}9,000 \\
(4,991)\end{array}$ & 0,192 & 0,401 & \\
\hline & & & & & & & $W$ & $p$ & $r r b$ \\
\hline $\begin{array}{l}\text { Total de Problema } \\
\text { de comportamento }\end{array}$ & $\begin{array}{l}20,121 \\
(9,780)\end{array}$ & $\begin{array}{r}21,152 \\
(11,404)\end{array}$ & 0,318 & $-0,176$ & $\begin{array}{l}26,050 \\
(5,165)\end{array}$ & $\begin{array}{l}27,867 \\
(4,391)\end{array}$ & 24,500 & 0,272 & $-0,372$ \\
\hline
\end{tabular}




\begin{tabular}{|c|c|c|c|c|c|c|c|c|c|}
\hline $\begin{array}{c}\text { Problema de } \\
\text { Comportamento } \\
\text { externalizante }\end{array}$ & $\begin{array}{c}23,000 \\
(16,479)\end{array}$ & $\begin{array}{c}25,455 \\
(19,066)\end{array}$ & 0,070 & $-0,326$ & $\begin{array}{l}27,167 \\
(5,096)\end{array}$ & $\begin{array}{l}29,333 \\
(4,271)\end{array}$ & 12,000 & 0,228 & $-0,467$ \\
\hline $\begin{array}{l}\text { Problema de } \\
\text { comportamento } \\
\text { internalizante }\end{array}$ & $\begin{array}{c}(17,242) \\
(8,246)\end{array}$ & $\begin{array}{l}16,848 \\
(7,400)\end{array}$ & 0,709 & 0,065 & $\begin{array}{l}19,250 \\
(5,065)\end{array}$ & $\begin{array}{l}19,667 \\
(4,942)\end{array}$ & 20,000 & 0,811 & $-0,111$ \\
\hline
\end{tabular}

Nota. GI- grupo de intervenção; GE=grupo de espera; Int=intervenção; Esp=espera; $\mathrm{n}=$ tamanho da amostra; GI N=33;GE N=12; $d p=$ desvio padrão; $t=$ estatística do teste t de student $\mathrm{gl}=$ grau de liberdade; $p \leq 0,05, d=$ tamanho de efeito; $w=$ teste wilcoxon; $r \mathrm{rb}=$ rank-biserial correlation.

De acordo com a Tabela 2, observa-se que não houve diferenças significativas para GI, antes e após a intervenção, entre as médias das variáveis investigadas. O mesmo foi observado para os participantes de GE.

A Tabela 3 apresenta resultados dos grupos nas variáveis avaliadas pelo PIPS aplicado pela psicóloga. 
Tabela 3.

Comparação Entre GI e GE, Antes E Após A Intervenção E A Espera, Respectivamente, Nas Variáveis Investigadas Pelo PIPS.

\begin{tabular}{|c|c|c|c|c|c|c|c|c|c|}
\hline \multirow{3}{*}{ Variável } & \multicolumn{3}{|c|}{ GI } & & & \multicolumn{3}{|c|}{ GE } & \multirow{3}{*}{$d$} \\
\hline & Antes Int & Após Int & & $p$ & $d$ & Antes Esp & Após Esp & $p$ & \\
\hline & $\begin{array}{l}\text { Média } \\
\text { (dp) }\end{array}$ & $\begin{array}{l}\text { Média } \\
\text { (dp) }\end{array}$ & & & & $\begin{array}{l}\text { Média } \\
\text { (dp) }\end{array}$ & $\begin{array}{l}\text { Média } \\
\text { (dp) }\end{array}$ & & \\
\hline \multirow[t]{2}{*}{$\begin{array}{l}\text { Taxa de } \\
\text { relevância }\end{array}$} & $\begin{array}{c}0,719 \\
(0,166)\end{array}$ & $\begin{array}{c}0,857 \\
(0,149)\end{array}$ & & $<, 001$ & $-0,677$ & $\begin{array}{c}0,785 \\
(0,181)\end{array}$ & $\begin{array}{c}0,910 \\
-0,127\end{array}$ & 0,010 & 0,897 \\
\hline & & & $W$ & $p$ & rrb & & & & \\
\hline
\end{tabular}

Nota. GI- grupo de intervenção; GE=grupo de espera; int=intervenção; esp=espera; $\mathrm{n}=$ tamanho da amostra; $d p=$ desvio padrão; $t=$ estatística do teste $\mathrm{t}$ de student gl = grau de liberdade; $p \leq 0,05, d=$ tamanho de efeito; $w=$ teste wilcoxon; ; rrb= rank-biserial correlation.

De acordo com a Tabela 3, houve aumento significativo na média de taxa de relevância para GI após a intervenção, sendo o mesmo observado em GE.

A seguir, a tabela 4 apresenta resultados referentes ao número de respostas relevantes dados pelas crianças, ao responderem ao PIPS. 
Tabela 4.

Comparação Entre Grupo De Intervenção E Grupo de Espera, Antes E Após A Intervenção E A Espera, Respectivamente, Com Relação Ao Número De Respostas Relevantes Dados Pelas Crianças No Teste PIPS.

\begin{tabular}{|c|c|c|c|c|}
\hline \multirow{3}{*}{ Criança } & \multicolumn{2}{|c|}{ GI } & \multicolumn{2}{|c|}{ GE } \\
\hline & $\begin{array}{c}\text { Número de respostas } \\
\text { relevantes }\end{array}$ & $\begin{array}{l}\text { Número de respostas } \\
\text { relevantes }\end{array}$ & $\begin{array}{l}\text { Número de respostas } \\
\text { relevantes }\end{array}$ & $\begin{array}{c}\text { Número de respostas } \\
\text { relevantes }\end{array}$ \\
\hline & Antes Int & Após Int & Antes Esp & Após Esp \\
\hline 2 & 3 & 7 & 10 & 8 \\
\hline 3 & 11 & 9 & 9 & 5 \\
\hline 4 & 9 & 10 & 11 & 8 \\
\hline 7 & 5 & 8 & 3 & 8 \\
\hline 8 & 9 & 10 & 11 & 6 \\
\hline 9 & 5 & 10 & 5 & 7 \\
\hline 10 & 11 & 9 & 5 & 7 \\
\hline 11 & 5 & 7 & 10 & 9 \\
\hline 12 & 7 & 6 & 3 & 5 \\
\hline 18 & 7 & 6 & & \\
\hline 19 & 7 & 7 & & \\
\hline 20 & 2 & 6 & & \\
\hline 21 & 7 & 8 & & \\
\hline 22 & 2 & 8 & & \\
\hline
\end{tabular}




\begin{tabular}{lcc}
\hline 23 & 8 & 9 \\
24 & 13 & 6 \\
25 & 12 & 8 \\
26 & 7 & 10 \\
27 & 4 & 6 \\
28 & 11 & 8 \\
29 & 9 & 8 \\
30 & 14 & 6 \\
31 & 8 & 6 \\
32 & 6 & 8 \\
\hline
\end{tabular}

Nota. GI- grupo de intervenção; GE=grupo de espera; int=intervenção; esp=espera

De acordo com a Tabela 4, das 33 crianças, 18 tiveram aumento do número de respostas significativas, 3 crianças mantiveram o mesmo número de respostas antes e após a intervenção e 12 crianças tiveram uma diminuição do número de respostas. Já com relação ao GE, de 12 crianças, 7 tiveram aumento do número de respostas significativas, 2 crianças mantiveram o mesmo número de respostas antes e após a espera e 3 crianças tiveram uma diminuição do número de respostas.

\section{Discussão}

A discussão a seguir apresentará considerações sobre o presente trabalho que teve por objetivo geral verificar os efeitos de um programa de prevenção universal para o desenvolvimento de habilidades de solução de problemas interpessoais, em um ensaio de campo com alunos da Educação Infantil, de modo a verificar a replicabilidade dos resultados obtidos com alunos do primeiro ano do Ensino Fundamental (Elias \& Marturano, 2016). Como objetivo específico buscou-se comparar as habilidades de solução de problemas interpessoais, total de habilidades sociais e problemas de comportamento antes e após a intervenção 
No que tange aos resultados obtidos por GI, pode-se perceber que, segundo os pais (avaliação pelo SDQ), as crianças apresentaram melhoras após a intervenção em variáveis como sintomas emocionais, problema de conduta e total de dificuldades, ou seja, apresentaram diminuição significativa nas médias após a intervenção, com tamanho de efeito médio. Quanto à classificação de problema de comportamento, também avaliado pelos pais, foi observado inicialmente que 58\% apresentavam comportamentos não clínicos e $42 \%$ apresentavam comportamentos clínicos ou limítrofes. Após, dos que apresentavam problemas de comportamento, 57\% melhoraram. A diminuição significativa das variáveis sintomas emocionais, problema de conduta e total de dificuldades, referentes ao GI, segundo os pais, indicam o efeito positivo da intervenção do Programa Posso Pensar. Esses resultados corroboram diversos estudos que comprovam a eficácia de programas de Treinamentos de Habilidades Sociais, que envolvem o ensino de novas habilidades ou na ampliação do repertório já existentes (Del Prette \& Del Prette, 2011; Elias \& Marturano, 2016).

$\mathrm{Na}$ avaliação dos professores, GI não apresentou diferenças comportamentais significativas após a intervenção, entre as médias das variáveis investigadas no GI. Salienta-se que antes da intervenção as professoras já avaliaram as crianças como tendo muitos problemas de comportamento externalizantes (proporcionais às habilidades sociais). Assim, mesmo que tenham apresentado melhoras em alguns comportamentos, estes provavelmente não foram observados e reforçados por professores, o que contribuiu negativamente para a manutenção dos ganhos. De acordo com a literatura, problemas de comportamento são concorrentes às habilidades sociais, já que restringem as possibilidades de emissão de comportamentos pró-sociais (Gresham \& Elliott, 1990; Del Prette et al., 2011) e restringem o acesso da criança a reforçadores importantes para a aprendizagem e desenvolvimento socioemocional (Bolsoni-Silva \& Del Prette, 2003). No caso desse estudo, as crianças do GI já apresentavam antes da intervenção problemas de comportamento significativos segundo avaliação de pais e professores.

Elias e Marturano (2016), ressaltam a importância de as professoras receberem treinamento e aplicarem o programa em sala, pois durante as supervisões que ocorrem, tal fato poderia ter sido apontado. Portanto, destaca-se a importância de as professoras receberem treinamento e aplicarem o programa em sala, pois durante as supervisões que ocorrem, tal fato poderia ter sido apontado.

$\mathrm{Na}$ avaliação direta da criança realizada quanto às HSPI, GI apresentou aumento significativo na média de taxa de relevância após a intervenção. De acordo Borges e 
Marturano (2009), o desenvolvimento das HSPI em específico, colaboram para um melhor desenvolvimento socioemocional e auxiliam na redução de problemas de comportamento.

Os resultados apresentados por GI vão parcialmente ao encontro dos achados de Elias e Marturano (2016), ao usar o programa com alunos do Ensino Fundamental I. Contudo, ressalta-se que os participantes não foram avaliados com os mesmos instrumentos para problemas de comportamento e HSPI (devido à faixa etária), mas, fazendo um correlato, não apresentavam tantos problemas de comportamento inicialmente.

No que tange aos resultados do GE, não foram encontradas diferenças significativas na avaliação dos pais de habilidades e dificuldades investigadas pelo SDQ. Quanto à classificação comportamental, antes da espera apenas duas apresentavam classificação clínica ou limítrofe para problemas de comportamento e as demais (83\%) foram avaliadas como não clínicas. Após a espera das que apresentavam problemas uma piorou e uma melhorou e, ainda, uma terceira passou a apresentar problema de comportamento. Já pela perspectiva dos professores, GE não apresentou diferenças significativas antes e após a intervenção nas variáveis investigadas. Esses resultados convergem com os de GI, ao apontar as dificuldades que a escola tem para lidar com dificuldades comportamentais de alunos. A formação continuada de professores é essencial para orientações no sentido de desenvolverem as próprias habilidades sociais para ensiná-las aos alunos (Bolsoni-Silva Perallis \& Nunes, 2018; Elias \& Marturano, 2016).

$\mathrm{Na}$ avaliação direta das crianças quanto as habilidades de solução de problemas interpessoais, GE também apresentou aumento significativo na média de taxa de relevância após a intervenção. O aumento da média nessa variável em GE, mesmo sem receber a intervenção, pode ser explicado pelo papel fundamental da escola em desenvolver habilidades acadêmicas e sociais, sendo um contexto essencial para a promoção e exercício de habilidades relevantes ao longo dos próximos anos da vida. (Del Prette \& Del Prette, 2003; Correia-Zanini \& Marturano, 2016); a escola tende ainda a reforçar positivamente alunos sem problemas de comportamento (Gresham \& Elliott, 1990), o que caracterizou a maior parte dos participantes do GE.

A partir das colocações acima, tem-se que os resultados encontrados corroboraram parcialmente com os encontrados por Elias e Marturano (2016) e Elias e Amaral (2016). Ao avaliarem os efeitos do Programa Posso Pensar, quando aplicado a crianças do 
Ensino Fundamental, essas autoras sinalizaram ganhos dos participantes nas diferentes variáveis investigadas. No presente estudo, os resultados se replicaram apenas em algumas variáveis quando o mesmo programa foi aplicado a crianças da Educação Infantil.

\section{Considerações finais}

Diante do exposto, conclui-se que a intervenção realizada, utilizando-se o Programa Posso Pensar, apresentou ganhos nos participantes em algumas variáveis investigadas segundo os pais. Infere-se que os resultados poderiam ter sido maiores se as professoras tivessem sido treinadas e elas mesmas aplicado o programa em sala de aula, e refinando suas intervenções quanto aos problemas de comportamento e; se a pesquisadora tivesse tido um maior contato com as crianças, antes e durante o desenvolvimento do programa. Por fim, infere-se que o número de participantes também foi uma limitação para a comparação entre grupos e generalização para outras turmas. Sugere-se que novos estudos com o programa na Educação Infantil, caso ocorram, sejam conduzidos por professores.

\section{Referências}

Achenbach, T. M., \& Edelbrock, C. S. (1979). The Child Behavior Profile: II. Boys aged 12-16 and girls aged 6-11 and 12-16. Journal of consulting and clinical psychology, 47(2), 223.

Bandeira, M., Rocha, S. S., Souza, T. M. P., Del Prette, Z. A. P., \& Del Prette, A. (2006). Comportamentos problemáticos em estudantes do ensino fundamental: características da ocorrência e relação com habilidades sociais e dificuldades de aprendizagem. Estudos de Psicologia, 11(2), 199-208.

Bolsoni-Silva, A. T., \& Del Prette, A. (2003). Problemas de comportamento: um panorama da área. Revista Brasileira de Terapia Comportamental e Cognitiva, 5(2), 91-103.

Bolsoni-Silva, A. T., Perallis, C; Nunes, P. (2018). Problemas de Comportamento, Competência Social e Desempenho Acadêmico: Um Estudo Comparativo de Crianças no Ambiente Escolar e Familiar. Trends in Psychology, 26(3), 1189-1204.

Borges, D. S. C., \& Marturano, E. M. (2009). Aprendendo a gerenciar conflitos: um programa de intervenção para a $1^{a}$ série do ensino fundamental. Paidéia, 19(42), 17-26.

Correia-Zanini, M. R. G. \& Marturano, E. M. (2016). Primeiros Passos no Ensino Fundamental: Competência Cognitiva, Habilidades Sociais, Comportamento e Estresse. Psico-USF [online], 21 (2), 305-317.

Del Prette, Z. A. P., \& Del Prette, A. (2005). Psicologia das habilidades sociais na infância: Teoria e prática. Petrópolis, RJ: Vozes.

Del Prette, Z. A. P., \& Del Prette, A. (2011). Práticas baseadas em evidência e treinamento de habilidades sociais. Em A. Del Prette \& Z. A. P. Prette (Orgs.), Habilidades 
sociais: intervenções efetivas em grupo (pp. 261-288). São Paulo, SP: Casa do Psicólogo.

Del Prette, Z.A., \& Del Prette A. (2017). Compentência Social e Habilidades Sociais; manual teórico-prático. Petropólis: Vozes.

Dias, T. P., Lopes, D. C., \& Del Prette, Z. A. P. (2015). Programas de intervenção em habilidades sociais para crianças: propostas para a educação infantil e o ensino fundamental. Em Z. A. P. Del Prette, A. B. Soares, C. S. Pereira-Guizzo, M. F. Wagner, \& V. B. R. Leme. (Orgs.), Habilidades sociais: Diálogos e intercâmbios sobre pesquisa e prática (pp. 128-159). Novo Hamburgo: Sinopsys.

Elias, L. C. S., \& Amaral, M. V. (2016). Habilidades Sociais, Comportamentos e Desempenho Acadêmico em Escolares antes e após Intervenção. Psico-USF, Bragança Paulista, 21(1), 49-61.

Elias, L. C. S. \& Marturano, E. M. (2016). Promovendo habilidades de solução de problemas interpessoais em crianças. Interação Psicol.,20 (1), 91-100.

Falcão, A. P. \& Bolsoni-Silva, A. T., Magri, N., Moretto, L. A. (2016). PromoveCrianças: treinamento de habilidades sociais. São Paulo: Hogrefe.

Fleitlich-Bilyk, B. \& Goodman, R. (2001). Social factors associated with child mental health problems in Brazil: cross sectional survey. British Meducal Journal, 323, 599-600.

Goodman, R. (1997). The Strengths and Difficulties Questionnaire: A Research Note. J. Child Psychol. Psychiat. 38, 5, 581-58.

Gresham, F. M., \& Elliott, S. N. (1990). Social skills rating system: Manual. Circle Pines, MN: American Guidance Service. 19.

Kirkhaug, B., Drugli, M. B., Handegard, B. H. Stian Lydersen, Åsheim, M., Fossum, S. (2016). Does the Incredible Years Teacher Classroom Management Training programme have positive effects for Young children exhibiting severe externalizing problems in school?: a quasi-experimental pre-post study. BMC Psychiatry.

Marôco, J. (2011). Análise estatística com o SPSS statistics (5a ed.). Pero Pinheiro, Portugal: Report Number.

Marturano, S.; Bolsoni-Silva, A. T. \& Elias, L. C. S. (2015). Intervenções na escola. In. Sheila Giardini Murta, Cristineide Leandro-França, Karine Brito dos Santos e Larissa Polejack (Org.) Prevenção e promoção em saúde mental: Fundamentos, Planejamento e Estratégias de Intervenção (pp.54-74). Novo Hamburgo: Sinopsys Editora e Sistemas Ltda.

Marturano, E. M.; Elias, L. C. S. \& Versuti, F. M. (2017). Solução de problemas e conflitos interpessoais. In Del Prette, Z. A. P \& Del Prette, A. (Eds). Habilidades sociais e competência social para uma vida melhor. (pp. 83-89). São Carlos, SP: EdUFSCAR.

Merrell, K. W. (2002). Preschool and Kindergarten Behavior Scales - Second edition. Austin, TX: PRO-ED.

Murta, S.G.C.; Santos, F.L. \& Polejack, L.. (2015). Prevenção e Promoção em Saúde Mental - Fundamentos, Planejamento e Estratégias de Intervenção.864p.

Rodrigues, M. C., Dias, J. P. \& Freitas, M. F. R. L. (2010). Resolução de problemas interpessoais: promovendo o desenvolvimento sociocognitivo na escola. Psicologia em Estudo, 15, 831-839.

Shure, M. B. (2006). Eu posso resolver problemas: educação infantil e ensino funadamental: um programa de solução cognitive para problemas interpessoais. (E. M. Marturano, A. M. A. Motta, \& L. C. S. Elias, Trads.). Petrópolis: Vozes.

\section{Discussão Geral}


A discussão a seguir apresentará algumas considerações sobre o presente estudo, que teve por objetivo geral avaliar efeitos de um treinamento de habilidades sociais, com ênfase em habilidades de solução de problemas interpessoais (Programa Posso Pensar), em um ensaio de campo, com alunos da Educação Infantil, de modo a verificar a replicabilidade dos resultados obtidos com alunos dos primeiros anos do Ensino Fundamental I (Elias \& Marturano, 2016). Para responder ao objetivo, foram realizados três estudos.

O Estudo 1 teve como objetivo revisar sistematicamente a literatura acerca de programas de intervenção para o desenvolvimento de habilidades sociais na Educação Infantil, bem como identificar suas principais características, diferenças e semelhanças.

Dos 828 artigos encontrados nas bases de dados, apenas oito se enquadraram nos critérios de inclusão e investigaram os efeitos de um treinamento para o desenvolvimento de habilidades sociais, comparando os escores de determinadas variáveis antes e após a intervenção (habilidades sociais, problemas de comportamento, dentre outras), considerando a população entre 3 e 6 anos, no formato de grupo e no contexto escolar. Ficou bastante evidente, assim, a falta de estudos na área e a ausência destes no contexto brasileiro, apesar da importância do tema. Importância reafirmada pela Base Nacional Curricular (BNCC) - texto que orienta a educação nacional e que preza pelo desenvolvimento de competência social, que implica no desenvolvimento de habilidades sociais, que são fatores importantes de proteção para o desenvolvimento (CasaliRobalinho, 2013).

De acordo com Del Prette et al. (2011), há a necessidade do investimento em pesquisas e em programas de Treinamento de Habilidades Sociais (THS) para o estabelecimento de novas condições de aprendizagem e aprimoramento das mesmas. Segundo a APA (2006), os programas de intervenção devem ser baseados em evidências, cumprindo os objetivos estabelecidos, atuando como propostas de promoção de saúde mental. Bronfenbrenner (1996) já apontava para a importância se pensar o desenvolvimento, de forma a propor bases científicas, para o planejamento de políticas e de programas públicos eficazes, que possam neutralizar ou diminuir as influências prejudiciais ao desenvolvimento. Dentro desta perspectiva, faz-se importante pensar em intervenções que sejam desenhadas de forma a ampliar o repertório de habilidades sociais, com o intuito de ampliar a competência social e auxiliar nos processos proximais (desenvolvimento). 
Os tipos de prevenção utilizados pelos programas também consistem em um fator importante de ser discutido. Dentre os estudos analisados na revisão, destaca-se que a maioria deles investigou os efeitos de programas de prevenção universal, apontando resultados positivos com relação a aumento de habilidades sociais e diminuição de problema de comportamento. No entanto, pode-se ressaltar, que um estudo (Ladwig et al, 2018) avaliou um programa de prevenção indicada, sinalizando resultados positivos em relação à diminuição na porcentagem de crianças consideradas clínicas ou limítrofes para problema de comportamento, enquanto um outro estudo, que avaliou um programa universal aplicado a crianças consideradas clínicas para problema de comportamento, também apresentou melhoras, porém, com ressalvas, já que os tamanhos de efeitos foram considerados pequenos (Drugli et al., 2017).

Vale et al. (2018), também avaliaram um programa universal e apontaram que na maioria das crianças houve aumento de habilidades sociais e diminuição de problema de comportamento. Contudo, participantes avaliados como apresentando alto risco para problema de comportamento e pertencentes a famílias com baixo poder aquisitivo, tiveram aumento nas habilidades sociais, mas não houve melhora com relação aos problemas de comportamento. Destaca-se assim que, a depender das medidas de algumas variáveis eleitas como foco de ação, a prevenção universal pode não se mostrar efetiva, enquanto intervenções seletivas ou indicadas seriam mais efetivas e eficazes (Abreu et. al, 2015). Além disso, a interferência de variáveis não controladas e que se mostram adversas ao desenvolvimento, afetam a possibilidade de ganhar possíveis recursos quando se trata de desenhos de promoção e prevenção (Yunes, 2015).

Outro ponto a ser destacado na revisão sistemática foi que, em todos os artigos analisados, os treinamentos foram realizados pelos professores que, antes disso, foram treinados. Esse dado reforça a importância das habilidades sociais educativas-HSE (Del Prette \& Del Prette, 2017). As HSE são apontadas como fatores essenciais para o desenvolvimento socioemocional infantil (Bolsoni-Silva et al, 2018; Marturano \& Elias, 2017; Rosin-Pinola, Del Prette, \& Del Prette, 2007). No Brasil, treinamentos para HSE tem sido implementado com professores (Vila, 2005; Rosin-Pinola, 2010; Rosin-Pinola, Marturano, Elias e Del Prette, 2018), devido ao papel central que estes tem na vida das crianças, sendo os principais agentes educacionais da escola e fundamentais no desenvolvimento escolar e socioemocional dos alunos. 
Conforme ressaltam Correia-Zanini e Marturano (2016), as crianças passam muito tempo na escola e, por isso, esse ambiente passa a ser o contexto mais importante do desenvolvimento delas, além do ambiente familiar. Assim, fica evidente a necessidade de capacitar os professores, de forma a desenvolver repertório comportamental também nos educadores, para que sejam reforçadores de condutas esperadas da criança (Feitosa, et al., 2018; Rodrigues, Dias \& Freitas, 2010).

A importância da escola foi destacada no artigo de Sarker et al (2016), incluído na revisão sistemática apresentada. Os autores encontraram diferenças significativas em escores de habilidades sociais, a favor de crianças que frequentavam a pré-escola, quando as compararam com crianças que não frequentavam; destacaram o papel da experiência escolar no desenvolvimento de habilidades sociais, contribuindo para o sucesso acadêmico e social.

A infância é considerada por muitos estudiosos um período crítico para o desenvolvimento de habilidades sociais, devido ao fato de terem seus primeiros contatos além do ambiente familiar, o que possibilita a ampliação de contato com outros modelos e da plasticidade do comportamento social infantil (Del Prette \& Del Prette, 2017; Marturano \& Elias, 2016; Correi-Zanini \& Marturano, 2016). Teóricos do desenvolvimento têm destacado a importância do processo de socialização na qualidade de vida psicológica e social dos indivíduos (Da Dalt de Mangione \& Difabio de Anglat, 2002), e ao sucesso das etapas formativas destes. Considerando que o processo de socialização da criança se intensifica na escola, deve-se considerar o papel fundamental da Educação Infantil (Gonçalves \& Murta, 2008).

Dada a relevância dos treinamentos para desenvolvimento de habilidades sociais na Educação Infantil, foram conduzidos dois estudos com o fim de investigar os efeitos de um Treinamento de Habilidades Sociais, com ênfase em Habilidades de Solução de Problemas Interpessoais (Programa Posso Pensar - PPP), em um ensaio de campo com alunos da Educação Infantil, de modo a verificar a replicabilidade dos resultados obtidos com alunos dos primeiros anos do Ensino Fundamental I (Elias \& Marturano, 2016).

O Estudo 2 teve como objetivo verificar os efeitos de um programa para o desenvolvimento de habilidades de solução de problemas interpessoais, em alunos da Educação Infantil, sobre as variáveis de habilidades sociais, habilidades de solução de 
problemas interpessoais e problemas de comportamento, realizando a comparação entre grupos (alunos expostos ao programa e alunos não expostos) antes e após a intervenção.

A avaliação realizada antes da intervenção e a espera, respectivamente, indicou que não foram observadas diferenças significativas entre os grupos (GI e GE) nas variáveis investigas pelos pais e pela psicóloga. No entanto, na avaliação dos professores, as crianças de GI apresentavam significativamente maiores escores no total de problemas de comportamento e em suas duas classes internalizante e externalizante quando comparados a GE, tendo tamanho de efeito de médio para grande. Na avaliação feita após a intervenção após a intervenção e a espera, respectivamente, também não foram observadas diferenças significativas nas variáveis investigadas segundo os pais e a pesquisadora. No entanto, na avaliação dos professores, as crianças de GI continuaram apresentando escores significativamente maiores em problemas de comportamento (total, internalizante e externalizante) comparado com GE; GE, a seu turno, passou a apresentar resultados significativamente superiores a GI no total de habilidades sociais, cooperação, independência e interação sociais, com tamanho de efeito importante.

Dessa forma, percebe-se que o programa não foi efetivo para GI. Isso pode ser explicado pela concorrência de problema de comportamento com habilidades sociais. Segundo Gresham e Elliott (1990), os problemas de comportamento competem com a aquisição e desempenho de habilidades sociais, restringindo, assim, oportunidades de emissão de comportamentos pró-sociais. Crianças com um repertório deficitário de habilidades sociais tendem a apresentar maior ocorrência de problemas de comportamento (Bandeira, Rocha, Souza, et al., 2006; Casali-Robalinho, 2013; Cia \& Barham, 2009) e menor desempenho acadêmico (Jovarini, Leme \& Correia-Zanini, 2018). O fato de o treinamento ser caracterizado como um programa de prevenção universal e ter sido aplicado a crianças que já tinham problemas de comportamento pode explicar os dados encontrados pelo Estudo 2. Como apontado acima, há ressalvas quanto à efetividade desse tipo de prevenção aplicado a indivíduos que já são considerados clínicos (Murta et. al., 2015). Segundo Kirkhaug (2016), programas universais não são efetivos quando aplicados a crianças com problemas de comportamentos graves; nesse quadro deve-se pensar em programas de tratamento ou de prevenção indicada. $\mathrm{O}$ autor testou um programa universal de intervenção escolar intitulado The Incredible Years Teacher Classroom management program (IY-TCM) junto a crianças com problemas de comportamento a nível clínico do Ensino Fundamental. A intervenção utilizada na 
pesquisa citada, também não foi efetiva para a diminuição de problema de comportamento, o que sugere que intervenções de prevenção universal não são eficazes para aumentar habilidades sociais e diminuir problemas de comportamento quando estes já existem e são graves. De acordo com a literatura, programas de prevenção indicada são efetivos para reduzir, consistentemente, problemas de comportamento em crianças de Ensino Fundamental (Shure, 2006; Elias \& Marturano, 2014).

Outro aspecto que pode ter contribuído para a não efetividade do programa é o fato de ter sido aplicado por uma pesquisadora de maneira pontual, sendo que o treinamento era realizado alguns dias da semana e concentrado em uma hora. Segundo Bronfenbrenner e Morris (1998), o desenvolvimento humano se realiza através de processos proximais, que podem ser entendidos como as formas de interação entre o organismo e o ambiente, as quais operam ao longo do tempo. Para que essas interações sejam eficazes, elas devem ocorrer com regularidade, em períodos prolongados, e deve haver interações recíprocas entre a pessoa que se desenvolve e as pessoas do seu ambiente imediato. Nesse sentido, haveria maiores possibilidades da intervenção se mostrar efetiva caso fosse aplicada ao longo de um tempo maior e pelos professores, que já haviam estabelecido uma relação recíproca com as crianças. A Organização Mundial da Saúde também defende esse ponto de vista, afirmando que práticas preventivas devem integrar o currículo de forma contínua e não só transversal, além de colocar o ensino de habilidades sociais como fator protetivo para o desenvolvimento infantil (WHO, 1999; Rodrigues, Dias \& Freitas, 2010; Elias \& Marturano, 2016).

O aumento de habilidades sociais do GE pode ser explicado pelo papel fundamental da escola como um ambiente natural de desenvolvimento de habilidades sociais, como já discutido aqui, o que provavelmente ocorreu pela ausência de problemas de comportamento, fazendo com que as crianças recebessem reforçadores sociais por seus bons comportamentos, aumentando os escores dos mesmos (Del Prette \& Del Prette, 2003; Correia-Zanini \& Marturano, 2016; Feitosa, et al., 2018; Rodrigues, Dias \& Freitas, 2010).

A fim de aprofundar as análises, o objetivo do Estudo 3 foi comparar as habilidades de solução de problemas interpessoais, total de habilidades sociais e problemas de comportamento antes e após a intervenção, verificando as mudanças intragrupo, comparando as variáveis de cada grupo com ele mesmo. 
Após a intervenção, foi verificada a diminuição significativa das variáveis sintomas emocionais, problema de conduta e total de dificuldades, referentes ao GI, segundo a avaliação dos pais. Esses dados indicam o efeito positivo da intervenção do PPP e corroboram diversos estudos que comprovam a eficácia de programas de Treinamentos de Habilidades Sociais, que envolvem o ensino de novas habilidades ou na ampliação do repertório já existentes (Del Prette \& Del Prette, 2011; Elias \& Marturano, 2016). Na avaliação dos professores, GI não apresentou diferenças comportamentais significativas após a intervenção, entre as médias das variáveis investigadas. Já na avaliação realizada pela psicóloga quanto às habilidades de solução de problemas interpessoais, GI apresentou aumento significativo na média de taxa de relevância, após a intervenção. De acordo Borges e Marturano (2009), o desenvolvimento das habilidades de solução de problemas interpessoais em específico, colaboram para um melhor desenvolvimento socioemocional e auxiliam na redução de problemas de comportamento. O repertório limitado de alternativas de solução de problemas é um dos fatores que leva à agressividade infantil e, indiretamente, ao isolamento social a que crianças agressivas são submetidas (Chrispino, 2007; Rodrigues, Dias \& Freitas, 2010), daí a relevância desse efeito do treinamento realizado. Os resultados apresentados por GI vão parcialmente ao encontro dos achados de Elias e Marturano (2016), ao usar o programa com alunos do Ensino Fundamental I. Contudo, ressalta-se que os participantes não foram avaliados com os mesmos instrumentos para problemas de comportamento e habilidades de solução de problemas interpessoais (devido à faixa etária), mas, fazendo um correlato, não apresentavam tantos problemas de comportamento inicialmente.

Quanto à avaliação de GE, tanto os pais quanto os professores não encontraram diferença significativas entre as variáveis analisadas. Estes resultados convergem com os do GI ao apontar as dificuldades que a escola tem para lidar com problemas comportamentais de alunos. A formação continuada de professores é essencial para orientações no sentido de desenvolverem as próprias habilidades sociais para, posteriormente, ensiná-las aos alunos (Bolsoni-Silva Perallis \& Nunes, 2018; Elias \& Marturano, 2016). Segundo a avaliação da psicóloga, na avaliação direta das crianças quanto às habilidades de solução de problemas interpessoais, GE também apresentou aumento significativo na média de taxa de relevância após a intervenção. O aumento da média nessa variável em GE, mesmo sem receber a intervenção, pode ser explicado pelo papel fundamental da escola em desenvolver habilidades acadêmicas e sociais, sendo um 
contexto essencial para a promoção e exercício de habilidades relevantes ao longo dos próximos anos da vida. (Del Prette \& Del Prette, 2003; Correia-Zanini \& Marturano, 2016); a escola tende ainda a reforçar positivamente alunos sem problemas de comportamento (Gresham \& Elliott, 1990), o que caracterizou a maior parte dos participantes de GE. Destaca-se que as habilidades de solução de problema promovem uma forma reflexiva de tomada de decisão, já que se baseia na análise das consequências de cada comportamento emitido, levando a um enfrentamento mais adaptativo e saudável (Rodrigues, Dias \& Freitas, 2010). Por fim, essas habilidades são aprendidas a partir da experiência dos indivíduos e pode ser entendida como um conjunto de habilidades e como um processo de aprendizagem (Marturano, Elias \& Versuti, 2017).

Diante do exposto tem-se de forma clara a importância do microssistema escola no desenvolvimento dos alunos, assim como do macrossistema através de políticas públicas destinadas a escola (quer a professores e alunos) que impactam diretamente nas ações diárias de sala de aula (Bronfenbrenner,1996).

\section{Considerações Finais}

A partir das colocações acima, tem-se que os resultados encontrados do presente estudo corroboraram parcialmente com os encontrados por Elias e Marturano (2016) e Elias e Amaral (2016); ao avaliarem os efeitos do Programa Posso Pensar, quando aplicado a crianças do Ensino Fundamental, essas autoras sinalizaram ganhos dos participantes nas diferentes variáveis investigadas.

Infere-se que as limitações encontradas referem-se a quatro fatores que merecem atenção em próximos estudos com o PPP ou outros programas. O primeiro relaciona-se ao fato de que a aplicação realizada no presente estudo foi realizada pela pesquisadora e não pelas professoras como nos estudos de Elias e Marturano (2016) e Elias e Amaral (2016), o que dificulta o uso do vocabulário e diálogo proposto originalmente no PPP, que deve ser incorporado no currículo escolar, já que a pesquisadora tinha contato com as crianças apenas uma vez por semana. Um segundo, pareceu relacionado às crianças apresentarem problemas de comportamentos significativos, sendo que a literatura tem apresentado que programas universais apresentam pouco impacto a essas crianças. $\mathrm{O}$ terceiro fator diz respeito à constituição dos grupos; escolas e salas que participaram do estudo foram indicadas pelas autoridades da Secretaria de Educação, tendo assim um possível viés; tornando impossível a equivalência inicial dos grupos nas diferentes 
variáveis investigadas antes da intervenção e espera. Finalmente, um quarto fator a ser considerado, é que crianças pré-escolares apresentam características comportamentais típicas da fase do desenvolvimento e assim as intervenções necessitam ter um menor tempo e uma frequência maior, de forma a promover maiores ganhos.

Conclui-se que ganhos podem ser potencializados a partir dos pontos destacados acima e que apesar de ser uma área ainda pouco explorada, é de extrema importância a realização de outros estudos, visto que intervenções preventivas na Educação Infantil podem atuar como proteção ao desenvolvimento do escolar. 


\section{Referências Gerais}

Achenbach, T. M., \& Edelbrock, C. S. (1979). The Child Behavior Profile: II. Boys aged 12-16 and girls aged 6-11 and 12-16. Journal of consulting and clinical psychology, 47(2), 223.

APA. (2002). Survey of top companies highlights mental health's role in worker productivity. 33, (9), 14.

Bandeira, M., Rocha, S. S., Souza, T. M. P., Del Prette, Z. A. P., \& Del Prette, A. (2006). Comportamentos problemáticos em estudantes do ensino fundamental: características da ocorrência e relação com habilidades sociais e dificuldades de aprendizagem. Estudos de Psicologia, 11(2), 199-208.

Barker, E. D., Vitaro, F., Lacourse, E., Fontaine, N. M. G., Carbonneau, R., \& Tremblay, R. E. (2010). Testing the developmental distinctiveness of male proactive and reactive aggression with a nested longitudinal experimental intervention. Aggressive Behavior, 36(2), 127-140.

Bolsoni-Silva, A. T., Borelli, L. M. (2012). Treinamento de Habilidades Sociais Educativas Parentais: Comparação de Procedimentos a partir do Tempo de Intervenção. Estudos e Pesquisas em Psicologia, 12(1), 36-58.

Bolsoni-Silva, A. T., \& Del Prette, A. (2003). Problemas de comportamento: um panorama da área. Revista Brasileira de Terapia Comportamental e Cognitiva, 5(2), 91-103.

Bolsoni-Silva, A. T., Mariano, M. L., Loureiro, S. R., Bonaccorsi, C. (2013). Contexto escolar: práticas educativas do professor, comportamento e habilidades sociais infantis. Revista Semestral da Associação Brasileira de Psicologia Escolar e Educacional, 17(2), 259-269.

Bolsoni-Silva, A. T., Marturano, E. M., \& Freiria, R. L. B. (2010). Indicativos de problemas de comportamento e de habilidades sociais em crianças: um estudo longitudinal. Psicologia: Reflexão e Crítica, 23(3), 506-515.

Bolsoni-Silva, A. T., Perallis, C; Nunes, P. (2018). Problemas de Comportamento, Competência Social e Desempenho Acadêmico: Um Estudo Comparativo de Crianças no Ambiente Escolar e Familiar. Trends in Psychology, 26(3), 1189-1204.

Bolsoni-Silva, A. T., Silveira, F. F., \& Marturano, E. M. (2008). Promovendo habilidades sociais educativas parentais na prevenção de problemas de comportamento. Revista Brasileira de Terapia Comportamental e Cognitiva, 10(2), 125-142.

Borges, D. S. C., \& Marturano, E. M. (2009). Aprendendo a gerenciar conflitos: um programa de intervenção para a $1^{a}$ série do ensino fundamental. Paidéia, 19(42), $17-26$.

Borges, D. S. C., \& Marturano, E. M. (2010). Melhorando a convivência em sala de aula: responsabilidades compartilhadas. Temas em Psicologia, 18(1), 123-136.

Breslau, N., Breslau, J., Miller, E., \& Raykov, T. (2011). Behavior problems at ages 6 and 11 and high school academic achievement: Longitudinal latent variable modeling. Psychiatry Research, 185(3), 433437. https://doi.org/10.1016/j.psychres.2010.07.027

Bronfenbrenner, U. (1996). A ecologia do desenvolvimento humano: experimentos naturais e planejados. (M. A. V. Veronesi, Trad.). Porto Alegre: Artes Médicas.

Bronfenbrenner, U. \& Morris, P. (1998). The ecology of developmental processes. In W. Damon (Series Ed.) \& R. M. Lerner (Vol. Ed.), Handbook of child psychology. Theoretical models of human development (Vol. 1, pp. 993-1027). New York: John Wiley \& Sons. 
Casali-Robalinho, I. G. (2013). Relações entre automonitoria, problemas de comportamento e habilidades sociais na infância. Dissertação de mestrado, Programa de Pós-Graduação em Psicologia, Universidade Federal de São Carlos, São Carlos, SP.

Chrispino, A. (2007). Gestão do conflito escolar: da classificação dos conflitos aos modelos de mediação. Ensaio: Avaliação e Políticas Públicas em Educação, 15(54), 11-28.

Cia, F., \& Barham, E. J. (2009). Repertório de habilidades sociais, problemas de comportamento, autoconceito e desempenho acadêmico de crianças no início da escolarização. Estudos de Psicologia, 26(1), 45-55.

Correia-Zanini, M. R. G. (2013). Um estudo prospectivo sobre escolar de criança nos primeiros anos do Ensino Fundamental (Tese de doutorado não publicada). Universidade de São Paulo, Ribeirão Preto, SP.

Correia-Zanini, M. R. G. \& Marturano, E. M. (2016). Primeiros Passos no Ensino Fundamental: Competência Cognitiva, Habilidades Sociais, Comportamento e Estresse. Psico-USF [online], 21 (2), 305-317.

Del Prette, Z. A. P. \& Del Prette, A. (2001). Psicologia das habilidades sociais: terapia e educação. Petrópolis, RJ: Vozes.

Da Dalt de Mangione, E., \& Difabio de Anglat, H. (2002). Asertividad, su relación con los estilos educativos familiares. Interdisciplinaria, 19(2), 119-140.

Del Prette, Z. A. P., \& Del Prette, A. (2003). Habilidades sociais e dificuldades de aprendizagem: Teoria e pesquisa sob um enfoque multimodal. In: A. Del Prette \& A. P. Del Prette (Orgs.), Habilidades Sociais, Desenvolvimento e Aprendizagem: Questões conceituais, avaliação e intervenção (pp. 167-206). Campinas: Alínea.

Del Prette, Z. A. P., \& Del Prette, A. (2005). Psicologia das habilidades sociais na infância: Teoria e prática. Petrópolis, RJ: Vozes.

Del Prette, Z. A. P., \& Del Prette, A. (2006). Avaliação multimodal de habilidades sociais em crianças: Procedimentos, instrumentos e indicadores. In: Bandeira, M., Del Prette, Z. A. P., \& Del Prette, A. (Orgs.), Estudos sobre habilidades sociais e relacionamento interpessoal (pp. 47-68). São Paulo: Casa do Psicólogo.

Del Prette, Z. A. P., \& Del Prette, A. (2009). Avaliação de habilidades sociais: Bases conceituais, instrumentos e procedimentos. Em Del Prette e Del Prette (Orgs.), Psicologia das habilidades sociais: Diversidade teórica e suas implicações (pp. 187229). Petrópolis, RJ: Vozes.

Del Prette, A., \& Del Prette, Z. A. P. (2010). Programa vivencial de habilidades sociais: Características sob a perspectiva da análise do comportamento. In M. R. Garcia, P. Abreu, E. N. P. de Cillo, P. B. Faleiros, \& P. P. Queiroz (Orgz.). Comportamento e Cognição: Terapia Comportamental e Cognitiva (pp. 127-139). Santo André: ESETec

Del Prette, Z. A. P., \& Del Prette, A. (2011). Práticas baseadas em evidência e treinamento de habilidades sociais. Em A. Del Prette \& Z. A. P. Prette (Orgs.), Habilidades sociais: intervenções efetivas em grupo (pp. 261-288). São Paulo, SP: Casa do Psicólogo.

Del Prette, Z.A., \& Del Prette A. (2017). Compentência Social e Habilidades Sociais; manual teórico-prático. Petropólis: Vozes.

Del Prette, Z. A. P., Rocha, M. M., \& Del Prette, A. (2011). Programas de habilidades sociais na infância: Modelo triádico de intervenção com pais. Em C. Petersen \& M. Wainer (Orgs.), Terapias Cognitivo-Comportamentais para crianças e adolescentes (pp. 46-61). Porto Alegre: Artmed. 
Dias, T. P., Lopes, D. C., \& Del Prette, Z. A. P. (2015). Programas de intervenção em habilidades sociais para crianças: propostas para a educação infantil e o ensino fundamental. Em Z. A. P. Del Prette, A. B. Soares, C. S. Pereira-Guizzo, M. F. Wagner, \& V. B. R. Leme. (Orgs.), Habilidades sociais: Diálogos e intercâmbios sobre pesquisa e prática (pp. 128-159). Novo Hamburgo: Sinopsys.

DiPerna, J. C. (2006). Academic enablers and student achievement: Implications for assessement and interventions service in the schools. Psychology in the Schools, 43(1), 7-17.

Elias, L. C. S., \& Amaral, M. V. (2016). Habilidades Sociais, Comportamentos e Desempenho Acadêmico em Escolares antes e após Intervenção. Psico-USF, Bragança Paulista, 21(1), 49-61.

Elias, L. C. S., \& Marturano, E. M. (2014). "Eu posso resolver problemas" e oficinas de linguagem: intervenções para queixa escolar. Psicologia: Teoria e Pesquisa, 30(1), 35-44.

Elias, L. C. S. \& Marturano, E. M. (2016). Promovendo habilidades de solução de problemas interpessoais em crianças. Interação Psicol.,20 (1), 91-100.

Elias, L. C. S., Marturano, E. M., \& Motta-Oliveira, A. M. A. (2012). Eu posso resolver problemas: Um programa para o desenvolvimento de habilidades de solução de problemas interpessoais. Temas em Psicologia, 20, 521-535.

Falcão, A. P. \& Bolsoni-Silva, A. T., Magri, N., Moretto, L. A. (2016). PromoveCrianças: treinamento de habilidades sociais. São Paulo: Hogrefe.

Feitosa, F. B., Del Prette Z. A. P., Del Prette, A., \& Loureiro, S. R. (2011). Explorando relações entre o comportamento social e o desempenho acadêmico em crianças. Estudos e Pesquisas em Psicologia, 11(2), 442-445.

Fernandes, L. M., Leme, V. B. R., Elias, L. C. S., \& Soares, A. B. (2018). Preditores do desempenho escolar ao final do ensino fundamental: histórico de reprovação, habilidades sociais e apoio social. Temas em Psicologia, 26(1), 215-228.

Garnica, K. R. H. (2009). Avaliação e treinamento de habilidades sociais de crianças em idade pré-escolar. (Dissertação de Mestrado não publicada). Universidade Estadual Paulista, Bauru, SP.

Gonçalves, E. S., \& Murta, S. G. (2008). Avaliação dos efeitos de uma modalidade de treinamento de habilidades sociais para crianças. Psicologia: Reflexão e Crítica, 21(3), 430-436.

Gresham, F. M., \& Elliott, S. N. (1990). Social skills rating system: Manual. Circle Pines, MN: American Guidance Service. 19.

Habigzang, L.; Lampert, S.; De Antoni, C.; Koller, S. (2004). A violência no contexto escolar e a inserção ecológica da Psicologia: um relato de experiência. In: KOLLER, Sílvia. Ecologia do desenvolvimento humano. São Paulo: Casa do Psicólogo.

Jovarini, N. V.; Leme, V. B. R.; Correia-Zanini, M. R. G. (2018). Influence of Social Skills and Stressors on Academic Achievement in the Sixth-Grade. Paidéia (Ribeirão Preto), 28, e2819.

Kratochwill, T. R., Albers, C. A., \& Shernoff, E. S. (2004). School-based intervention. Child Adolescent Psychiatric Clinics of North America, 13, 885-903.

Kirkhaug, B., Drugli, M. B., Handegard, B. H. Stian Lydersen, Åsheim, M., Fossum, S. (2016). Does the Incredible Years Teacher Classroom Management Training programme have positive effects for Young children exhibiting severe externalizing problems in school?: a quasi-experimental pre-post study. BMC Psychiatry.

Leme, V. B. R., Del Prette, Z. A., Koller, S. H., \& Del Prette, A. (2015). Habilidades sociais e o modelo bioecológico do desenvolvimento humano: análise e perspectivas. Psicologia \& Sociedade, 28(1), 181-193. 
Loeber, R. (1991). Antisocial behavior: more enduring than changeable? Journal of American Academy of Child and Adolescent Psychiatry, 30, 393-397.

Lopes, D. C. (2013). Programa universal de habilidades sociais aplicado pelo professor: impacto sobre comportamentos sociais e acadêmicos. Tese de Doutorado, Programa de Pós-Graduação em Psicologia, Universidade Federal de São Carlos, São Carlos, SP.

Marturano, E. M, \& Elias, L. C. S. (2016). Família, dificuldades no aprendizado e problemas de comportamento em escolares. Educar em Revista, (59), 123-139.

Marturano, E. M.; Elias, L. C. S. \& Versuti, F. M. (2017). Solução de problemas e conflitos interpessoais. In Del Prette, Z. A. P \& Del Prette, A. (Eds). Habilidades sociais e competência social para uma vida melhor. (pp. 83-89). São Carlos, SP: EdUFSCAR.

McCabe, P.C., Altamura, M. (2011). Empirically valid strategies to improve social and emotional competence of preschool children. Psychology in the Schools, 48(5), 513540.

Michelson, L., Sugai, D., Wood, R., \& Kazdin, A. (1987). Las habilidades sociales en la infancia: evaluación y tratamiento. Martínez Roca: Barcelona.

Montroy, J. J., Bowles, R. P., Skibbe, L. E., \& Foster, T. D. (2014). Social skills and problem behaviors as mediators of the relationship between behavioral selfregulation and academic achievement. Early Childhood Research Quarterly, 29(3), 298-309. https://doi.org/10.1016/j.ecresq.2014.03.002

Mrazek, P. B., \& Haggerty, R. J. (1994). Reducing risks for mental disorders: frontiers for preventive intervention research. Washington, DC: The National Acade mies Press.

Murta, S.G.C.; Santos, F.L. \& Polejack, L.. (2015). Prevenção e Promoção em Saúde Mental - Fundamentos, Planejamento e Estratégias de Intervenção.864p.

Pinheiro, M. I. S., Haase, V. H., Del Prette, A., Amarante, C. L. D., \& Del Prette, Z. A. P. (2006). Treinamento de habilidades sociais educativas para pais de crianças com problemas de comportamento. Psicologia: Reflexão e Crítica, 19(3), 407-414.

Poletto, M., \& Koller, S. H. (2008). Contextos ecológicos: Promotores de resiliência, fatores de risco e de proteção [Ecological contexts: furthering resilience, risk and protection factors]. Estudos de Psicologia, 25(3), 405416. https://doi.org/10.1590/S0103-166X2008000300009

Reppold, C. T., Pacheco, J., Bardagi, M., \& Hutz, C. (2002). Prevenção de problemas de comportamento e desenvolvimento de competências psicossociais em crianças e adolescentes: uma análise das práticas educativas e dos estilos parentais. Em C. S. Hutz, (Org.), Situações de risco e vulnerabilidade na infância e na adolescência: aspectos teóricos e estratégias de intervenção (pp. 7-51). São Paulo: Casa do Psicólogo.

Rodrigues, M. C., Dias, J. P. \& Freitas, M. F. R. L. (2010). Resolução de problemas interpessoais: promovendo o desenvolvimento sociocognitivo na escola. Psicologia em Estudo, 15, 831-839.

Rocha, M. M., Del Prette, Z. A. P., \& Del Prette, A. (2011). Programa de habilidades sociais educativas com mães de crianças com déficit de atenção e hiperatividade. Em A. Del Prette \& Z. A. P. Del Prette (Orgs.), Habilidades sociais: intervenções efetivas em grupo (pp. 261-288). São Paulo, SP: Casa do Psicólogo.

Rosin-Pinola, A. R. (2010). Efeitos de um programa de treinamento de habilidades sociais educativas junto a professores de alunos com deficiência mental incluídos. Tese de Doutorado, Programa de Pós-Graduação em em Psicologia, Universidade de São Paulo, Ribeirão Preto, SP. 
Rosin-Pinola, A. R., Marturano, E. M., Elias, L. C. S., \& Del Prette, Z. A. P. (2017). Ensinando habilidades sociais educativas para professores no contexto da inclusão escolar. Educação Especial, 30(59), 737- 750.

Sabbag, G. M., \& Bolsoni-Silva, A. T. (2011). A relação das Habilidades Sociais educativas e das práticas educativas maternas com os problemas de comportamento em adolescentes. Estudos e Pesquisas em Psicologia, 11(2), 423-441.

Salvo C. G., Mazzarotto I. H. K., Löhr S. S. (2005). Promoção de habilidades sociais em pré-escolares. Rev Bras Cresc Desenv Hum (1), 46-55.

Shure, M. B. (2006). Eu posso resolver problemas: educação infantil e ensino funadamental: um programa de solução cognitive para problemas interpessoais. (E. M. Marturano, A. M. A. Motta, \& L. C. S. Elias, Trads.). Petrópolis: Vozes.

World Health Organization. (1999). The World health report: 1999: Making a difference. WorldHealthOrganization. https://apps.who.int/iris/handle/10665/42167 
Anexo 1.

\begin{tabular}{|c|c|c|c|}
\hline Lição & Objetivo & Atividades & Reforço \\
\hline 1 - Prestar atenção & $\begin{array}{l}\text { Mostrar a importância de prestar } \\
\text { atenção }\end{array}$ & $\begin{array}{l}\text { História, compreensão do texto e encenação } \\
\text { da pesquisadora, indicando as } \\
\text { consequências de não prestar atenção }\end{array}$ & $\begin{array}{l}\text { Retomar tema e Desenho sobre o tema } \\
\text { discutido }\end{array}$ \\
\hline $\begin{array}{l}\text { 2- Felicidade e } \\
\text { tristeza }\end{array}$ & $\begin{array}{lll}\text { Estimular a } & \text { expressão } & \text { de } \\
\text { sentimentos e } & \text { identificar } & \text { as } \\
\text { diferenças entre pessoas e situações. }\end{array}$ & $\begin{array}{l}\text { História, compreensão do texto e } \\
\text { brincadeira de caretas }\end{array}$ & $\begin{array}{l}\text { Retomar tema e Desenho e atividade em } \\
\text { duplas para que cada um pergunte o que } \\
\text { deixa o par triste e feliz. }\end{array}$ \\
\hline $\begin{array}{l}3-\text { Bravo, com } \\
\text { raiva }\end{array}$ & $\begin{array}{l}\text { Aprender a pensar nesses } \\
\text { sentimentos para aprender a } \\
\text { controlar e falar deles. }\end{array}$ & $\begin{array}{l}\text { História, compreensão do texto e teatro com } \\
\text { participação das crianças sobre situação- } \\
\text { problema. }\end{array}$ & $\begin{array}{l}\text { Retomar tema e brincadeira de trenzinho, } \\
\text { estimulando cada uma expressar o que a } \\
\text { deixa com raiva, no momento em que } \\
\text { voltar pro lugar. }\end{array}$ \\
\hline $\begin{array}{l}4-\text { Gosto e não } \\
\text { gosto }\end{array}$ & $\begin{array}{l}\text { Identificar semelhanças e diferenças } \\
\text { nos gostos e desgostos de cada um. }\end{array}$ & $\begin{array}{l}\text { História, compreensão do texto e jogo no } \\
\text { qual são feitas sobre os gostos das crianças } \\
\text { e as preferências são anotadas. }\end{array}$ & $\begin{array}{l}\text { Retomar tema e Em duplas, cada um tem } \\
\text { que descobrir uma coisa que o amigo do } \\
\text { lado gosta para contar para a classe }\end{array}$ \\
\hline 5- Medo & $\begin{array}{l}\text { Validar o medo, ensinar } \\
\text { reconhecê-lo e controla-lo }\end{array}$ & $\begin{array}{l}\text { História, compreensão do texto e } \\
\text { brincadeira na qual quem pegar a bola, fala } \\
\text { um medo que tem e quem compartilha desse } \\
\text { sentimento, levanta a mão. }\end{array}$ & $\begin{array}{l}\text { Retomar o tema e questionar medos de } \\
\text { adultos que moram com eles. }\end{array}$ \\
\hline 6- Preocupado & $\begin{array}{l}\text { Estimular que expressem suas } \\
\text { preocupações }\end{array}$ & $\begin{array}{l}\text { História, compreensão do texto e } \\
\text { brincadeira de trenzinho passando embaixo } \\
\text { da ponte (quando quebra em alguma }\end{array}$ & $\begin{array}{l}\text { Retomar tema e Desenho sobre esse } \\
\text { sentimento. }\end{array}$ \\
\hline
\end{tabular}




\begin{tabular}{|c|c|c|c|}
\hline & & $\begin{array}{l}\text { criança, esta compartilha o que a deixa } \\
\text { preocupada) }\end{array}$ & \\
\hline 7-Irritado & $\begin{array}{l}\text { Estimular que expressem o que as } \\
\text { deixa irritadas. }\end{array}$ & $\begin{array}{l}\text { História, compreensão do texto e } \\
\text { brincadeira de batata quente, quando } \\
\text { queimar, a criança fala algo que a deixa } \\
\text { irritada. }\end{array}$ & $\begin{array}{l}\text { Retomar tema e pedir para que } \\
\text { compartilhem o que deixa as pessoas que } \\
\text { gostam irritadas. }\end{array}$ \\
\hline 8-Vergonha & $\begin{array}{l}\text { Estimular que expressem o que as } \\
\text { deixa com vergonha. }\end{array}$ & $\begin{array}{l}\text { História, compreensão do texto e } \\
\text { brincadeira com fantoche- em duplas } \\
\text { falarem uma situação em que sentiram } \\
\text { vergonha }\end{array}$ & $\begin{array}{l}\text { Retomar tema e Desenho sobre uma } \\
\text { situação em que sentiram vergonha. }\end{array}$ \\
\hline $\begin{array}{l}\text { 9-Perguntar } \\
\text { escutar }\end{array}$ & $\begin{array}{l}\text { Falar sobre a importância de saber } \\
\text { perguntar e escutar o que as pessoas } \\
\text { dizem, para entender o que as } \\
\text { pessoas pensam e o que elas sentem. }\end{array}$ & $\begin{array}{l}\text { História, compreensão do texto e } \\
\text { brincadeira de repórter - em duplas, na } \\
\text { frente do grupo, fazer perguntas sobre } \\
\text { temas trabalhados. }\end{array}$ & $\begin{array}{l}\text { Retomar tema e solicitar que façam a } \\
\text { brincadeira de repórter com os pais. }\end{array}$ \\
\hline 10- Paciência & $\begin{array}{l}\text { Explicar o que é ter paciência e as } \\
\text { consequências vantagens dela. }\end{array}$ & $\begin{array}{l}\text { História, compreensão do texto e } \\
\text { brincadeira de vivo ou morto com perguntas } \\
\text { sobre situações que exigem paciência. }\end{array}$ & $\begin{array}{l}\text { Retomar tema e solicitar que façam } \\
\text { desenho sobre o tema. }\end{array}$ \\
\hline $\begin{array}{l}\text { 11- Revisão dos } \\
\text { sentimentos e temas } \\
\text { trabalhados. }\end{array}$ & Retomar todos os temas anteriores. & $\begin{array}{l}\text { História, compreensão do texto e } \\
\text { questionamento sobre os sentimentos dos } \\
\text { personagens e as consequências. }\end{array}$ & $\begin{array}{l}\text { Retomar tema e elaborar uma história em } \\
\text { conjunto. }\end{array}$ \\
\hline
\end{tabular}




\begin{tabular}{|c|c|c|c|}
\hline \begin{tabular}{ll|} 
12- Somos \\
diferentes
\end{tabular} & $\begin{array}{l}\text { Falar sobre a importância de pensar } \\
\text { e respeitar as diferenças para evitar } \\
\text { problemas. }\end{array}$ & $\begin{array}{l}\text { História, compreensão do texto e } \\
\text { brincadeira }- \text { quem tem aquela } \\
\text { característica entra no círculo. }\end{array}$ & $\begin{array}{l}\text { Retomar tema e, em duplas, descobrir uma } \\
\text { diferença do amigo e depois compartilhar } \\
\text { com a classe. }\end{array}$ \\
\hline $\begin{array}{l}13 \text { - Empatia - se } \\
\text { colocar no lugar do } \\
\text { outro }\end{array}$ & que é empatia e treiná-la. & $\begin{array}{l}\text { História, compreensão do texto e encenação } \\
\text { para que os outros adivinhem o que o outro } \\
\text { está sentindo e como poderiam ajudar. }\end{array}$ & $\begin{array}{l}\text { Retomar o tema e desenhar o que cada } \\
\text { personagem da nova história sentiu. }\end{array}$ \\
\hline 14- Antes e depois & $\begin{array}{l}\text { Estimular a pensar na sequência dos } \\
\text { eventos. }\end{array}$ & $\begin{array}{l}\text { História, compreensão do texto e } \\
\text { brincadeira de música na qual são dados } \\
\text { comandos que eles deverão seguir }\end{array}$ & $\begin{array}{l}\text { Solicitar que perguntem aos pais o que } \\
\text { fizeram antes e depois de os levarem na } \\
\text { escola. }\end{array}$ \\
\hline $\begin{array}{l}\text { 15- Revisão dos } \\
\text { temas trabalhados }\end{array}$ & Retomar todos & $\begin{array}{l}\text { Apresentar cada tema e relembrar seu } \\
\text { significado, solicitando que pintem o } \\
\text { quadro e solicitar que as crianças construam } \\
\text { uma história, em conjunto, utilizando todos } \\
\text { os temas. }\end{array}$ & $\begin{array}{l}\text { Chamar um de cada vez ao centro do } \\
\text { círculo para contar algo sobre o tema. }\end{array}$ \\
\hline $\begin{array}{l}\text { 16- Entender, } \\
\text { pensar e agir. }\end{array}$ & $\begin{array}{l}\text { Estimular que devemos entender } \\
\text { bem o que está acontecendo, pensar } \\
\text { em soluções e depois decidir o que } \\
\text { fazer. }\end{array}$ & $\begin{array}{l}\text { História, estimular ideias de como os } \\
\text { personagens podem resolver o problema e } \\
\text { estimular as consequências para cada uma } \\
\text { delas. Brincadeira de corrida entre dois } \\
\text { grupos com número diferente de crianças e }\end{array}$ & $\begin{array}{l}\text { Solicitar que cada um desenhe um } \\
\text { problema e duas soluções para esse } \\
\text { problema. }\end{array}$ \\
\hline
\end{tabular}




\begin{tabular}{|c|c|c|c|}
\hline & & $\begin{array}{l}\text { questionar como esse problema poderia ser } \\
\text { resolvido. }\end{array}$ & \\
\hline $\begin{array}{l}\text { 17- Entender, } \\
\text { pensar e agir. }\end{array}$ & $\begin{array}{l}\text { Estimular que devemos entender } \\
\text { bem o que está acontecendo, pensar } \\
\text { em soluções e depois decidir o que } \\
\text { fazer. }\end{array}$ & $\begin{array}{l}\text { História, identificação do problema, dos } \\
\text { sentimentos de cada personagem e das } \\
\text { possíveis soluções para o problema e as } \\
\text { consequências para cada uma e } \\
\text { dramatização da história. }\end{array}$ & $\begin{array}{l}\text { Pedir para que contem em casa a história } \\
\text { trabalhada e perguntem para um } \\
\text { responsável que solução eles teriam para o } \\
\text { problema }\end{array}$ \\
\hline $\begin{array}{l}\text { 18- O que está } \\
\text { acontecendo? }\end{array}$ & $\begin{array}{l}\text { Falar sobre a importância de } \\
\text { perguntar, escutar o que todos falam } \\
\text { para depois poder dizer alguma } \\
\text { coisa }\end{array}$ & $\begin{array}{l}\text { História, compreensão do texto, } \\
\text { identificação dos sentimentos dos } \\
\text { identificação do problema, dos sentimentos } \\
\text { de cada personagem e das possíveis } \\
\text { soluções para o problema e as } \\
\text { consequências para cada uma. Encenação } \\
\text { de expressões e as crianças devem } \\
\text { perguntar o que está acontecendo e o que } \\
\text { poderia ser feito para resolver o problema. }\end{array}$ & $\begin{array}{l}\text { Retomar o tema e perguntar ao seu par um } \\
\text { problema que tem, escutar e pensar em } \\
\text { uma solução para o problema; depois } \\
\text { devem contar para o restante do grupo. }\end{array}$ \\
\hline $\begin{array}{l}\text { 19- Tenho que } \\
\text { pensar }\end{array}$ & $\begin{array}{l}\text { Falar sobre a importância de pensar } \\
\text { nas consequências. }\end{array}$ & $\begin{array}{l}\text { História, dividir a sala em grupos e pedir } \\
\text { que cada um fale uma consequência que } \\
\text { teve a atitude do personagem. }\end{array}$ & $\begin{array}{l}\text { Retomar o tema e fazer um desenho em } \\
\text { conjunto. }\end{array}$ \\
\hline
\end{tabular}




\begin{tabular}{|c|c|c|c|}
\hline 20- Problema nosso & $\begin{array}{l}\text { Discutir problemas que temos em } \\
\text { comum e diferentes. }\end{array}$ & $\begin{array}{l}\text { História, perguntar problemas que eles tem, } \\
\text { como resolvem e quais são as } \\
\text { consequências e brincadeira de morto-vivo, } \\
\text { quando disser uma situação que as crianças } \\
\text { tem em comum ficam de pé e quando não } \\
\text { tiver agacham }\end{array}$ & $\begin{array}{l}\text { Retomar o tema e solicitar que façam um } \\
\text { desenho sobre um problema que tiveram, } \\
\text { como resolveram e qual foi a } \\
\text { consequência. }\end{array}$ \\
\hline 21- Imagine que & $\begin{array}{l}\text { Discutir sobre sentimentos, ações e } \\
\text { consequências diante de diferentes } \\
\text { situações. }\end{array}$ & $\begin{array}{l}\text { Fábula, questionamento sobre sentimentos } \\
\text { dos personagens e as consequências das } \\
\text { ações destes. Propor que o grupo crie um } \\
\text { final alternativo para a história e listar as } \\
\text { consequências de cada sugestão. }\end{array}$ & $\begin{array}{l}\text { Retomar o tema e brincadeira da batata } \\
\text { quente: em quem parar deverá dizer o que } \\
\text { acontece que deixa ele com o sentimento } \\
\text { ou comportamento que você vai falar. }\end{array}$ \\
\hline 22- Imagine que & $\begin{array}{l}\text { Conversar com as crianças a } \\
\text { necessidade de ter conhecimento } \\
\text { real das situações antes de fazer } \\
\text { suposições. }\end{array}$ & $\begin{array}{l}\text { História, compreensão do texto, dos } \\
\text { sentimentos e pensamentos dos } \\
\text { personagens, questionar os erros cometidos, } \\
\text { jogo de mímica com situações-problema, } \\
\text { explorando soluções e consequências para } \\
\text { cada uma. }\end{array}$ & $\begin{array}{l}\text { Retomar o tema, questionar se já se } \\
\text { meteram em confusão porque não tinham } \\
\text { certeza de uma coisa, as possíveis } \\
\text { soluções e consequências. }\end{array}$ \\
\hline 23-Pergunte e pense & $\begin{array}{l}\text { Dizer que devemos perguntar para } \\
\text { as pessoas o que pensam e sentem }\end{array}$ & $\begin{array}{l}\text { História, compreensão do texto, listar } \\
\text { soluções e consequências. }\end{array}$ & $\begin{array}{l}\text { Pedir que contem em casa a história e } \\
\text { perguntar para os pais as possíveis } \\
\text { soluções e consequências. }\end{array}$ \\
\hline
\end{tabular}




\begin{tabular}{|c|c|c|c|}
\hline & $\begin{array}{l}\text { para depois pensar em como } \\
\text { resolver os problemas. }\end{array}$ & & \\
\hline $\begin{array}{l}\text { 24-Persistência } \\
\text { coragem }\end{array}$ & $\begin{array}{l}\text { Conversar sobre persistência } \mathrm{e} \\
\text { coragem para resolver problemas. }\end{array}$ & $\begin{array}{l}\text { História, brincadeira em roda, na qual cada } \\
\text { dupla de crianças irá para o centro do grupo } \\
\text { para resolverem um problema e falar as } \\
\text { consequências de cada solução. }\end{array}$ & $\begin{array}{l}\text { Retomar o tema e desenhar uma situação } \\
\text { em que tiveram um problema e foram } \\
\text { corajosos e persistentes ou que não foram, } \\
\text { mas gostariam de ter sido. }\end{array}$ \\
\hline 25-Resistir & $\begin{array}{l}\text { Conversar sobre a importância de } \\
\text { aprender a resistir, a se controlar } \\
\text { para não se meter em confusão }\end{array}$ & $\begin{array}{l}\text { História, compreensão do texto brincadeira } \\
\text { do percurso no chão, no qual em cada } \\
\text { “casa”, as crianças tem que apresentar uma } \\
\text { solução para a situação problema e suas } \\
\text { consequências. }\end{array}$ & $\begin{array}{l}\text { Retomar o tema, solicitar relatos de } \\
\text { situações em que não tiveram resistência e } \\
\text { as consequências foram ruins e o que } \\
\text { fariam de diferente. }\end{array}$ \\
\hline $\begin{array}{l}\text { 26-Pensar, pensar e } \\
\text { depois agir }\end{array}$ & $\begin{array}{l}\text { Conversar sobre a importância de } \\
\text { pensar para não cometermos tantos } \\
\text { erros }\end{array}$ & $\begin{array}{l}\text { História, compreensão do texto, solicitar } \\
\text { soluções e consequências. Realizar a } \\
\text { dramatização da história. }\end{array}$ & $\begin{array}{l}\text { Solicite que pergunte para alguém em casa } \\
\text { (um responsável), que contem uma } \\
\text { situação em que pensam muito antes de } \\
\text { agir, ou que não pensaram muito e se } \\
\text { meteram em confusão }\end{array}$ \\
\hline $\begin{array}{l}\text { 27- Pensando e } \\
\text { resolvendo juntos }\end{array}$ & $\begin{array}{l}\text { Conversar sobre a importância de } \\
\text { pedir ajuda e ajudar quando for } \\
\text { solicitado. }\end{array}$ & $\begin{array}{l}\text { História, compreensão do texto e } \\
\text { elaboração de uma história em conjunto, } \\
\text { discutindo os possíveis problemas e } \\
\text { soluções que podem aparecer. }\end{array}$ & $\begin{array}{l}\text { Retomar o tema e propor que façam } \\
\text { desenhos sobre a história, em duplas. }\end{array}$ \\
\hline
\end{tabular}




\begin{tabular}{|c|c|c|c|}
\hline $\begin{array}{l}\text { 28- Qual } \\
\text { caminho? }\end{array}$ & $\begin{array}{l}\text { Conversar sobre as diferentes } \\
\text { possibilidades de escolhas. }\end{array}$ & $\begin{array}{l}\text { História, compreensão da história e } \\
\text { brincadeira de trenzinho, na qual as crianças } \\
\text { deverão escolher caminhos diante das } \\
\text { situações apresentadas. }\end{array}$ & $\begin{array}{l}\text { Retomar o tema e solicitar para que façam } \\
\text { um desenho de algo que aconteceu com } \\
\text { eles, com a sequência de acontecimentos. }\end{array}$ \\
\hline 29 - O que faço? & $\begin{array}{l}\text { Conversar sobre escolhas diante de } \\
\text { problemas com outras pessoas. }\end{array}$ & $\begin{array}{l}\text { História, compreensão do texto, farão um } \\
\text { exercício de pensar em diferentes caminhos } \\
\text { que cada personagem poderia ter tomado }\end{array}$ & $\begin{array}{l}\text { Retomar o tema e a história e pensar sobre } \\
\text { as consequências de cada caminho. }\end{array}$ \\
\hline $\begin{array}{l}\text { 30- } \quad \text { O que } \\
\text { aconteceu? }\end{array}$ & $\begin{array}{l}\text { Conversar sobre o quanto é } \\
\text { importante perguntar o que } \\
\text { aconteceu ou o que está } \\
\text { acontecendo, porque descobrimos o } \\
\text { que as pessoas estão sentindo e } \\
\text { pensando para evitar confusão. }\end{array}$ & $\begin{array}{l}\text { História, compreensão do texto e } \\
\text { brincadeira na qual você vai falar algumas } \\
\text { situações e eles terão que dizer que razões } \\
\text { os fazem se comportar de determinada } \\
\text { forma. }\end{array}$ & $\begin{array}{l}\text { Solicite que façam um desenho da } \\
\text { situação que o grupo demonstrou ter } \\
\text { razões iguais para dado comportamento. }\end{array}$ \\
\hline $\begin{array}{l}\text { 31-Antes penso e } \\
\text { depois faço }\end{array}$ & $\begin{array}{l}\text { Conversar sobre a importância de } \\
\text { pensar antes de agir para evitar } \\
\text { consequências ruins }\end{array}$ & $\begin{array}{l}\text { História, compreensão do texto, propor que } \\
\text { as crianças deem soluções para os } \\
\text { problemas apresentados e indiquem as } \\
\text { consequências e fazer a brincadeira mais } \\
\text { votada, entre três. }\end{array}$ & $\begin{array}{l}\text { Retomar tema, retomar história, trabalhar } \\
\text { soluções e consequências para o problema } \\
\text { da história. }\end{array}$ \\
\hline
\end{tabular}




\begin{tabular}{|c|c|c|c|}
\hline $\begin{array}{lll}\text { 32-Falo, faço } & \text { e } \\
\text { depois... } & & \end{array}$ & $\begin{array}{l}\text { Conversar sobre as consequências } \\
\text { do que fazemos e falamos. }\end{array}$ & $\begin{array}{l}\text { História, compreensão da história, trabalhar } \\
\text { as soluções e consequências do problema } \\
\text { apresentado e brincadeira de corre cutia, } \\
\text { resolvendo problemas. }\end{array}$ & $\begin{array}{l}\text { Retomar tema e solicitar que as crianças } \\
\text { desenhem ou escrevam a solução para } \\
\text { uma situação problema apresentada. }\end{array}$ \\
\hline $\begin{array}{l}\text { 33- } \\
\text { diferentes } \\
\text { pensamos } \\
\text { diferentes }\end{array}$ & $\begin{array}{l}\text { Conversar sobre o quanto é } \\
\text { importante prestarmos atenção nas } \\
\text { diferenças para evitar problemas } \\
\text { com as pessoas. }\end{array}$ & $\begin{array}{l}\text { História, compreensão da história, } \\
\text { questione se já se meteram em confusão por } \\
\text { não conhecer direito a outra pessoa, ou por } \\
\text { não saber o que a pessoa gosta ou pensa e } \\
\text { peça para pensarem em diferentes soluções } \\
\text { e consequências. }\end{array}$ & $\begin{array}{l}\text { Pedir para que as crianças perguntem em } \\
\text { casa para alguém significativo, o que } \\
\text { fariam se fossem comer na casa de alguém } \\
\text { e tivesse uma comida que não gostassem. }\end{array}$ \\
\hline $\begin{array}{l}\text { 34- Respeitar } \\
\text { outro }\end{array}$ & $\begin{array}{l}\text { Conversar sobre a importância de } \\
\text { prestar atenção no que as pessoas } \\
\text { dizem e fazem para conhecer e } \\
\text { respeitar as diferenças. }\end{array}$ & $\begin{array}{l}\text { História, compreensão do texto e dividir as } \\
\text { crianças em duplas para que proponham } \\
\text { uma solução para determinado problema e } \\
\text { sua respectiva consequência. }\end{array}$ & $\begin{array}{l}\text { Retomar tema e pedir para a criança as } \\
\text { possíveis soluções e consequências. }\end{array}$ \\
\hline $\begin{array}{l}\text { 35- Evitando } \\
\text { problemas }\end{array}$ & $\begin{array}{l}\text { Conversar sobre a importância de } \\
\text { conhecer o outro para evitar } \\
\text { problemas. }\end{array}$ & $\begin{array}{l}\text { História, compreensão da história e } \\
\text { estimular que as crianças sugiram soluções } \\
\text { para o problema e as possíveis } \\
\text { consequências. }\end{array}$ & $\begin{array}{l}\text { Retomar o tema e solicitar que desenhem } \\
\text { uma solução com a conseqüência para o } \\
\text { problema da história. }\end{array}$ \\
\hline $\begin{array}{l}\text { 36-Controlar para } \\
\text { pensar }\end{array}$ & $\begin{array}{l}\text { Conversar sobre como pensar ajuda } \\
\text { a termos controle em situações }\end{array}$ & $\begin{array}{l}\text { História, compreensão do texto, questionar } \\
\text { sobre os pensamentos que o personagem }\end{array}$ & $\begin{array}{l}\text { Retomar tema, Solicite que as crianças } \\
\text { utilizem em casa a técnica de contar até }\end{array}$ \\
\hline
\end{tabular}




\begin{tabular}{|c|c|c|c|}
\hline & $\begin{array}{l}\text { difícieis e isso a não termos } \\
\text { problemas com as outras pessoas. }\end{array}$ & $\begin{array}{l}\text { teve para se controlar e as consequências } \\
\text { que teria se não tivesse conseguido. Propor } \\
\text { exercício de respiração (contar até três) }\end{array}$ & $\begin{array}{l}\text { três e respirar fundo, para se controlar e } \\
\text { pensar melhor, caso alguma coisa os } \\
\text { deixem nervosos, bravos, solicitar que } \\
\text { façam desenho de uma situação na qual } \\
\text { deveriam ter se controlado, contado e } \\
\text { respirado fundo para pensar melhor }\end{array}$ \\
\hline $\begin{array}{l}\text { 37- Controlar para } \\
\text { pensar }\end{array}$ & $\begin{array}{l}\text { Conversar sobre a importância de se } \\
\text { controlar para pensar melhor e não } \\
\text { ter problemas ou a resolver } \\
\text { problemas. }\end{array}$ & $\begin{array}{l}\text { História, compreensão do texto, brincadeira } \\
\text { de roda, na qual cada um deverá resolver } \\
\text { uma situação problema, mas antes todos } \\
\text { juntos deverão respirar fundo, contar até } \\
\text { três e sair do círculo se não conseguir dar a } \\
\text { resposta. }\end{array}$ & $\begin{array}{l}\text { Retomar o tema, Solicite para usarem em } \\
\text { casa a técnica de sair de perto da situação } \\
\text { que os incomoda para não se envolverem } \\
\text { em problemas e para poderem pensar em } \\
\text { como resolver, solicite que desenhem } \\
\text { uma situação que tiveram problema e que } \\
\text { se tivessem saído de perto teriam evitado. }\end{array}$ \\
\hline $\begin{array}{l}\text { 38-O que vem } \\
\text { depois? }\end{array}$ & $\begin{array}{l}\text { Conversar sobre as consequências } \\
\text { das decisões que tomamos. }\end{array}$ & $\begin{array}{l}\text { História, compreensão da história, dividir a } \\
\text { sala dois grupos e solicitar que um } \\
\text { apresente a solução para o problema } \\
\text { apresentado e o outra, consequência. }\end{array}$ & $\begin{array}{l}\text { Solicite que perguntem em casa para } \\
\text { alguém significativo o que faria frente a } \\
\text { um problema especificado por você. }\end{array}$ \\
\hline $\begin{array}{l}\text { 39-Observando, } \\
\text { pensando }\end{array}$ & $\begin{array}{l}\text { Retomar o que aprenderam no } \\
\text { programa }\end{array}$ & $\begin{array}{l}\text { História, compreensão da história, } \\
\text { questionar qual era o problema da história, } \\
\text { os sentimentos dos personagens, como }\end{array}$ & $\begin{array}{l}\text { Solicite que desenhem a história com as } \\
\text { mudanças realizadas e que coloquem seus } \\
\text { desenhos na caixa de sentimentos. }\end{array}$ \\
\hline
\end{tabular}




\begin{tabular}{|l|l|l|}
\hline $\begin{array}{l}\text { resolvendo } \\
\text { problemas. }\end{array}$ & $\begin{array}{l}\text { poderiam ter evitado o problema, quais } \\
\text { outras soluções e consequências. Recontar a } \\
\text { história, com as mudanças sugeridas. }\end{array}$ \\
\hline 40- Vamos sempre & Fechamento do grupo & $\begin{array}{l}\text { Entrega de todos os desenhos produzidos } \\
\text { por eles ao longo dos encontros. Fazer a } \\
\text { brincadeira "Chefinho mandou", } \\
\text { retomando cada tema abordado no } \\
\text { programa. Entrega dos diplominhas, e eles } \\
\text { deverão decidir a forma de organização da } \\
\text { entrega. Dar um feedback a cada um na hora } \\
\text { de entregar. }\end{array}$ \\
\hline
\end{tabular}




\section{Anexo 2.}

PREFEITURA MUNICIPAL DE SERTÃOZINHO

Secretaria Municipal de Educaçào e Cultura

Oficio SEC n' 228/2016

Assunto: Execuşåo de Projeto

Sertฐ̄ozinho, 04 de julho de 2016.

Prezada Senhora,

Venho através deste, autorizar a execuçăo do Projeto de Pesquisa intitulado "DESENVOLVIMENTO DE HABILIDADES SOCIAIS EM ALUNOS DA EDUCAÇĂO INFANTIL", na Rede Municipal de Ensino de Sertåozinho/SP.

Sem mais para o momento

Atenciosamente,

Lum lumpece

Oţivia Alexandrina Portugat Assumpça

Secretária Municipal de Educaçăo e Cultura

Sra. Luciana Carla dos Santos Elias

Docente do Departamento de Psicologia

FFCLRP - USP

PQEFETURA MUNICIPAL DE SERTĀOZINHO SECRETARIA MUNICIPAL DE EDUCACĀO E CUITURA

Rua Washington tuis, 1040 - Jardim Sumare - Sertăozinho - SP Cep: 14.170-610

Fone: (16) 39466900 Fax (16) 39466901

Emall: educaçso 


\section{Apêndice A}

\section{Termo de Consentimento Livre e Esclarecido}

Nome da pesquisa: "Replicabilidade do Programa Posso Pensar com Crianças da Educação Infantil"

Orientadora: Luciana Carla dos Santos Elias CRP: 06/4671-2

Pesquisador responsável: Letícia Melo de Paulo

Prezado(a), gostaríamos de convidá-lo(a) a participar do nosso projeto de estudo intitulado "Replicabilidade do Programa Posso Pensar com Crianças da Educação Infantill”. Destacamos que este convite está sendo feito a outros professores da Educação Infantil do município, assim como seus responsáveis. Estudos nacionais e internacionais têm apontado que o desenvolvimento de habilidades sociais em crianças, auxilia no desenvolvimento escolar, assim como promove comportamentos mais aceitos socialmente, atuando as habilidades sociais como fator de proteção ao desenvolvimento. Assim temos como objetivo realizar um Treinamento de Habilidades Sociais para crianças da Educação Infantil e verificar as possíveis mudanças promovidas por esse treinamento, quer nas habilidades sociais, no desempenho escolar e problemas de comportamento dessas crianças. O treino em habilidades de sociais será realizado por mim (psicóloga e aluna de Pós-Graduação em Psicologia) e supervisionado pela orientadora acima citada; o treino ocorrerá na escola, durante todo o semestre, de uma a duas vezes por semana com duração de uma hora, sempre no final da aula. O treino consiste em atividades em torno de palavras que levam a criança a pensar em como resolver seus problemas interpessoais; essas atividades são diálogos, jogos, leituras, desenhos e brincadeiras. Nosso objetivo é ensinar a criança a pensar e não no que pensar, todas as ideias são respeitadas e trabalhadas quanto a sua eficácia. Antes e após o treinamento faremos avaliações em seu aluno (a) para verificarmos as habilidades sociais, habilidades de solução de problemas interpessoais, desempenho acadêmico e problemas de comportamento. A senhora (or) assim como os responsáveis responderão questões sobre o comportamento da criança na escola. Para responder as questões a senhora levará em torno de 15 minutos, que poderá ser respondido agora em seguida da leitura desse termo ou em dia previamente marcado. Participando dessa pesquisa o seu aluno (a) estará ajudando a desenvolver um modelo de intervenção para o desenvolvimento de habilidades de sociais com foco nas habilidades de solução de problemas interpessoais em contexto escolar, através do qual seu aluno(a) e outras crianças posteriormente 
poderão se beneficiar. No que tange a riscos e benefícios dessa pesquisa, destacamos que os riscos são mínimos relacionados a um possível desconforto afetivo que as perguntas da avaliação podem causar em você ou nas crianças durante as atividades dos encontros. No entanto, frente essas situações realizaremos intervenções no sentido de minimizar esses sentimentos. Quanto aos possíveis benefícios, a presente pesquisa será importante para ampliar a área de conhecimento, no que tange o desenvolvimento de habilidades sociais na Educação Infantil. Nós pesquisadoras (eu e minha orientadora), estamos compromissados com o Código de Ética do Psicólogo, assegurando o anonimato das crianças e total sigilo quanto aos dados obtidos durante a pesquisa. Os resultados deste estudo serão utilizados para compreensão das variáveis estudadas e serão divulgados no meio científico através de relatórios, manuscritos e em congressos; para a escola e pais/responsáveis, esses resultados serão divulgados através de uma devolutiva verbal. É importante ressaltar que nós pesquisadoras estaremos durante todo o período do projeto disponíveis para tirar qualquer dúvida que possa existir quanto ao nosso trabalho, esse contato poderá ser agendado na escola ou pelo telefone 16-3315-0195 da coordenadora do estudo Profa. Dra. Luciana C.S. Elias. Caso a(o) senhora(or) não concorde com a participação de seu aluno(a) ou ele(a) decida parar a participação no grupo, deixamos claro que ele assim poderá fazê-lo a qualquer momento, sem nenhum constrangimento e sem nenhum prejuízo. Quanto a qualquer dúvida ética poderá entrar em contato com Comitê de Ética em Pesquisa da Faculdade de Filosofia, Ciências e Letras de Ribeirão Preto - USP, Avenida Bandeirantes, 3900 - Bloco 01 -Prédio da Administração - sala 07, 14040-901 -Ribeirão Preto - SP - Brasil, Fone: (16) 3315-4811 - Atendimento de $2^{\mathrm{a}}$ a $6^{\mathrm{a}}$ das $13 \mathrm{~h} 30$ às 17h30 e E-mail: coetp@ffclrp.usp.br. Deixamos claro ainda que a senhora (or), pode vir a retirar seu consentimento de participação da criança na pesquisa em qualquer momento. Ressaltamos que a participação de seu aluno (a) no projeto não envolve gastos para a senhora (or), visto que seu aluno(a) já estará na escola, podendo haver ressarcimento no caso de eventuais despesas ligadas ao estudo. Ressaltamos que você pode desistir de participar deste estudo e retirar seu consentimento a qualquer momento, sem que lhe acarrete nenhum tipo de prejuízo.

$\mathrm{Eu}$

professora responsável por
RG , estudante da série, li e concordo em participar, do projeto de pesquisa que está sendo realizado com crianças que estudam na Educação Infantil da escola Declaro estar ciente do objetivo e do 
caráter confidencial da pesquisa e de que sou livre para recusar ou me retirar da mesma a qualquer momento. Declaro também que assinei duas vias desse termo, tendo recebido uma dessas vias.

de de 20 


\section{Apêndice B}

\section{Termo de Consentimento Livre e Esclarecido}

Nome da pesquisa: "Replicabilidade do Programa Posso Pensar com Crianças da Educação Infantil"

Orientadora: Luciana Carla dos Santos Elias CRP: 06/4671-2

Pesquisador responsável: Letícia Melo de Paulo

Prezado(a), gostaríamos de convidá-lo(a) a participar do nosso projeto de estudo intitulado "Replicabilidade do Programa Posso Pensar com Crianças da Educação Infantil". Destacamos que este convite está sendo feito a outros pais ou responsáveis pelos alunos da Educação Infantil do município, assim como suas professoras. Estudos nacionais e internacionais têm apontado que o desenvolvimento de habilidades sociais em crianças, auxilia no desenvolvimento escolar, assim como promove comportamentos mais aceitos socialmente, atuando as habilidades sociais como fator de proteção ao desenvolvimento. Assim temos como objetivo realizar um Treinamento de Habilidades Sociais para crianças da Educação Infantil e verificar as possíveis mudanças promovidas por esse treinamento, quer nas habilidades sociais, no desempenho escolar e problemas de comportamento dessas crianças. O treino em habilidades de sociais será realizado por mim (psicóloga e aluna de Pós-Graduação em Psicologia) e supervisionado pela orientadora acima citada; o treino ocorrerá na escola, durante todo o semestre, de uma a duas vezes por semana com duração de uma hora, sempre no final da aula. $\mathrm{O}$ treino consiste em atividades em torno de palavras que levam a criança a pensar em como resolver seus problemas interpessoais; essas atividades são diálogos, jogos, leituras, desenhos e brincadeiras. Nosso objetivo é ensinar a criança a pensar e não no que pensar, todas as ideias são respeitadas e trabalhadas quanto a sua eficácia. Antes e após o treinamento faremos avaliações em seu filho (a) para verificarmos as habilidades sociais, habilidades de solução de problemas interpessoais, desempenho acadêmico e problemas de comportamento. A senhora (or) assim como as professoras responderão questões sobre o comportamento da criança na escola. Para responder as questões a senhora levará em torno de 15 minutos, que poderá ser respondido agora em seguida da leitura desse termo ou em dia previamente marcado. Participando dessa pesquisa o seu filho (a) estará ajudando a desenvolver um modelo de intervenção para o desenvolvimento de habilidades de sociais com foco nas habilidades de solução de problemas interpessoais em contexto escolar, através do qual seu filho (a) e outras crianças posteriormente 
poderão se beneficiar. No que tange a riscos e benefícios dessa pesquisa, destacamos que os riscos são mínimos relacionados a um possível desconforto afetivo que as perguntas da avaliação podem causar em você pai/responsável ou nas crianças durante as atividades dos encontros. No entanto, frente essas situações realizaremos intervenções no sentido de minimizar esses sentimentos. Quanto aos possíveis benefícios, a presente pesquisa será importante para ampliar a área de conhecimento, no que tange o desenvolvimento de habilidades sociais na Educação Infantil. Nós pesquisadoras (eu e minha orientadora), estamos compromissados com o Código de Ética do Psicólogo, assegurando o anonimato das crianças e total sigilo quanto aos dados obtidos durante a pesquisa. Os resultados deste estudo serão utilizados para compreensão das variáveis estudadas e serão divulgados no meio científico através de relatórios, manuscritos e em congressos; para a escola e pais/responsáveis, esses resultados serão divulgados através de uma devolutiva verbal. É importante ressaltar que nós pesquisadoras estaremos durante todo o período do projeto disponíveis para tirar qualquer dúvida que possa existir quanto ao nosso trabalho, esse contato poderá ser agendado na escola ou pelo telefone 16-3315-0195 da coordenadora do estudo Profa. Dra. Luciana C.S. Elias. Caso a(o) senhora(or) não concorde com a participação de seu filho(a) ou ele(a) decida parar a participação no grupo, deixamos claro que ele assim poderá fazê-lo a qualquer momento, sem nenhum constrangimento e sem nenhum prejuízo. Quanto a qualquer dúvida ética poderá entrar em contato com Comitê de Ética em Pesquisa da Faculdade de Filosofia, Ciências e Letras de Ribeirão Preto - USP, Avenida Bandeirantes, 3900 - Bloco 01 -Prédio da Administração - sala 07, 14040-901 -Ribeirão Preto - SP - Brasil, Fone: (16) 3315-4811 - Atendimento de $2^{\mathrm{a}}$ a $6^{\mathrm{a}}$ das $13 \mathrm{~h} 30$ às 17h30 e E-mail: coetp@ffclrp.usp.br . Deixamos claro ainda que a senhora (or), pode vir a retirar seu consentimento de participação da criança na pesquisa em qualquer momento. Ressaltamos que a participação de seu filho (a) no projeto não envolve gastos para a senhora (or), visto que seu filho (a) já estará na escola, podendo haver ressarcimento no caso de eventuais despesas ligadas ao estudo. Ressaltamos que você pode desistir de participar deste estudo e retirar seu consentimento a qualquer momento, sem que lhe acarrete nenhum tipo de prejuízo.

$\mathrm{Eu}$

pai/mãe/responsável por
RG estudante da série, li e concordo em participar, do projeto de pesquisa que está sendo realizado com crianças que estudam na Educação Infantil da escola Declaro estar ciente do objetivo e do 
caráter confidencial da pesquisa e de que sou livre para recusar ou me retirar da mesma a qualquer momento. Declaro também que assinei duas vias desse termo, tendo recebido uma dessas vias.

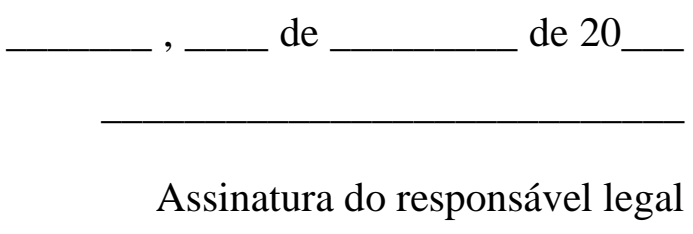

Assinatura do pesquisador

Assinatura do responsável legal 